\title{
AJUSTE E COMPARAÇÃO DE MODELOS DE SIMULAÇÃO DA PRODUTIVIDADE PARA A DETERMINAÇÃO DO RISCO CLIMÁTICO DA CULTURA DO GIRASSOL (Helianthus annuus L.)
}

\section{GLAUCO DE SOUZA ROLIM}

\author{
Engenheiro Agrônomo.
}

Orientador: Prof. Dr. PAULO CESAR SENTELHAS

Dissertação apresentada à Escola Superior de Agricultura "Luiz de Queiroz", da Universidade de São Paulo, para obtenção do título de Mestre em Agronomia, Área de Concentração: Física do Ambiente Agrícola

PIRACICABA

Estado de São Paulo - Brasil

Março / 2000 


\title{
Dados Internacionais de Catalogaçāo na Publicaçāo (CIP) DIVISĀO DE BIBLIOTECA E DOCUMENTAÇĀO - Campus "Luiz de Queiroz"/USP
}

\author{
Rolim, Glauco de Souza \\ Ajuste e comparação de modelos de simulaçaō da produtividade para a \\ deteminação do risco climático da cultura do girrassol (Helianchus annuus L.) / Glauco \\ de Souza Rolim. - - Piracicaba, 2000. \\ $125 \mathrm{p}$. \\ Dissertação (mestrado) - - Escola Superior de Agricultura Luiz de Queiroz, 2000. \\ Bibliografia. \\ 1. Climatologia 2. Fotoperiodismo 3. Girassol 4. Modelo matemático 5. \\ Produtividade agricola 6. Risco I. Titulo
}

CDD 633.39

\section{"Permitida a copia total ou parcial destedocumento, desde que citada a fonte 0 autor}


Dedico este trabalho a meus pais Celio e Lourdes pelo amor e apoio que vocês sempre me ofereceram.

A minha noiva Samira pelo amor e carinho que nos une. As minhas irmãs Cecilia e Ligia pelo amor e amizade e ao Pepê que sempre nos traz muitas alegrias. 


\section{AGRADECIMENTOS}

- Ao Prof. Dr. Paulo Cesar Sentelhas pela orientação, amizade e apoio constante durante a elaboração do trabalho;

- À pesquisadora do Instituto Agronômico de Campinas (IAC) Dra. Maria Regina Gonsalves Ungaro pela permanante disponibilidade em nos receber e pelas valiosas contribuições em todas as fases do trabalho;

- Aos Professores do Departamento de Ciências Exatas-Área de Física e Meteorologia: Nilson, Angelocci, Pereira, Sérgio, pelos ensinamentos e pela amizade;

- Ao Prof. Dr. Barbieri pela orientação anterior ao presente trabalho, pelos ensinamentos e pela amizade;

- Ao Prof. Dr. Sílvio Sandoval Zocchi do Departamento de Ciências Exatas-Área de Matemática e Estatística (ESALQ-USP) pelas sugestões durante a calibração dos cultivares;

- Ao Instituto Agronômico de Campinas - IAC, Centro de Ecofisiologia e Biofísica e ao Instituto Agronômico do Paraná - IAPAR, pela concessão dos dados;

- Ao acadêmico Matheus Oliveira Chaves pela amizade e apoio com o programa DSSAT;

- Ao colega Jean Dalmo Marques pela amizade e apoio com os dados de solos das localidades;

- A(o)s colegas Karen, Sylvia, Késia, Luciana, Jeane, Fábio, Rafael, Evandro, Juan pela amizade e o ótimo convívio durante o curso;

- Ao Robinson Luiz Tuon pela amizade e apoio constante com os equipamentos de informática;

- Aos Funcionários do Departamento de Ciências Exatas-Área de Física e Meteorologia pelo apoio;

- A CAPES pela concessão da bolsa, sem a qual não teria sido possível a obtenção do título;

- E a todos aqueles que contribuíram direta ou indiretamente para o sucesso deste trabalho; 


\section{ÍNDICE}

LISTA DE FIGURAS ................................................................................................

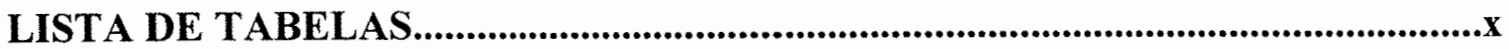

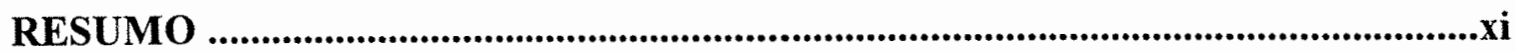

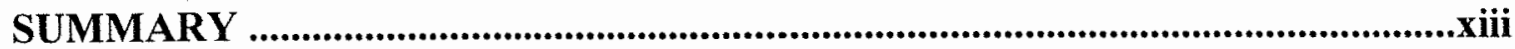

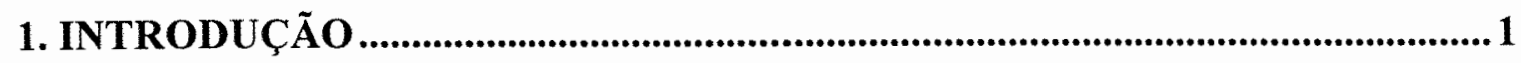

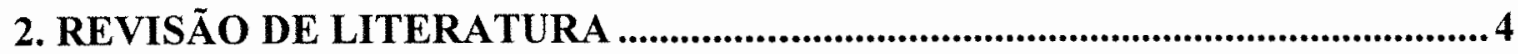

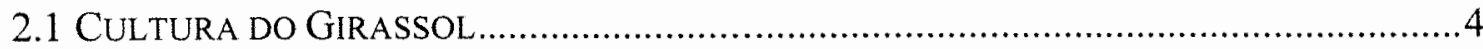

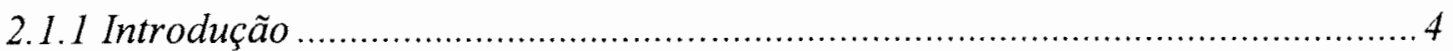

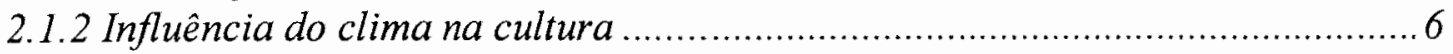

2.1.2.1 Temperatura e Fotoperíodo ……...........................................................6

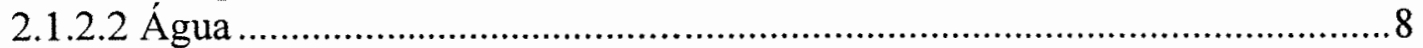

2.2 Modelagem E Simulação da PRodutividade de Culturas ………...................

2.2.1 Conceitos e definições ..............................................................................

2.2.2 Importância do uso de modelos de simulação da produtividade agrícola .......14

2.2.3 Emprego de Modelos de Simulação no planejamento agrícola ...................... 15

2.2.4 Modelos de simulação da fenologia e produtividade da cultura do girassol .. 15

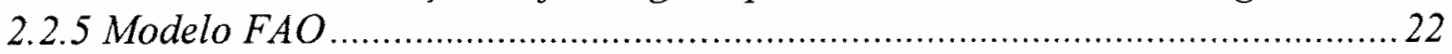

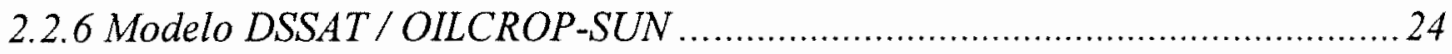

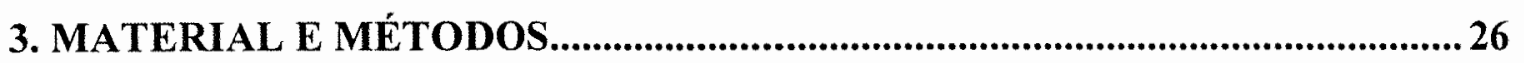

3.1. LOCAL E DADOS UTILIZADOS PARA CALIBRAÇÃO …………………………........26

3.2 MODELOS DE SIMULAÇÃO DA CULTURA DO GIRASSOL …….................................27

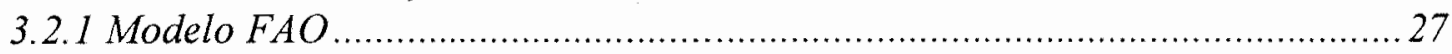

3.2.1.1 Produtividade Potencial (Método da Zona Agroecológica)......................28

3.2.1.2 Produtividade Real (Doorenbos \& Kassam, 1979) .....................................30

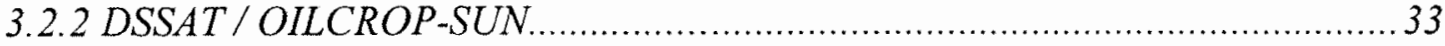

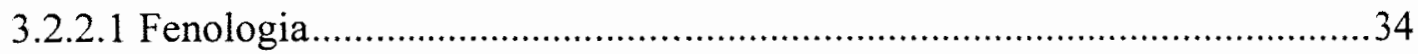

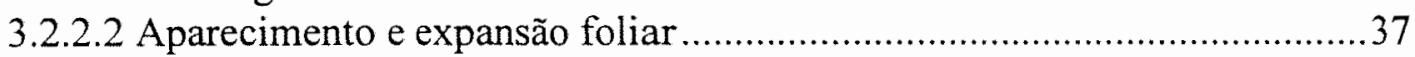

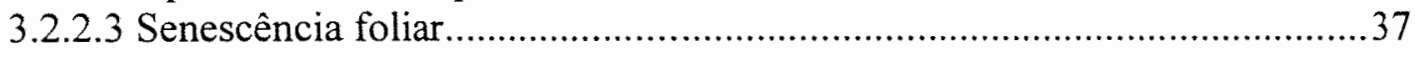

3.2.2.4 Profundidade e densidade do sistema radicular ..........................................38

3.2.2.5 Interceptação de radiação solar e acúmulo de biomassa ..............................38

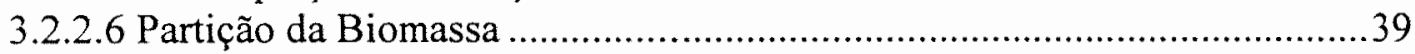

3.2.2.6 Determinação da produção de grãos ........................................................40

3.2.2.7 Balanço de nitrogênio na cultura...................................................................4

3.2.2.8 Calibração do Modelo OILCROP-SUN para os cultivares estudados.......42

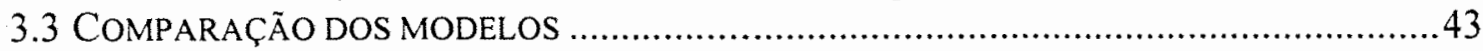


4. RESULTADOS E DISCUSSÃO

4.1 CALIBRAÇÃO DO MODELO DSSAT/OILCROP-SUN PARA OS CULTIVARES EM MONTE ALEGRE DO Sul, SP

4.1.1 Cultivar IAC-Anhandy.

4.1.2 Cultivares Contisol-621 e VNIIMK.

4.2 COMPARAÇÃO DOS MODELOS DSSAT /OILCROP-SUN E FAO PARA AS LOCALIDADES NO ESTADO DE SÃo PAULO E NO PARANÁ

4.2.1 Duração do ciclo total.

4.2.2 Produtividade Potencial

4.2.3 Produtividade Real...

4.2.4 Quebra Relativa de Produtividade

5. CONCLUSÕES.. 


\section{LISTA DE FIGURAS}

Figura 1 - Fluxo de informações que representa o conhecimento atual sobre a modelagem em girassol (modificado de Steer et al., 1993).

Figura 2 - Exemplo de arquivo do sistema DSSAT com informações sobre as características físico-químico-hídricas do solo Podzólico Vermelho Amarelo Ortoclásico, da área experimental em Monte Alegre do Sul, SP (Legenda no Anexo 2) (Fonte: Rotta et al. 1971).

Figura 3 - Determinação da profundidade de semeadura ideal em relação à duração da subfase semeadura - emergência, para o cultivar IACAnhandy, em Monte Alegre do Sul, SP.

Figura 4 - Resultado final da calibração da profundidade de semeadura (SDEPTH), para o cultivar IAC-Anhandy, em Monte Alegre do Sul, SP.

Figura 5 - ERRO decorrente de diferentes valores de $\mathrm{P} 1$ e $\mathrm{P} 2$, em relação à determinação da fase emergência - primeira antese, do cultivar IACAnhandy, em Monte Alegre do Sul, SP.

Figura 6 - Coeficiente linear (a) decorrente de diferentes valores de P1 e P2, em relação à determinação da fase emergência - primeira antese, do cultivar IAC-Anhandy, em Monte Alegre do Sul, SP.

Figura 7 - Coeficiente angular (b) decorrente de diferentes valores de P1 e P2, em relação à determinação da fase emergência - primeira antese, do cultivar IAC-Anhandy, em Monte Alegre do Sul, SP.

Figura 8 - Coeficiente de correlação $\left(\mathrm{r}^{2}\right)$ decorrentes de diferentes valores de P1 e P2, em relação à determinação da fase emergência - primeira antese, do cultivar IAC-Anhandy, em Monte Alegre do Sul, SP.

Figura 9 - Resultado final da calibração dos coeficiente P1 e P2, em relação à duração da fase emergência - primeira antese, para o cultivar IACAnhandy, em Monte Alegre do Sul, SP.

Figura 10 - Calibração do coeficiente de duração do preenchimento dos grãos

(P5) feito em relação à duração do ciclo total da cultura do girassol, cultivar IAC-Anhandy, em Monte Alegre do Sul, SP

Figura 11 - Resultado Final da calibração do coeficiente P5, em relação à duração do ciclo total da cultura, para o cultivar IAC-Anhandy, em Monte Alegre do Sul, SP. 
Figura 12 - Calibração da profundidade de semeadura (SDEPTH) para os cultivares Contisol-621 (a) e VNIIMK (b), feito em relação à duração da fase semeadura- emergência (A), em Monte Alegre do Sul, SP.

Figura 13 - Resultado final da calibração dos coeficientes: P1 e P2 (em relação à duração da fase emergência - primeira antese) (a), P5 (em relação à duração do ciclo total da cultura) (b), para o cultivar Contisol-621, em Monte Alegre do Sul, SP....

Figura 14 - Resultado final da calibração dos coeficientes: P1 e P2 (em relação à duração da fase emergência - primeira antese) (a), P5 (em relação à duração do ciclo total da cultura) (b), para o cultivar VNIIMK, em Monte Alegre do Sul, SP.

Figura 15 - Relação do número de dias do ciclo total médio determinado pelos modelos FAO e DSSAT para os cultivares de girassol, IACAnhandy, Contisol-621 e VNIIMK nas localidades de Piracicaba (PI), Ribeirão Preto (RP) e Manduri (MA), no Estado de São Paulo.

Figura 16 - Relação do número de dias do ciclo total médio determinados pelos modelos FAO e DSSAT para os cultivares de girassol IACAnhandy, Contisol-621 e VNIIMK nas localidades de Ponta Grossa (PG) e Paranavaí (PA), no Estado do Paraná.

Figura 17 - Produtividade Potencial (PP) média nas diferentes datas de semeadura para os cultivares IAC-Anhandy, Contisol-621 e VNIIMK simuladas pelos modelos FAO e DSSAT, nas localidades de Piracicaba (a), de Ribeirão Preto (b) e de Manduri (c), no Estado de São Paulo.

Figura 18 - Produtividade Potencial (PP) média nas diferentes datas de semeadura para os cultivares IAC-Anhandy, Contisol-621 e VNIIMK simuladas pelos modelos FAO e DSSAT, nas localidades de Ponta Grossa (a) e de Paranavaí (b), no Estado do Paraná.

Figura 19 - Temperatura do ar (a), radiação solar global (b), precipitação (c) e fotoperíodo (d) mensais para as localidades de Piracicaba, de Ribeirão Preto, e de Manduri, no Estado de São Paulo, e de Ponta Grossa e de Paranavaí, no Estado do Paraná.

Figura 20 - Frequência Relativa de Produtividades Potenciais (PP) simuladas pelos modelos FAO e DSSAT para todas as datas de semeadura analisadas, para os cultivares IAC-Anhandy, Contisol-621 e VNIIMK, nas localidades de Piracicaba (a), de Ribeirão Preto (b) e de Manduri (c), no Estado de São Paulo. 
Figura 21 - Frequência Relativa Produtividades Potenciais (PP) simuladas pelos modelos FAO e DSSAT para todas as datas de semeaduras analisadas, para os cultivares IAC-Anhandy, Contisol-621 e VNIIMK, nas localidade de Ponta Grossa (a) e de Paranavaí (b), no Estado do Paraná.

Figura 22 - Relação entre as Produtividades Potenciais (PP) médias simuladas pelos modelos FAO e DSSAT para os cultivares IAC-Anhandy, Contisol-621 e VNIIMK para Piracicaba (PI), Ribeirão Preto (RP) e Manduri (MA), no Estado de São Paulo.

Figura 23 - Relação entre as Produtividades Potenciais (PP) médias simuladas pelo modelo FAO e DSSAT para os cultivares IAC-Anhandy, Contisol-621 e VNIIMK para Ponta Grossa (PG) e Paranavaí (PA), no Estado do Paraná.

Figura 24 - Produtividade Real (PR) média nas diferentes datas de semeadura para os cultivares IAC-Anhandy, Contisol-621 e VNIIMK simuladas pelos modelos FAO e DSSAT, nas localidades de Piracicaba (a), de Ribeirão Preto (b) e de Manduri (c), no Estado de São Paulo.

Figura 25 - Produtividade Real (PR) média nas diferentes datas de semeadura para os cultivares IAC-Anhandy, Contisol-621 e VNIIMK simuladas pelos modelos FAO e DSSAT, nas localidades de Ponta Grossa (a) e de Paranavaí (b), no Estado do Paraná.

Figura 26 - Extratos dos balanços hídricos climatológicos normais mensais, segundo Thorthwaite \& Mather (1955), para CAD igual a $50 \mathrm{~mm}$, das localidades de Piracicaba (a), de Ribeirão Preto (b), e de Manduri (c), no Estado de São Paulo, e de Ponta Grossa (d) e de Paranavaí (e), no Estado do Paraná.

Figura 27 - Frequência Relativa das Produtividades Reais (PR) simuladas pelos modelos FAO e DSSAT para todas as datas de semeadura analisadas nas localidades de Piracicaba (a), de Ribeirão Preto (b) e de Manduri (c), no Estado de São Paulo.

Figura 28 - Frequências Relativa das Produtividades Reais (PR) simuladas pelos modelos FAO e DSSAT para todas as datas de semeadura analisadas nas localidades de Ponta Grossa (a) e de Paranavaí (b), no Estado do Paraná.

Figura 29 - Relação entre as Produtividades Reais (PR) médias simuladas pelo modelos FAO e DSSAT para os cultivares IAC-Anhandy, Contisol e VNIIMK para Piracicaba (PI), Ribeirão Preto (RB) e Manduri (MA), no Estado de São Paulo 
Figura 30 - Relação entre as Produtividades Reais (PR) médias simuladas pelos modelos FAO e DSSAT para os cultivares IAC-Anhandy, Contisol e VNIIMK para Ponta Grossa (PG) e Paranavaí (PA), no Estado do Paraná.

Figura 31 - Quebra Relativa de Produtividade média nas diferentes datas de semeadura para os cultivares IAC- Anhandy, Contisol-621 e VNIIMK simulada pelos modelos FAO e DSSAT, nas cidades de Piracicaba (a), Ribeirão Preto (b) e Manduri (c), no Estado de São Paulo

Figura 32 - Quebra Relativa de Produtividade média nas diferentes datas de semeadura para os cultivares IAC- Anhandy, Contisol-621 e VNIIMK simulada pelos modelos FAO e DSSAT, nas cidades de Ponta Grossa (a) e Paranavaí (b), no Estado do Paraná.

Figura 33 - Frequências Relativa da Quebra Relativa de Produtividade simulada pelo modelo FAO e DSSAT para todas as datas de semeadura analisadas, para os cultivares IAC-Anhandy, Contisol-621 e VNIIMK, nas cidades de Piracicaba (a), Ribeirão Preto (b) e Manduri (c), no Estado de São Paulo.

Figura 34 - Frequências Relativa de Quebra Relativa de Produtividade simulada pelo modelo FAO e DSSAT para todas as datas de semeadura analisadas, para os cultivares IAC-Anhandy, Contisol-621 e VNIIMK, nas cidades de Ponta Grossa (a) e Paranavai (b), no Estado do Paraná.

Figura 35 - Relação entre as Quebras Relativas de Produtividade simuladas pelos modelos FAO e DSSAT para os cultivares IAC-Anhandy, Contisol621 e VNIIMK para Piracicaba (PI), Ribeirão Preto (RP) e Manduri (MA), no Estado de São Paulo. 


\section{LISTA DE TABELAS}

Tabela 1 - Produção Mundial, em milhões de toneladas, das principais culturas de plantas oleaginosas, no período de 1991 a 1997.

Tabela 2 - Dados iniciais da cultura do girassol para uso no modelo FAO 31

Tabela 3 - Valores Médios da soma térmica, em ${ }^{\circ} \mathrm{C}$.dia, para os cultivares IACAnhandy, Contisol-621 e VNIIMK, para o ciclo total e para cada subperíodo (1- Estabelecimento, 2- Desenvolvimento Vegetativo, 3Florescimento, 4- Frutificação, 5- Maturação), levando-se em consideração as diferentes temperaturas-base, determinadas por Sentelhas et al. (1994).

Tabela 4 - Coeficientes da estimativa de kc em função de graus-dia (equação 13) para os cultivares IAC-Anhandy, Contisol-621 e VNIIMK.

Tabela 5 - Fases e sub-fases usados no modelo OILCROP-SUN 34

Tabela 6 - Localidades utilizadas nas simulações dos modelos FAO e DSSAT/OILCROP-SUN

Tabela 7 - Valores calibrados dos coeficientes genéticos P1 (coeficiente da duração do período juvenil), P2 (coeficiente fotoperíódico) e P5 (coeficiente da duração da fase primeira antese - maturidade fisiológica) para o modelo DSSAT/OILCROP-SUN dos culivares, IAC-Anhandy, Contisol-621 e VNIIMK.

Tabela 8 - Produtividade Potencial média dos cultivares IAC-Anhandy, Contisol-621 e VNIIMK nas localidades de Piracicaba, de Ribeirão Preto, e de Manduri, no Estado de São Paulo,e de Ponta Grossa e de Paranavaí, no Estado do Paraná, simuladas pelo modelo FAO e DSSAT.

Tabela 9 - Diferença média absoluta, máxima e mínima entre os valores de Produtividade Potencial simulados pelos modelos FAO e DSSAT para as localidades analisadas.

Tabela 10 - Diferença média absoluta, máxima e mínima entre os valores de Produtividade Real simulados pelos modelos FAO e DSSAT para as localidades analisadas.

Tabela 11- Diferença média absoluta, máxima e mínima entre os valores de Quebra Relativa de Produtividade simuladas pelos modelo FAO e DSSAT para cada localidade 


\title{
AJUSTE E COMPARAÇÃO DE MODELOS DE SIMULAÇÃO DA PRODUTIVIDADE PARA A DETERMINAÇÃO DO RISCO CLIMÁTICO DA CULTURA DO GIRASSOL (Helianthus annuus L.)
}

\author{
Autor: GLAUCO DE SOUZA ROLIM \\ Orientador: Prof. Dr. PAULO CESAR SENTELHAS
}

\section{RESUMO}

Este trabalho foi desenvolvido com o objetivo de determinar as melhores épocas de semeadura para a cultura do girassol em condições irrigadas e de sequeiro, nas localidades de Piracicaba, Ribeirão Preto, Manduri, no Estado de São Paulo e Ponta Grossa e Paranavaí, no Estado do Paraná. Para esta determinação foram comparadas as Produtividades Potencial e Real e a Quebra Relativa de Produtividade, simuladas por dois modelos, sendo um complexo, pertencente ao Sistema DSSAT (Decision Support System for Agrotechnology Transfer), chamado OILCROP-SUN e outro, mais simples, preconizado pela FAO (Produtividade Potencial - Médodo da zona agroecológica e Produtividade Real (Doorenbos\& Kassam, 1979)).

Para a utilização do modelo DSSAT/OILCROP-SUN, primeiramente foi feita a calibração dos coeficientes genéticos para os cultivares, com dados fenológicos, climáticos e de solo, medidos em Monte Alegre do Sul, SP. A calibração foi feita testando-se diversos valores para cada coeficiente, procurando-se a minimização da soma do quadrado dos erros (coeficiente linear mais próximo a zero e o coeficiente angular mais próximo a 1) entre os dados medidos e os simulados. Os resultados dos coeficientes genéticos P1 (coeficiente da duração do período juvenil), P2 (coeficiente fotoperiódico) e P5 (coeficiente da duração da fase primeira antese - maturidade fisiológica) foram respectivamente: $265^{\circ} \mathrm{C}$.dia, 0,3 dia.hora ${ }^{-1}, 780^{\circ} \mathrm{C}$.dia, para o cultivar 
IAC-Anhandy; $235{ }^{\circ} \mathrm{C}$.dia, 1 dia.hora ${ }^{-1}, 560{ }^{\circ} \mathrm{C}$.dia, para o híbrido Contisol-621 e $260^{\circ} \mathrm{C}$.dia, 1dia.hora ${ }^{-1}, 560^{\circ} \mathrm{C}$.dia, para o cultivar VNIIMK. Outros coeficientes como G2 (número máximo de grãos por capítulo, medido em condições ótimas de crescimento), G3 (taxa de crescimento potencial da amêndoa, mg.dia ${ }^{-1}$ ) e, por fim, O1 (conteúdo máximo de óleo na amêndoa, \%) foram considerados iguais a , 2800, 1,7 e 65 respectivamente, adotando-se os mesmos valores para todos os cultivares.

Depois de concluída a fase de calibração, foi possível a simulação da produtividade pelos dois modelos, em semeaduras decendiais, em diferentes números de anos para cada localidade.

Observou-se, então, que as maiores diferenças ocorreram nas estimativas da Produtividade Potencial, evidenciando que os modelos levam em consideração diferentes variáveis em seus cálculos. Já as estimativas de Produtividade Real e a Quebra Relativa de Produtividade foram muito próximas entre os modelos, com exceção de Paranavaí (PR). De forma geral, pode-se afirmar que, apesar das diferenças dos valores entre os dois modelos, eles determinaram aproximadamente as mesmas épocas de semeadura para a obtenção das maiores produtividades, tando em condições irrigadas como de sequeiro.

As melhores épocas de semeadura para a produção em sequeiro determinadas pelos dois modelos para todos os cultivares, estão entre 01/10 e 20/01 em Piracicaba, Ribeirão Preto e Manduri, no Estado de São Paulo. No Estado do Paraná, as melhores épocas de semeadura são entre 01/04 e 01/10 em Ponta Grossa e entre 01/07 e 20/11 em Paranavaí. Já as melhores épocas de semeadura em condições irrigadas, estão entre 01/04 e 01/09 nas localidades do Estado de São Paulo e em Ponta Grossa (PR) e entre 10/07 e 01/02 em Paranavaí (PR). 


\title{
ADJUST AND COMPARISON OF YIELD SIMULATION MODELS FOR DETERMINATION OF THE CLIMATIC RISK IN SUNFLOWER ( Helianthus annuus L.) CROP
}

\author{
Author :GLAUCO DE SOUZA ROLIM \\ Adviser: Prof. Dr. PAULO CESAR SENTELHAS
}

\section{SUMMARY}

This work was developed aiming the determination of the sunflower crop best sowing dates in irrigated and rainfed conditions at Piracicaba, Ribeirão Preto, Manduri in São Paulo State, and at Ponta Grossa and Paranavaí in Paraná State. For this, the Potential and Real Yield and the Relative Yield Loss were compared by two models; one of them is complex and belong to the DSSAT system (Decisiong Support System for Agrotechnology Transfer), called OILCROP-SUN, and the other, more simple, developed by FAO (Potential Productivity - agroecological zone method and Real Productivity - Doorenbos \& Kassam , 1979).

For the utilization of DSSAT/OILCROP-SUN model, it was firstly made the calibration of the genetic coefficients for the cultivars with fenological, climatic and soil data mesured in Monte Alegre do Sul, SP. The calibration was made testing various values for each coefficient, aiming the minimization of the square summation error (linear coefficient close to zero and angular coefficient close to 1) between mesured and simulated data. The results of genetic coefficient P1 (juvenile phase duration coefficient), P2 (fotoperiodic sensitive coefficient) and P5 (duration of the first anthesis - fisiological maturity coefficient) were respectively: $265^{\circ} \mathrm{C}$.day, 0,3 day.hour ${ }^{-1}, 780$ ${ }^{\circ} \mathrm{C}$.day for the Anhandy cultivar; $235^{\circ} \mathrm{C}$.day, 1 day.hour ${ }^{-1}, 560^{\circ} \mathrm{C}$.day for the Contisol- 621 hybrid and $260{ }^{\circ} \mathrm{C}$.day, 1 day.hour ${ }^{-1}, 560^{\circ} \mathrm{C}$.day for the VNIIMK cultivar. Other 
coefficients such as G2 (maximum number of grain per head, measured in optimal conditions and low plant population density), G3 (rate of potential kernel growth, mg.day ${ }^{-1}$ ) and $\mathrm{O} 1$ (Maximum kernel oil content, \%) were considered equals to 2800, 1,7 and 65 respectively, being used the same values for all cultivars.

After concluding the calibration phase, it was possible simulate the crop yield by both models for 36 sowing dates per year for each region.

So, it was observed that the major differences happened in estimatives of Potential Yield, showing that the models consider different variables in their simulations. Otherwise, the Real Yield and Relative Yield Loss estimatives were similar between the models, excepting Paranavaí (PR). In general sense, despite of the diferences between the two models, in irrigated and rainfed conditions, both determinated the same sowing periods for obtention of the highest yield.

The best sowing periods for rainfed conditions determined by both models for all cultivars were from 01/10 to 20/01 in Piracicaba, Ribeirão Preto and Manduri, in São Paulo State. In Paraná State, the best sowing periods were from 01/04 to 01/10 in Ponta Grossa and from 01/07 to 20/11 in Paranavaí. Otherwise, in irrigated conditions, the best sowing periods were from 01/04 to 01/09 in locations of São Paulo and Ponta Grossa (PR) and from 10/07 to 01/02 in Paranavaí (PR). 


\section{INTRODUÇÃO}

A sustentabilidade, ou seja, a capacidade de um sistema produtivo conservar-se no mercado, preservar o ambiente e ter bons retornos financeiros, é frequentemente ameaçada por fatores de risco.

Dentre os fatores de risco na agricultura, destaca-se o climático que pode ser decorrente de variações na disponibilidade hídrica, de eventos climáticos extremos ou inadequados, além de sua influência na incidência de pragas e doenças.

Desse modo, estudos tornam-se necessários para trazer respostas ou técnicas adequadas para a minimização desse risco. Todavia, muitas vezes o conhecimento já adquirido pode ser prontamente transferido para outras regiões, evitando novos e dispendiosos experimentos.

A modelagem de culturas é uma das formas de como o conhecimento pode ser transferido e utilizado para o alcance de diferentes objetivos. Por exemplo, pelos agricultores, na determinação do melhor cultivar e data de semeadura mais adequada, e na escolha de melhor estratégia no manejo da irrigação; pelas empresas rurais, no planejamento do uso dos campos e na previsão de metas a serem cumpridas nos seus diversos níveis hierárquicos; pelo governo, no zoneamento agroecológico, na determinação de políticas regionais e nacionais, e na estocagem ou venda dos produtos agrícolas para a regulação dos preços; pelos pesquisadores, na busca do entendimento dos sistemas agrícolas nos seus diversos níveis de especialização.

Os modelos de simulação usam o conhecimento já adquirido pelos resultados dos experimentos a campo e, principalmente, propicia uma extrapolação para novas condições ambientais, desde que devidamente ajustados, pois integra informações de vários ramos do conhecimento como, por exemplo, agrometeorologia, solos, genética, 
fisiologia, economia e entomologia, para a resolução dos problemas que afetam a produtividade agrícola, identificando os pontos de estrangulamento que irão afetar sobremaneira a sustentabilidade em determinada região.

No Brasil, grande ênfase no uso da modelagem está sendo dada nos estudos de zoneamento climático nos Estados de Santa Catarina, Rio Grande do Sul, São Paulo, nas regiões Centro-Oeste, Nordeste (Assad, 1999; Thomé et al. 1999) e em sistemas de monitoramento ambiental como no Estado do Paraná (Faria,1999).

Uma das culturas ainda pouco estudadas no Brasil, com relação à aplicação de modelos de simulação, é a do girassol. Esse fato é decorrente da pouca exploração econômica atual da cultura. Todavia, o desenvolvimento e a utilização de modelos para ela é importante, pois a cultura tem um grande potencial de expansão, sendo, atualmente, a que mais cresce no Brasil, devido a alta qualidade de seu óleo e a sua fácil extração industrial, utilização na alimentação animal, especialmente na forma de silagem, além de ampla adaptação à diferentes condições climáticas.

A modelagem da cultura do girassol vem sendo feita em diversas partes do mundo: Estados Unidos (Goyne et al., 1989), Austrália (Steer et al., 1993) e Europa (Villalobos \& Ritchie, 1992), onde, normalmente, tem grande interesse econômico; resultando em modelos que estão sendo usados para os mais diversos fins.

Em função do exposto, o presente trabalho tem por objetivo utilizar dois modelos de simulação para a cultura do girassol o OILCROP-SUN (Villalobos et al., 1996), complexo e adaptado ao sistema DSSAT; e o modelo FAO de previsão de produtividade potencial e real (Doorenbos \& Kassam, 1979), mais simples, para três cultivares de girassol, nas seguintes etapas:

a) Calibrar o modelo DSSAT/OILCROP-SUN para os cultivares de girassol IACAnhandy, Contisol-621 e VNIIMK;

b) Comparar a performance dos modelos OILCROP-SUN e FAO com relação à estimativa da produtividade potencial, real e quebra relativa de produtividade, para os cultivares acima citados, em cidades dos Estados de São Paulo e do Paraná. 
c) Aplicar os modelos OILCROP-SUN e o modelo FAO em várias localidades dos Estados de São Paulo e do Paraná, para a determinação das épocas de semeadura com menores riscos, para as condições de sequeiro e irrigada. 


\section{REVISÃO DE LITERATURA}

\subsection{Cultura do Girassol}

\subsubsection{Introdução}

O girassol é originário da América do Norte, mais precisamente do norte do México e do Estado de Nebraska nos EUA. Inicialmente foi domesticado e disseminado por todo o continente americano pelos ameríndios, que selecionaram preferencialmente plantas com uma única haste. Posteriormente, o girassol foi levado pelos colonizadores para o continente europeu, por volta do século XVI, como planta ornamental. A cultura foi introduzida na Rússia no século XVIII, e por volta de 1830, teve início a produção de óleo de girassol em escala comercial. A importância da planta em escala mundial, como fonte de óleo comestível, surgiu após a $2^{\circ}$ Guerra Mundial (Câmara,1998).

A utilização mais tradicional da cultura refere-se ao consumo in natura de seus frutos (aquênios) por humanos e aves. Mas atualmente, mais de $90 \%$ da produção mundial destina-se à produção industrial de óleo comestível (Câmara, 1998).

Roessing (1997) mostrou que o girassol foi a quinta maior produtora de grãos em utilização no mundo no período de 1991 a 1997 (Tabela 1), sendo explorada, praticamente, em todos os continentes (Cobia \& Zimmer, 1978). Atualmente, a Argentina, a Rússia, a Ucrânia, a França e os EUA são responsáveis por $56 \%$ da produção mundial, com um total de 20,9 milhões de hectares. A produtividade tem sido superior em regiões de clima temperado, embora exista excelente potencial nos climas tropicais, desde que seja desenvolvida tecnologia adequada. O Brasil ocupa a $45^{\text {a }}$ posição mundial, com uma produção de 30.000 ton $a^{-1}{ }^{-1}$, numa área de 60.000 hectares. 
Tabela 1 - Produção Mundial de grãos, em milhões de toneladas, das principais culturas de plantas oleaginosas, no período de 1991 a 1997.

\begin{tabular}{lrrrrrr}
\hline Oleaginosas & $1991 / 92$ & $1992 / 93$ & $1993 / 94$ & $1994 / 95$ & $1995 / 96$ & $1996 / 97$ \\
\hline Soja & 107,13 & 116,72 & 113,61 & 137,83 & 127,54 & 133,99 \\
Algodão & 36,60 & 31,53 & 29,72 & 32,99 & 35,20 & 34,05 \\
Colza & 27,87 & 25,36 & 27,01 & 30,22 & 31,94 & 30,63 \\
Amendoim & 22,24 & 23,17 & 23,46 & 26,45 & 25,43 & 26,14 \\
Girassol & 21,56 & 21,25 & 20,91 & 23,05 & 23,71 & 24,14 \\
Copra & 4,73 & 4,73 & 4,66 & 4,96 & 4,88 & 5,33 \\
Palm Kernel & 3,41 & 4,00 & 4,36 & - & - & - \\
\hline TOTAL & $\mathbf{2 2 3 , 5 4}$ & $\mathbf{2 2 6 , 7 6}$ & $\mathbf{2 2 3 , 7 3}$ & $\mathbf{2 5 5 , 5 0}$ & $\mathbf{2 4 8 , 7 0}$ & $\mathbf{2 5 4 , 2 8}$ \\
\hline
\end{tabular}

Fonte: Roessing (1997).

No Brasil, uma grande parte do território é considerada apta para o cultivo de girassol por apresentar condições climáticas satisfatórias (Ungaro, 1986). Na prática costuma-se dizer que quando as condições são boas para o milho, também são para o girassol.

Na década de 80, os Estados com maior potencial para a cultura eram São Paulo e Paraná, em especial este último, onde o girassol era plantado em sucessão à soja (Reyes et al., 1985). Atualmente, apesar da região Centro-Oeste ser considerada como a mais promissora para o desenvolvimento da cultura do girassol, está retornando ao Estado de São Paulo como uma alternativa para a rotação com a cultura de cana-deaçúcar (Câmara, 1997), principalmente, como uma opção para produção de silagem na safrinha.

Os principais problemas para o cultivo são: cultura relativamente nova no Brasil e falta de informações aos agricultores; poucas indústrias, levando a inseguranças quanto aos preços; pouca disponibilidade de genótipos resistentes às principais doenças; baixa tolerância a pequenos níveis de boro e acidez dos solos tropicais, fazendo com que a cultura seja mais exigente em fertilidade do solo; impedimentos de natureza química e fisica do solo; por fim, a elevada propensão ao ataque de pássaros na maturação final (Ungaro, 1986; Câmara, 1998). 
Apesar desses problemas, a cultura do girassol apresenta elevado potencial de produtividade e bom retorno financeiro, pois possui ampla adaptação a diferentes condições climáticas, ampla flexibilidade quanto às épocas de semeaduras, além de ampliar a possibilidade de uso de terras ociosas e permitir a utilização dos mesmos equipamentos destinados à cultura do milho, sorgo ou soja (semeadora e colhedora) com poucas adaptações; ela ainda é uma opção para sistemas de produção do tipo consorciação e rotação de culturas (Câmara, 1998).

Como o óleo de girassol possui melhores características em comparação as outras oleaginosas, existe um grande potencial para a cultura, visto que é crescente a demanda por produtos de melhor qualidade. O óleo de girassol é diferenciado por possuir uma alta concentração em ácido graxo linoléico (importante para prevenir e combater doenças cardiovasculares), alta capacidade de conservação por períodos prolongados, alto rendimento industrial e facilidade de extração do óleo, além da presença de vitaminas $A$, D e E (Rossi, 1997; Ungaro, 1981).

\subsubsection{Influência do clima na cultura}

\subsubsection{Temperatura e Fotoperíodo}

A duração do ciclo da cultura do girassol é afetada pelos seguintes elementos climáticos: temperatura do ar; radiação solar, precipitação e fotoperíodo (Goyne et al., 1978; Goyne \& Hammer, 1982; Rawson et al., 1984; Unger, 1990; Massignam \& Angelocci,1993a; Sentelhas et al. 1994). Entretanto, a temperatura e o estresse hídrico são considerados como os fatores de maior influência no desenvolvimento e rendimento da cultura (Goyne et al., 1978; Robinson, 1978; Rawson \& Hidmarsh, 1982). Na ausência de estresse hídrico, a radiação e a temperatura tornam-se os elementos de restrição à produtividade (Monteith, 1990; Chapman et al., 1993).

Considera-se que a temperatura média ideal para o desenvolvimento total da cultura varia de 15 a $30^{\circ} \mathrm{C}$ (El-Sharkawy \& Hesketh, 1964; Anderson,1977; Robinson,1978 e Silva,1981). 
A variação de temperatura afeta de forma diferenciada cada sub-período de desenvolvimento da cultura. Recém-germinada, a planta resiste a -4 a $-5^{\circ} \mathrm{C}$ (Pelegrini, 1985), todavia Schuster \& Boye (1971) verificaram que a exposição de seedlings às baixas temperaturas atrasa a época de florescimento. A ocorrência de geadas nos períodos de início do florescimento e de formação dos aquênios, causa o abortamento das flores, afetando a produtividade (Pelegrini, 1985).

As temperaturas diurnas e noturnas são igualmente importantes para o crescimento e desenvolvimento da cultura (Angelocci \& Villa Nova, 1985). A temperatura durante a floração afeta diretamente a fertilidade. Com temperaturas noturnas do ar superiores a $18^{\circ} \mathrm{C}$ e temperaturas diurnas ao redor de $25^{\circ} \mathrm{C}$, a secreção de néctar é mais abundante, facilitando a polinização por abelhas (Langridge \& Goodman, 1974). Harris et al. (1978) verificaram que altas temperaturas, particularmente à noite, causaram visível redução na qualidade de óleo, devido à desnaturação de enzimas que produzem o ácido linoléico, o que também foi verificado em condições brasileiras por Ungaro et al. (1997). Além das altas temperaturas, outros fatores podem ser responsáveis pela diminuição da quantidade de óleo: estresse hídrico (Talha e Osman, 1975); doenças (Brown et al., 1974); altos níveis de nitrogênio no solo (Onishchenko, 1968) e alta densidade populacional (Stoyanova, 1974).

A temperatura também interfere na taxa fotossintética uma vez que esta aumenta linearmente entre $0^{\circ} \mathrm{C}$ e $20-25^{\circ} \mathrm{C}$ (Paul et al., 1990), fica constante, por volta de 1,05 $\mathrm{g}\left(\mathrm{CO}_{2}\right) \cdot \mathrm{MJ}^{-1}(\mathrm{PAR})$, entre $24^{\circ} \mathrm{C}$ a $37^{\circ} \mathrm{C}$ (Chapman et al., 1993), e entre $37^{\circ} \mathrm{C}$ e $48^{\circ} \mathrm{C}$, decresce linearmente até zero (El-Sharkawy \& Hesketh, 1964).

Robinson (1978) e Sentelhas et al. (1994), consideram o girassol pouco sensivel ao fotoperiodo, por florescer numa larga faixa de comprimento do dia. Entretanto, existem discordâncias sobre o fotoperíodo adequado para o desenvolvimento da cultura após a iniciação floral. Alguns autores consideram que o desenvolvimento é promovido por dias curtos (Dyer et al., 1959; Schuster \& Boye, 1971), e outros por dias longos (Goyne et al.,1977; Anderson et al., 1978a;). Todavia, muitos destes trabalhos foram desenvolvidos em locais onde a temperatura e o fotoperiodo são fortemente 
correlacionados; nesta situação se torna difícil a observação dos efeitos puramente fotoperiódicos na cultura (Goyne et al. 1977).

Experimentos em ambientes controlados, foram desenvolvidos por Marc \& Palmer (1981) que, estudando a sensibilidade fotoperiódica na cultura do girassol, não encontraram diferenças significativas, no período de iniciação floral, em fotoperiodos entre 12 e 18 horas, sendo que, com 11 horas, o desenvolvimento dos primórdios foliares foi encurtado levando a uma antese precoce. Goyne \& Hammer (1982) constataram que, em fotoperíodos entre 10 e 12 horas houve uma redução no número de dias nos subperíodos emergência-aparecimento do botão floral e emergência-primeira antese, no número de folhas e na altura da planta na primeira antese. Em baixas temperaturas o cultivar Sunfola 68-2 apresentou resposta como neutro e o cultivar Hysun 30 como de dias longos. Em altas temperaturas ambos os cultivares apresentaram respostas como de dias curtos. Esses resultados demonstram que, no geral, a resposta ao fotoperíodo, depende da temperatura e do material genético utilizado.

Apesar da pouca sensibilidade ao fotoperíodo, tudo indica que o florescimento do girassol é governado por fatores ambientais, tais como temperatura e fotoperíodo conjuntamente (Goyne et al., 1977; Anderson et al. 1978b; Marc e Palmer, 1981; Goyne e Hammer, 1982), estresse hídrico (Mark \& Palmer, 1976), e fatores da própria planta, como a formação de no mínimo 12 a 13 pares de folhas (Habermann \& Wallace, 1958).

$O$ fotoperiodo longo tende a diminuir o periodo de florescimento e induz ao alongamento do caule. Fotoperíodos curtos agem de modo oposto, aumentando o período de florescimento e diminuindo o alongamento do caule (Dyer et al., 1959).

\subsubsection{2 Água}

A cultura tem necessidade hídrica de 600 a $1000 \mathrm{~mm}$ durante o seu ciclo, dependendo, fundamentalmente, do clima e da cultivar (Doorenbos \& Kassam, 1979). Da totalidade de água absorvida pela planta durante seu ciclo vegetativo, em média $22,4 \%$ são gastos desde a emergência até o início da formação do capítulo; cerca de $60 \%$ 
são absorvidos no período entre a formação do capítulo e início da floração e os $17,6 \%$ restantes, usados entre a floração e a colheita (Almeida, 1970).

Goyne et al. (1978) verificaram que o estresse hídrico é o principal fator de perda de rendimento do girassol, principalmente devido aos efeitos sobre a área foliar. Todavia, o excesso de chuvas e dias nublados durante o florescimento também são prejudiciais, podendo acarretar considerável quebra de produção (Ungaro, 1986).

Apesar do girassol produzir satisfatoriamente em condições de deficiência hídrica, em razão de seu sistema radicular denso e profundo (Robinson, 1978), existem três fases críticas que podem ser consideradas (Birch, 1982):

a) condições desfavoráveis de umidade no solo na semeadura poderá resultar em aumento excessivo no sub-período semeadura-emergência, com redução da população inicial de plantas;

b) restrição hídrica entre a diferenciação floral até o final da antese, causará quebras de produtividade de grãos (Talha \& Osman, 1975; Doorenbos \& Kassam, 1979; Ungaro, 1981);

c) estresse hídrico entre o enchimento de grãos e maturação, ocasionará perdas na quantidade e qualidade de óleo.

Além destas fases críticas, quebras de produtividade podem ocorrer, também, devido à presença de mancha de alternária (Alternaria helianthi, Hansf.), a principal doença da cultura. Sentelhas et al. (1996), trabalhando com os cultivares IAC-Anhandy, Contisol-621 e VNIIMK, constataram que essa doença está diretamente relacionada à quantidade de chuva e a temperatura mínima do ar durante o ciclo.

\subsection{Modelagem e Simulação da Produtividade de culturas}

\subsubsection{Conceitos e definições}

Modelo é a representação matemática de um sistema e modelagem é o processo de desenvolvimento desta representação (Jones et al., 1987). Em um sentido mais geral, pode-se dizer que modelo é o mesmo que hipótese (Jones et al., 1987) ou teoria 
(Philip,1991). Como tais, devem ter pressupostos claros e produzir respostas que possam ser testadas (Boote et al., 1996). Normalmente, os modelos de simulação de culturas dão enfoque orientado a processos. Os processos são encaixados em três categorias: transporte ou fluxo, transformação e armazenamento de massa ou energia, as quais são descritas por variáveis extensivas ou intensivas (Jones et al., 1987).

Os trabalhos sobre interceptação de luz, fotossintese e respiração, realizados por Loomis \& Williams (1963), De Wit (1965), Duncan et al. (1967) e de Wit et al. (1978), possibilitaram os primeiros passos na modelagem de culturas, pois o crescimento e a produtividade potencial tornaram-se quantitativamente relacionados ao total de energia do ambiente e ao total de biomassa das plantas.

A modelagem computadorizada, para simulação de culturas, surgiu por volta da década de 70, quando sistemas de análise e computadores apresentaram-se como novas ferramentas de trabalho para os pesquisadores (Bowen et al., 1973; de Wit \& Goudriaan, 1974).

Atualmente, o conhecimento de várias disciplinas como fisiologia vegetal, agrometeorologia, ciência do solo e agronomia são integradas de uma forma consistente, possibilitando simulações acuradas da dinâmica do crescimento de culturas e de sistemas agrícolas (Jame \& Cutforth, 1996). Normalmente, para se agregar todas estas áreas do conhecimento, os modelos são compartimentalizados em sub-modelos (Boote et al., 1996).

$\mathrm{O}$ uso de modelos de simulação de culturas na pesquisa tem aumentado substancialmente, o que é decorrente da melhoria de técnicas de modelagam e da maior capacidade dos computadores na realização de cálculos (Hanks \& Ritchie, 1991; Penning de Vries et al. 1991).

Apesar disso, a modelagem está ainda em um estágio inicial de desenvolvimento, uma vez que muitos modelos simulam apenas os principais fatores que afetam as culturas, como por exemplo, clima, água, disponibilidade de nitrogênio no solo e carbono para a fotossintese. Avanços na modelagem poderão incluir novos componentes como os efeitos do preparo da terra, pragas, doenças, ervas daninhas, salinidade do solo, excesso de água, entre outros (Jame \& Cutforth, 1996). 
Dois tipos distintos de modelos (ou sub-modelos) surgiram logo nos primeiros trabalhos: um essencialmente prático, que se baseava em análises de regressões para prever o desenvolvimento da cultura e outro, que procurava aumentar o conhecimento científico, procurando estabelecer as causas e os efeitos dos processos físicos e biológicos que ocorriam nas plantas e no ambiente (Passioura, 1973). Essas duas visões correspondem ao que Addiscott \& Wagenet (1985) chamaram de modelos funcionais e mecanísticos. Atualmente, segundo Monteith (1996), os modelos funcionais passaram a ser chamados de empíricos.

O uso de correlações e análises de regressões aplicadas em modelos empíricos fornecem um entendimento qualitativo das variáveis e suas interrelações, ou seja, mostram quais elementos do clima têm um maior poder de interferência sobre determinado processo na planta. Já as informações quantitativas, obtidas deste tipo de análise, são muito específicas para o local estudado, podendo esses modelos somente ser em usados em outras regiões se as condições climáticas, de solo e de manejo da cultura forem similares (Jame \& Cutforth, 1996; Passioura, 1996). Entretanto, com a devida calibração, alguns modelos empíricos vêm provando sua utilidade (Passioura, 1996).

Já os modelos mecanísticos procuram obter um melhor entendimento das relações de causa e efeito, visando uma melhor interpretação quantitativa e qualitativa do sistema. (Jones et al., 1986; Passioura, 1996). Um modelo desse tipo possui um forte embasamento físico e biológico, incluindo os mais importantes processos que governam o crescimento e o desenvolvimento da planta: fases fenológicas, desenvolvimento do dossel, ontogenia dos órgãos da planta, taxa de fotossíntese, alocação de assimilados e balanço de água, nitrogênio e carbono (Jame \& Cutforth, 1996). Por terem essas características, geralmente são mais adaptáveis para usos em diferentes condições climáticas e promovem uma síntese do conhecimento sobre os diversos aspectos que governam o desenvolvimento e a produtividade de determinada cultura (Boote et al. 1996).

Segundo Costa (1997), existem ainda outras subdivisões para a classificação dos modelos: os modelos determinísticos e os estocásticos. Modelos determinísticos são aqueles que as respostas, ou os resultados obtidos, são fornecidos sem nenhum grau de 
probabilidade. Normalmente, o determinismo da resposta é uma característica dos modelos mecanísticos. Modelos estocásticos são aqueles que apresentam algum grau de probabilidade associado à sua resposta, característica comum dos modelos empíricos.

$\mathrm{Na}$ realidade, a maioria dos modelos de simulação de culturas são uma mistura de empiricismo e mecanicidade. Mesmo os mais mecanísticos dos modelos usam empiricismo em algum nivel hierárquico de sua estrutura (Boote et al., 1996).

Monteith (1981) constatou que não existe melhoria na previsão de produtividade com o aumento da complexidade dos modelos, independentemente do seu tipo. Devido a isto, alertou que as pesquisas deveriam fazer esforços para condensar seus modelos, removendo componentes que contribuam somente com 'ruídos', ou seja, aqueles que não trazem melhorias significativas nas previsões numéricas nos resultados finais (Monteith 1996).

Existe um grande número de exemplos em que modelos altamente detalhados ou reducionistas tiveram um desempenho pior do que modelos simples na previsão de produtividade. Por exemplo, na cultura do algodão, um modelo de balanço hídrico simples foi superior aos modelos COTTAM e GOSSYM (Asare et al., 1992). Uma equação empírica teve melhor desempenho que o modelo CERES na previsão da produtividade potencial do trigo no México (Bell \& Fischer, 1994). O modelo SOYGRO foi inferior à uma simples média ponderada na previsão de produtividade de soja (Colson et al. 1995). Entretanto, muitas vezes deve-se considerar as limitações dos modelos empíricos, como já discutido anteriormente.

A estimativa e a exploração dos limites da produtividade das culturas é uma das prioridades da maioria dos programas de pesquisa agrícola e, a partir disso, a modelagem e o teste de modelos em novos ambientes têm sido uma prática constante (Barni et al. 1995). Segundo Jones et al. (1987), as etapas na modelagem e/ou a utilização de um modelo para novas condições ambientais compõem-se de:

a) Desenvolvimento: criação de um modelo teórico e a elaboração de um programa;

b) Verificação: é o processo pelo qual a lógica da programação é comparada com o modelo teórico proposto; 
c) Calibração: é o ajuste feito nos parâmetros do modelo para dar a melhor acurácia entre os dados medidos e os simulados. Nos modelos empíricos, a calibração é o único meio pelo qual os coeficientes do sistema podem ser determinados. Apesar da calibração ser contrária ao princípio dos modelos mecanísticos, ela é necessária na adaptação de um modelo existente para uma nova região. Este procedimento pode ser descartado somente quando um modelo mecanístico 'perfeito' é desenvolvido, o que atualmente é impossível (Monteith, 1996). A calibração deveria ser conduzida usando poucos e bem definidos experimentos no qual o solo, as condições climáticas e os detalhes do crescimento da cultura fossem cuidadosamente monitorados, caso contrário, muito tempo seria perdido no processo de tentativa-e-erro para o ajuste de curvas especificas (Jame \& Cutforth, 1996; Boote et al. 1996).

Na etapa de calibração dos modelos, comumente são usados critérios estatísticos para determinar o grau de ajuste entre os dados simulados e os medidos; como: a linha simulada passando dentro de um certa faixa de desvio padrão; a minimização da soma dos quadrados dos erros dos dados simulados; alto valor de $r^{2}$, preferencialmente próximo à linha 1:1 com intercepto em zero (Boote, 1994). Às vezes, é necessário o uso de meios mais avançados na calibração, como a utilização das técnicas de regressão linear e não-linear. Por exemplo, o método simplex 'dowhill', foi usado para estimar os parâmetros fenológicos na cultura da soja, minimizando o erro do quadrado da soma entre os dados observados e simulados (Grimm et al., 1993). Villalobos et al. (1996) utilizou a técnica de otimização multivariada para a determinação dos coeficientes do modelo OILCROP-SUN na cultura do Girassol.

d) Validação: é a determinação se o modelo trabalha bem com dados totalmente independentes, isto é, se ele prevê acuradamente o crescimento, produção e outros processos, usando dados que não foram previamente utilizados nas etapas de desenvolvimento e calibração (Jones et al., 1987). Normalmente, os resultados do processo de validação são usados para refinar o modelo ou guiar os pesquisadores a mais experimentos que produzirão um modelo melhor.

Oreskes et al. 1994 propuseram ser possível invalidar um modelo, jamais "tornálo válido" pois, como observado por Costa (1997), um modelo é uma teoria científica e 
como tal, pode ser falsificada mas nunca validada. A partir disto, o último autor propõe o termo "teste" do modelo.

De acordo com Monteith (1996), os pesquisadores se preocupam em demasia com rigorosas calibrações e validações, esquecendo que o conhecimento dos processos físicos e biológicos de certas culturas, muitas vezes, é incipiente.

\subsubsection{Importância do uso de modelos de simulação da produtividade agrícola}

A elaboração de modelos matemáticos de previsão do rendimento de uma cultura oferece uma série de vantagens pois: (i) o modelo resume, convenientemente, grande quantidade de informações; (ii) a modelagem estimula novas idéias e novas linhas de investigação científica; (iii) a elaboração de um modelo ajuda a detectar áreas onde o conhecimento é limitado; (iv) o modelo permite interpolações e previsões; (v) informações sobre diferentes processos fisiológicos podem ser reunidas em um único modelo para se ter idéia da cultura como um todo; (vi) a base matemática para as hipóteses adotadas permite compreender, quantitativamente, a natureza das interações ambiente-planta; (vii) possui uma forte aplicabilidade no ensino de qualquer nível, e, por fim, (viii) explorar estratégias para o gerenciamento e diminuição dos riscos na agricultura (Thornley, 1976). As novas idéias, advindas da modelagem, podem ser úteis para futuras ações, mesmo quando os resultados do modelo não foram ainda testados (Sinclair \& Seligman, 1996).

Possivelmente, o mais promissor uso de modelos de simulações será como ferramenta para a educação de agricultores. Eventualmente, os modelos de simulação se tornarão o principal agente para a transferência de tecnologia, juntamente com os serviços de extensão, cursos rápidos e boletins técnicos (Jame \& Cutforth, 1996). Bons agricultores são, geralmente, bons observadores do que está acontecendo nos seus campos; o envolvimento deles com modelos pode aumentar sua capacidade de observação (Hearn \& Brook, 1989). Atualmente, com o advento da Internet, a rapidez e o baixo custo poderão ser um agente na disseminação da utilização de modelos (Peart \& Curry, 1998). 


\subsubsection{Emprego de Modelos de Simulação no planejamento agrícola}

Modelos de crescimento de culturas têm sido usados como ferramentas de manejo para implementar e verificar a produtividade potencial de culturas em novas localidades (Aggarwal \& Penning de Vries, 1989; Muchow et al., 1991), para estimar a sensibilidade da produção em mudanças climáticas (Williams et al., 1988), para prever a produtividade antes da colheita (Duchon, 1986; Antunes et al., 1997; Camargo et al., 1999; Moraes et al., 1999; Ortolani et al., 1996; Barros et al., 1999), melhorar técnicas de manejo (van Keulen \& Wolf, 1986), otimizar a data de semeadura (Cardoso et al., 1999), melhorar a densidade de plantio, ajustar o espaçamento entre linhas, auxiliar na escolha de cultivares e aplicação adequada de fertilizantes para diferentes tipos de solos (Egli \& Bruening, 1992; Keating et al., 1993; Sing, 1993).

Dois exemplos interessantes de modelos que simulam a fenologia da cultura e que são usados para o controle de pragas são: o modelo SIRATAC para algodão na Austrália (Ives \& Hearn, 1987) e o modelo EPIRE para trigo na Holanda (Rabbinge \& Rijsdijk, 1983). Para os agricultores se beneficiarem do modelo, é necessário a afiliação ao sistema computacional; para tanto devem pagar uma taxa mensal e fornecer dados de suas glebas para o sistema. No centro de processamento, simulações são feitas para prover os agricultores de informações atualizadas do manejo para aquele período. Nos dois casos, há um constante crescimento de produtividade resultado de um manejo adequado de pragas. Entretanto, ambos os sistemas sofrem com a perda de membros depois dos sucessos iniciais. Este declínio na participação não é devido à insatisfação com o modelo, mas resulta do fato de que os agricultores aumetaram sua capacidade de observação de suas glebas, tornando-se autosuficientes em suas decisões (Weiss, 1994).

\subsubsection{Modelos de simulação da fenologia e produtividade da cultura do girassol}

A determinação da duração de eventos fenológicos em culturas é de extrema importância para a boa performance de modelos, principalmente para detectar o efeito de 
diferentes ambientes (Ritchie,1980). Isto se deve ao fato de que cada evento, no desenvolvimento das plantas, possui uma sensibilidade própria aos diversos estímulos do ambiente (Anderson, 1978b).

Siddiqui et al. (1975) desenvolveram uma classificação dos estágios de desenvolvimento do girassol; mas esta destinava-se à avaliação de doenças sendo muito detalhada para o uso em modelos de produtividade. Uma descrição mais apropriada para uso em modelos foi desenvolvida por Robinson (1978). Entretanto, não atendia às exigências dos modelos, podendo ser melhorada para dar uma definição mais acurada de alguns estágios descritos. Schneiter \& Miller (1981) desenvolveram, então, um sistema acurado e de fácil utilização. Eles dividiram a fenologia da cultura em duas grandes fases: $\left.1^{a}\right)$ a vegetativa $(V)$, subdividida em emergência até primeira folha e desenvolvimento posterior contabilizado pelo número de folhas verdadeiras (maiores que $4 \mathrm{~cm}$ de comprimento); $2^{2}$ ) a reprodutiva ( $R$ ), dividida em nove estágios baseados no desenvolvimento da inflorescência até a maturidade fisiológica das sementes.

O índice térmico, desenvolvido pelas idéias de Reáumur em 1735 (Wang, 1960), tem sido o método mais usado para previsões da duração de eventos fenológicos em culturas. Originalmente, ele assumiu que existia uma relação linear entre a taxa de desenvolvimento e a temperatura do ar. Atualmente, o conceito do índice térmico baseia-se no fato de que para uma planta atingir certo grau de desenvolvimento ela necessita de uma certa quantidade de energia. Esta energia é representada pelo somatório diário de temperaturas dentro da faixa das temperaturas-base no período considerado (Cross \& Zuber, 1972).

A validade biológica deste conceito tem sido questionada por diversos autores, como Went (1957) e Wang (1960), e sua utilização tem sido modificada para levar em consideração, por exemplo, a não-linearidade de respostas da taxa de crescimento (Gilmore \& Rogers, 1958; Massignam \& Angelocci, 1993) e a influência do fotoperíodo e estresse hídrico na resposta à temperatura (Brown \& Chapman, 1960; Thompson, 1969; Anderson et al., 1978b, Massignam \& Angelocci, 1993a). Apesar de suas limitações, Sentelhas \& Ungaro (1997) mostraram que o conceito do índice térmico foi o que apresentou menor variabilidade quando aplicado a diferentes cultivares de girassol. 
$\mathrm{O}$ índice térmico pressupõe a existência de uma temperatura-base inferior, que é aquela abaixo da qual a planta não se desenvolve e se o fizer, será em taxas muito reduzidas (Massignam \& Angelocci, 1993b). Ela pode ser calculada pelos seguintes métodos: método da minimização da variabilidade do coeficiente de variação, método do desvio padrão, método da regressão e método de intersecção da abscissa. Existem discordâncias na avaliação do melhor método (Arnold, 1959; Massignam \& Angelocci, 1993a), haja visto que muitas vezes a temperatura-base encontrada não tem representatividade fisiológica mas meramente estatística.

Goyne et al. (1989), classificaram 16 cultivares em grupos de respostas à temperatura. Quatro grupos distintos, em relação à duração do sub-período emergência aparecimento do botão floral foram classificados em: super-precoce, precoce, médio e tardio.

As temperaturas-base dos cultivares IAC-Anhandy, VNIIMK e do híbrido Contisol-621 foram determinadas por Sentelhas et al. (1994) como sendo iguais a $4,7^{\circ} \mathrm{C}$; $3,7^{\circ} \mathrm{C} ; 4,1^{\circ} \mathrm{C}$ respectivamente. Num estudo posterior com estes mesmos genótipos, no qual foram testados vários índices bioclimáticos, concluiu-se que o índice térmico foi o mais adequado para a estimativa da duração do ciclo total. $\mathrm{O}$ somatório de graus-dia para se completar o ciclo dos cultivares foram iguais a $1738^{\circ} \mathrm{C}$.dia para o IAC-Anhandy, $1714^{\circ} \mathrm{C}$.dia para o Contisol-621 e $1851{ }^{\circ} \mathrm{C}$.dia para o VNIIMK (Sentelhas \& Ungaro, 1997), utilizando-se uma temperatura-base de $4,2^{\circ} \mathrm{C}$ para os três cultivares.

Além da temperatura, outra variável importante para a determinação da duração dos estágios vegetativos e/ou reprodutivos na cultura é o fotoperíodo.

Muitas vezes, os trabalhos não identificam a interferência do fotoperíodo no desenvolvimento da cultura pela estreita relação existente entre ele e a temperatura (Massignam et al., 1993; Sentelhas et al., 1994).

Goyne et al. (1989) concluíram que modelos usados para prever o desenvolvimento do girassol poderão ser baseados somente na temperatura se o fotoperíodo estiver entre 14,5 a 16,2 horas. Para prever o desenvolvimento fora desta faixa, o fotoperíodo deverá ser incluído nos modelos. 
Modelos matemáticos baseados na variação de temperatura e fotoperíodo têm sido desenvolvidos para a previsão de sub-períodos na cultura do girassol. Anderson et al. (1978a) usando técnicas de análises estatísticas, desenvolveram um modelo de regressão múltipla, o qual incorporava a temperatura, o fotoperíodo e a umidade do solo, mostrando-se superior aos modelos de Keefer et al. (1976) e Goyne et al. (1977), que utilizavam unicamente o somatório de graus-dia para a previsão de vários sub-periodos da cultura.

O modelo de Hammer et al. (1982), que utiliza também o fotoperíodo e a temperatura, mostrou-se adaptável a diferentes condições climáticas e acurado para a previsão da antese na Austrália.

No caso da produtividade, outro importante componente em um modelo de crescimento de culturas é a modelagem da área foliar, a qual tem uma grande influência nas taxas de fotossíntese e transpiração (Warrington \& Kanemasu, 1983; Villalobos e Ritchie, 1992). A área foliar no girassol exerce grande influência no acúmulo de biomassa, portanto, o conhecimento de como a área foliar é controlada torna-se importante fator para o entendimento do crescimento da cultura. Para isto, deve-se considerar o número de folhas, a duração e a taxa de expansão de folhas individuais (Rawson \& Turner, 1982).

A taxa de aparecimento foliar em girassol é afetada pela temperatura e fotoperíodo conjuntamente (Rawson e Hindmarch, 1982), pelo estresse hídrico (Takami et al., 1981) e pela radiação solar (Rawson e Hindmarch, 1983). A taxa de desenvolvimento da área foliar depende, também, de condições ambientais durante os estágios iniciais do desenvolvimento da planta (Villalobos e Ritchie, 1992).

Estudos em casa de vegetação mostraram que a temperatura-base para a taxa de aparecimento de folhas foi igual a $4^{\circ} \mathrm{C}$ e que ela aumenta com temperaturas superiores a $27^{\circ} \mathrm{C}$. No mesmo estudo, o índice térmico em graus-dia por folha, ficou entre 20 e 25 ${ }^{\circ} \mathrm{C}$.dia (Villalobos \& Ritchie, 1992).

Barni et al. (1995), confirmando resultados prévios de outros autores, demonstraram que é possivel a previsão do índice de área foliar pelo somatório de grausdia e, a partir disto, a previsão do rendimento máximo. Observou, também, que a 
absorção da radiação solar fotossinteticamente ativa é estreitamente associada ao IAF e à estrutura da vegetação, resumida pelo coeficiente de extinção.

O estresse hídrico é uma das variáveis ambientais de penalização da produtividade na cultura do girassol. Os primeiros trabalhos que relacionaram a produção de matéria seca com a quantidade de água transpirada foram realizados por Briggs e Shantz $(1913)^{1}$, citados por Hanks \& Rasmussen (1982). Estes autores constataram a existência de relação linear entre as duas variáveis, para diversas culturas.

Para Monteith (1965), a estreita relação entre produção de matéria seca e transpiração pode ser explicada pelo fato de que o saldo de radiação (que determina em grande parte a intensidade de transpiração) e a radiação solar fotossinteticamente ativa (que determina a fotossíntese) são relacionados de forma linear.

A evapotranspiração relativa, relação entre evapotranspiração real e potencial, foi usada por Barni et al. (1996) no modelo multiplicativo de Jensen (1968) para a estimativa da produtividade de grãos de girassol. Os resultados mostraram uma elevada associação entre o rendimento de grãos e a evapotranspiração relativa no sub-período reprodutivo, para todos os cultivares avaliados. O modelo de Jensen (1968) pressupõe que existe relação do rendimento relativo de grãos e a evapotranspiração relativa em distintos sub-períodos do desenvolvimento da cultura.

O modelo de Smith et al. (1978), baseado em regressões múltiplas, simula o crescimento e a produtividade do cultivar Peredovik, o mais plantado na Austrália na época. Este modelo utiliza dados de umidade do solo, temperatura média diária e radiação solar, e foi usado para analisar dados semanais médios de 455 estações ao redor da Austrália, para definir áreas de potencial de produção sem irrigação. Uma das deficiências do modelo é a falta de simulação de doenças em áreas costeiras, onde há condições de umidade elevada. Apesar desta ressalva, o modelo fez boas previsões quando comparado com dados medidos em campo. A análise também mostrou a importância do nível de armazenamento de água no solo na simulação da produtividade nas áreas secas do interior da Austrália.

\footnotetext{
'BRIGGS, L.; SHANTZ, H. L. The water requirement of plants. I. Investigations in the Great Plains in 1910 and 1911. Bull. n² 284. U.S. Plant Ind., Washington, D. C., 1913.
} 
O cálculo do balanço hídrico pode ser usado para determinar se o ambiente é limitado energeticamente (suprimento hídrico pelo ambiente $>$ demanda hídrica pela cultura) ou limitado hidricamente (demanda hídrica pela cultura $>$ suprimento ), oferecendo meio simples para calcular a produção de biomassa, por considerar tanto a radiação interceptada e o uso eficiente da radiação em uma situação de limitação energética quanto a transpiração e a eficiência da transpiração em uma situação de limitação hídrica. Os coeficientes de uso eficiente de radiação e transpiração são constantes para uma cultura, não variando entre os diferentes ambientes (Monteith, 1981).

O modelo QSUN, desenvolvido por Chapman et al. (1993) para a cultura do girassol, usa a teoria de suprimento / demanda hídrica e energética, estimando o crescimento, o desenvolvimento e a produtividade de grãos. Dados diários de temperatura e fotoperíodo levam o sub-modelo de fenologia a prever os sub-periodos de emergência, aparecimento do botão floral, $50 \%$ da antese e maturidade fisiológica. Usando estes estágios, o sub-modelo de crescimento, juntamente com dados de radiação solar, precipitação e temperatura, estima a produção e senescência da área foliar e a extração de água do solo. A produção de biomassa é calculada do montante de radiação solar interceptada pelas folhas ou pelo montante de água disponível no sistema radicular, dependendo do fator limitante para o crescimento da cultura, radiação ou precipitação. A produtividade de grãos é calculada pela alocação de biomassa para os grãos na antese. A sensibilidade do modelo foi testada em diversos regimes de irrigação, indicando que o modelo QSUN foi mais sensível na razão biomassa produzida / água transpirada e na taxa de extração de água em situações de limitação hídrica.

$\mathrm{O}$ acúmulo de biomassa pode ser descrito em função da quantidade de radiação fotossinteticamente ativa (PAR) absorvida pelo dossel e a eficiência na qual a energia radiante é transformada em biomassa, ou seja, o montante de matéria seca produzida por unidade de PAR interceptada (Gallanger e Biscoe, 1978; Jones e Kiniry, 1986).

Barni et al. (1995) constataram que a eficiência energética da cultura do girassol é de $2,457 \mathrm{~g}$ (matéria seca). $\mathrm{MJ}^{-1}$ (PAR) entre a emergência até o final da antese e que é 
possível a determinação do rendimento máximo (sem deficiência hídrica) com base na radiação solar e temperatura do ar.

O modelo mecanístico desenvolvido por Steer et al. (1993) simula o crescimento e a produtividade para os cultivares australianos Hysun 30, HY30, SS132H, SS152H e SS25H. Nesse modelo, a taxa de crescimento da cultura está em função do uso eficiente da radiação solar, radiação incidente, coeficiente de extinção e índice de área foliar.

Um fator relacionado à concentração de nitrogênio, modula o crescimento da cultura através do seu efeito na taxa de expansão de cada folha e na taxa de senescência foliar depois da antese. Neste sentido, a concentração de nitrogênio nas folhas na iniciação floral e a densidade populacional no campo, afetam a acumulação de matéria seca da cultura. Entretanto, este modelo considera somente situações de culturas irrigadas.

Para o desenvolvimento de modelos mais mecanísticos, além do conhecimento do acúmulo de biomassa, é necessário que se determine como esta é dividida entre os diversos órgãos da planta (raízes, caule, folhas e capítulo) (Ritchie, 1991). Sabe-se que a densidade de plantio ocasiona um efeito na partição de biomassa e na produtividade da cultura (Villalobos et al., 1994). Todavia, ainda é necessário um conhecimento mais profundo sobre os processos fisiológicos que levam à esta partição (Thornley, 1972). Esta situação leva a uma necessidade de descrições quantitativas confiáveis de partição, para que se possa modelar o crescimento e a produtividade da cultura. Os coeficientes de partição, definidos como a taxa de crescimento de cada órgão em relação à taxa de crescimento da planta, são os parâmetros usados em modelos que descrevem esta variação no desenvolvimento de cada órgão em uma planta (Fick et al., 1973).

Hoire (1977) produziu uma descrição complexa da partição de biomassa para o girassol. Seu trabalho requer, entre outros dados, a estimativa da respiração de cada órgão nas fases de manutenção e de crescimento, que resulta em um coeficiente específico para cada órgão, que varia continuamente durante o desenvolvimento da cultura. Trapani et al. (1994) produziram um sistema de cálculo para descrever a partição de matéria seca, simples e robusto. Considerou-se que os coeficientes de partição permaneciam constantes durante cada sub-período da cultura, usando uma 
rotina de otimização não-linear para o cálculo de cada valor. Esse sistema foi utilizado, posteriormente, no modelo OILCROP-SUN (Villalobos et al., 1996).

Desse modo, verifica-se que, modelos de simulação da fenologia e da produtividade podem ser desenvolvidos em vários graus de complexidade, por exemplo, desde um modelo de soma térmica até um modelo de balanço de carbono para a partição de biomassa. O nível de complexidade requerido depende do objetivo a ser cumprido. A Figura 1 resume o fluxo de informações usadas por vários modelos aqui discutidos, na construção do conhecimento, na modelagem da cultura do girassol.

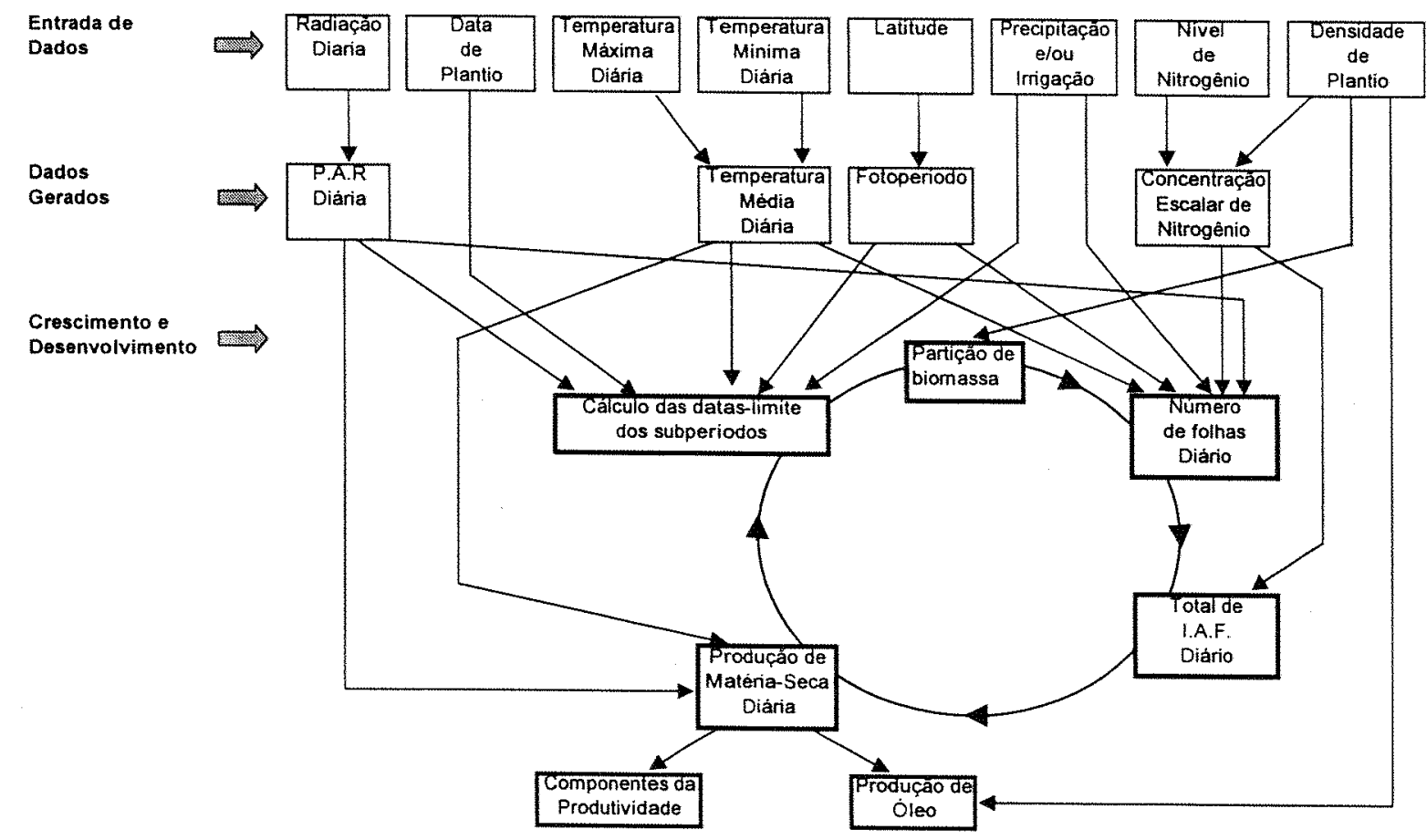

Figura 1 - Fluxo de informações que representa o conhecimento atual sobre a modelagem em girassol (modificado de Steer et al., 1993).

\subsubsection{Modelo FAO}

O modelo FAO para o cálculo da produtividade potencial e real (Doorenbos \& Kassam, 1979) é muito utilizado em projetos de sistemas de irrigação pois enfoca justamente a perda de produtividade em decorrència do déficit hídrico. 
Este modelo tem a limitação de poder ser usado somente com uma deficiência hídrica relativa de no máximo 50\% (Doorenbos \& Kassam, 1979). Outro fator que limita sua utilização é quando o coeficiente de sensibilidade $(\mathrm{ky})$ perde a sua eficácia devido a alterações no nível de manejo ou na tecnologia de produção utilizada, afetando as respostas da cultura em relação ao déficit hídrico. Este fato foi confirmado por Pedro Júnior et al. (1984) que, utilizando o modelo para a cultura da soja em diversas regiões do Estado de São Paulo, constatou que as diferenças de tecnologia foram responsáveis por variações de 8 a $25 \%$ nas estimativas de produtividade potencial e real.

Devido a estas limitações, o modelo tem sido modificado para considerar outras variáveis como a penalização da produtividade pelo extresse térmico, excedente hídrico (Camargo et al. ,1986; Ferraudo et al., 1995; Ortolani et al., 1996) e variações no índice de área foliar nas diferentes fases fenológicas (Barbieri \& Tuon, 1992), para uma melhor estimativa da produtividade.

Outra aplicação do modelo FAO é para a determinação das melhores épocas de semeadura, como realizado por Alfonsi (1996), para a cultura do milho, e por Pezzopane et al. (1997), para a cultura do feijão, ou, ainda, para detectar os efeitos das variações da disponibilidade hídrica na produtividade de diferentes culturas, como para o milho (Matzenauer et al., 1995; Soares, 1996); para o moranguinho (Serrano et al., 1992); e para a soja (Pedro Júnior et al., 1985). Esse modelo também é utilizado na otimização da irrigação, auxiliando na conservação de água em áreas agrícolas, como mostrado por Bernardo et al. (1988).

Poucos trabalhos são encontrados na literatura envolvendo a aplicação do modelo FAO para a cultura do girassol. Marin et al (1999) aplicou o referido modelo na tentativa de caracterizar as melhores épocas de semeadura para a cultura em três locais do Estado de São Paulo, encontrando resultados que confirmam aqueles obtidos em experimentos de campo (EMBRAPA, 1983; Campbell \& Athayde, 1988; Bevitóri \& Balla, 1997) que determinam o final de fevereiro como data limite à semeadura do girassol. 


\subsubsection{Modelo DSSAT / OILCROP-SUN}

Atualmente, sistemas informatizados de suporte à decisão estão disponíveis, permitindo, aos usuários, combinar o conhecimento da fenologia de uma cultura, às diversas opções de manejo, assim como aos aspectos econômicos. O sistema DSSAT (Tsuji et al., 1994), sistema de suporte à decisão para a transferência de agrotecnologia (Decision Suport System for Agrotechnology Transfer), é um exemplo de ferramenta de manejo que possibilita que administradores rurais combinem requerimentos biológicos de uma cultura às características físicas do ambiente para se obter objetivos específicos (Jame \& Cutforth, 1996). Ele foi desenvolvido pelo projeto IBSNAT (International Benchmark Sites Network for Agrotechnology Transfer), rede de referência internacional para a transferência de agrotecnologia.

O DSSAT é essencialmente um gerenciador de diversos modelos de culturas. Ele possibilita aumento nas capacidades de análise dos modelos por permitir (i) entrar, organizar e armazenar modelos e dados; (ii) calibrar e validar modelos de crescimento e (iii) avaliar diferentes técnicas de manejo em uma dada região (iv) realizar análises pontuais ou espaciais, utilizando um sistema de informações geográficas.

O verdadeiro valor do sistema DSSAT para a tomada de decisões se baseia na habilidade para analisar diferentes estratégias de manejo para uma cultura. A análise da performance de uma cultura poderá ser feita para diferentes tipos de solo, diferentes cultivares, datas de semeadura, densidade de semeadura e diferentes estratégias de irrigação e fertilização para a minimização dos riscos (Jame \& Cutforth, 1996).

O sistema DSSAT inclui modelos para as seguintes culturas: trigo, arroz, milho, cevada, sorgo, milheto, feijão, soja, amendoim, grão-de-bico, batata, mandioca, cana-deaçúcar, tomate, girassol e pastagem. Pode-se citar como exemplo os modelos das famílias CERES e GRO. O milho (Jones \& Kiniry, 1986; Ritchie, 1989) e trigo (Godwin et al., 1990) fazem parte da familia CERES e a soja (Jones et al., 1989), amendoim (Boote et al., 1989) e feijão (Hoogenboom et al., 1991) fazem parte da família GRO. Esses modelos simulam o crescimento, o desenvolvimento e a produtiviade para cultivares específicos, levando-se em consideração clima. dinâmica da umidade e do 
nitrogênio no solo e na cultura, de uma forma mecanística (Jones et al. 1989; Ritchie et al., 1990). Atualmente, os modelos não simulam o efeito de pragas e doenças nem o impacto da falta de nutrientes, com exceção para o nitrogênio (Goodwin et al., 1990). Nesses modelos a habilidade para suportar genótipos específicos é possibilitada pela incorporação de coeficientes genéticos que especificam como um dado genótipo responderá aos fatores ambientais (IBSNAT, 1989).

Em 1996, Villalobos et al. incluiram o modelo orientado a processos OILCROPSUN no sistema DSSAT, para modelar o crescimento e a produtividade da cultura do girassol, a partir de dados de temperatura, radiação e disponibilidade de água. Para tanto, o modelo simula a biomassa, o conteúdo de nitrogênio dos órgãos (raízes, caule, folhas e capítulo), o índice de área foliar e o balanço de água e nitrogênio no solo na escala diária. Os mesmos autores testaram o modelo com dados fenológicos do cultivar Sungro 380 em plantios na Espanha e Argentina, obtendo boa previsão da duração do subperíodo emergência - primeira antese, IAF, acúmulo de biomassa da parte aérea da cultura e produtividade de grãos, em várias densidades de plantio. Para cultivares e condições edafoclimáticas brasileiras não se tem ainda trabalhos com o modelo. 


\section{MATERIAL E MÉTODOS}

\subsection{Local e dados utilizados para calibração}

Os dados fenológicos dos cultivares IAC-Anhandy, Contisol-621 e VNIIMK foram obtidos em experimentos conduzidos pelas antigas Seções de Fisiologia Vegetal e Oleaginosas do Instituto Agronômico de Campinas, na Estação Experimental de Monte Alegre do Sul, SP (latitude: $22^{\circ} 40^{\prime}$ S; longitude $46^{\circ} 40^{\prime} \mathrm{W}$ e altitude: $777 \mathrm{~m}$ ).

Os dados coletados foram da duração em dias dos sub-períodos: semeadura emergência, emergência - fim da iniciação floral, florescimento e maturação, durante o período de 14 de janeiro de 1988 a 15 de dezembro de 1989, totalizando 20 épocas de semeadura (Anexo 1).

Os dados meteorológicos diários coletados foram: temperatura máxima e mínima do ar $\left({ }^{\circ} \mathrm{C}\right)$; precipitação $(\mathrm{mm})$ e insolação (horas). Esses dados foram obtidos no posto meteorológico da Seção de Climatologia Agrícola (atualmente Centro de Ecofisiologia e Biofísica) do Instituto Agronômico, localizado aproximadamente a $1 \mathrm{~km}$ da área do experimento. As temperaturas médias diárias $(\mathrm{T})$ foram calculadas em função das máximas e mínimas obtidas em abrigo termométrico.

A radiação global diária (Qg) foi estimada pela equação de Ångströn (1924) modificada por Prèscott (1940):

$$
\mathrm{Qg}=\mathrm{Q} \cdot\left(\mathrm{a}+\mathrm{b} \cdot \frac{\mathrm{n}}{\mathrm{N}}\right)
$$

sendo Qg a radiação global diária $\left(\mathrm{MJ} \cdot \mathrm{m}^{-2} \cdot \mathrm{dia}^{-1}\right)$; Qo a radiação solar no topo da atmosfera (MJ.m ${ }^{-2} \cdot d^{-1}{ }^{-1}$ ); $\mathrm{n}$ a insolação (horas); $\mathrm{N}$ o fotoperíodo (horas); $\mathrm{a} \mathrm{e} \mathrm{b}$ coeficientes empíricos, determinados pelas seguintes equaçoes, $a=0,29 \cdot \cos \theta$ (sendo 
que $\theta$ é a latitude em graus), e $b=0,52$, como proposto por Glover \& McCulloch (1958).

O ensaio foi conduzido em um Podzólico vermelho amarelo ortoclássico (Figura 2). Cada parcela continha 4 linhas com $8 \mathrm{~m}$ de comprimento, espaçadas de $0,7 \mathrm{~m}$, com 5 plantas por metro linear. Os tratos culturais utilizados no ensaio foram idênticos para os três cultivares: realização da adubação na semeadura e em cobertura; controle fitossanitário quando necessário e irrigações sempre que o armazenamento hídrico no solo fosse menor que $60 \%$ do valor da capacidade de água disponível (CAD) do perfil.

\begin{tabular}{|c|c|c|c|c|c|c|c|c|c|c|c|c|c|c|c|}
\hline GROO7 & 1001 & SCS & & 3 & 85 & & 0 & 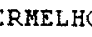 & $A M A$ & 00 & & & & & \\
\hline SITE & & COUNT & & & $\Delta T$ & LONG & $\operatorname{SCS} F$ & $M I L Y$ & & & & & & & \\
\hline M_ALE & GRE_SU & BRASII & & 22. & & 46.620 & OXIC & [ROPUD & HT & & & & & & \\
\hline SCOM & $S A L B$ & SLU1 & SLDR & SLRO & SLNF & SLPF & SMHB & SMPX & SHKE & & & & & & \\
\hline $\mathrm{YR}$ & 0.14 & 10.0 & 0.60 & 76 & 1.00 & 1.00 & IBO0 1 & IBO0 1 & IBOOI & & & & & & \\
\hline SLB & SLMH & SLLL & SDUL & SSAT & SRGF & SSKS & SBDH & SLOC & SLCL & SLSI & SLCF & SLNI & SLHW & SLHB & $S C E C$ \\
\hline 9 & AI & 0.145 & 0.262 & 0.346 & 0.75 & -99.0 & 1.16 & 2.23 & 25.0 & 20.5 & 2.0 & 0.19 & 5.4 & 4.5 & 23.0 \\
\hline 16 & A2 & 0.143 & 0.257 & 0.347 & 0.20 & -99.0 & 1.38 & 1.39 & 25.5 & 21.5 & 7.0 & 0.13 & 5.1 & 4.1 & 8.1 \\
\hline 29 & $\mathrm{~B} 1$ & 0.213 & 0.326 & 0.352 & 2.00 & -99.0 & 1.41 & 0.91 & 41.0 & 15.5 & 4.0 & 0.08 & 5.2 & 4.1 & 7.7 \\
\hline 50 & $\mathrm{BA}$ & 0.244 & 0.357 & 0.372 & 0.50 & -99.0 & 1.29 & 0.77 & 47.5 & 13.5 & 2.0 & 0.07 & 5.7 & 5.0 & 9.6 \\
\hline 70 & $\mathrm{BZ}$ & 0.248 & 0.362 & 0.377 & 0.15 & -99.0 & 1.20 & 0.65 & 48.0 & 14.5 & 1.0 & 0.05 & 5.3 & 4.3 & 6.7 \\
\hline 95 & B3 & 0.236 & 0.347 & 0.362 & 1.00 & -99.0 & 1.13 & 0.30 & 47.0 & 15.0 & 6.0 & 0.03 & 4.8 & 4.3 & 5.7 \\
\hline 155 & $\mathrm{CI}$ & 0.192 & 0.306 & 0.357 & 0.35 & -99.0 & 1.27 & 0.10 & 37.0 & 21.5 & 7.0 & -99 & 5.2 & 4.3 & 4.3 \\
\hline 185 & $c 2$ & 0.211 & 0.320 & 0.349 & 0.10 & -99.0 & 1.36 & 0.10 & 41.5 & 12.5 & 7.0 & -99 & 5.2 & 4.4 & 3.6 \\
\hline
\end{tabular}

Figura 2- Exemplo de arquivo do sistema DSSAT com informações sobre as características físico-químico-hídricas do solo Podzólico Vermelho Amarelo Ortoclásico, da área experimental em Monte Alegre do Sul, SP (Legenda no Anexo 2) (Fonte: Rotta et al. 1971).

\subsection{Modelos de simulação da cultura do girassol}

\subsubsection{Modelo FAO}

A FAO (Food and Agriculture Organization of the United Nations), considera que os processos no sistema solo-planta-atmosfera são complexos; contudo, para aplicação prática, este conhecimento deve ser reduzido para um número manejável de componentes para possibilitar análises significativas do efeito da água sobre a cultura. 


\subsubsection{Produtividade Potencial (Método da Zona Agroecológica)}

A metodologia para calcular a produtividade potencial da cultura foi desenvolvida para servir como estimativa em base continental. Contudo, o método também pode ser aplicado em localidades específicas.

Para determinado clima, a produtividade potencial possível de uma cultura padrão é calculada aplicando-se o conceito apresentado por de Wit (1965) a partir de dados de radiação solar, fazendo-se posteriormente correções para determinada cultura. Neste modelo pressupõe-se que as necessidades hídricas, de fertilidade e fitossanitárias da cultura estejam sendo plenamente satisfeitas. A metodologia usada no presente trabalho, emprega adaptações propostas por Barbieri \& Tuon (1992), que considera as variações do índice de área foliar durante o ciclo, possibilitando os cálculos para cada período fenológico.

A produtividade potencial ( $\mathrm{PP}, \mathrm{kg} \cdot \mathrm{ha}^{-1}$ de matéria seca) da cultura, é dada pelo somatório da produtividade potencial de cada subperíodo (p). Esta, por sua vez, é dada pela taxa de fotossintese bruta $\left(\mathrm{Fb}, \mathrm{kg} \cdot \mathrm{ha}^{-1}\right.$.dia) corrigida por fatores adimensionais relativos ao índice de área foliar (IAF) especifico para a cultura $\left(\mathrm{C}_{\mathrm{IAF}}\right)$, processo de respiração $\left(C_{R}\right)$, à parte colhida da planta $\left(C_{C}\right)$, multiplicado pelo número de dias correspondentes a fase considerada (ND):

$$
P P=\sum_{p=1}^{n}\left(F b \cdot C_{L H F} \cdot C_{R} \cdot C_{C} \cdot N D\right)
$$

A fotossíntese bruta é igual à soma daquela que ocorre durante o período nublado $(\mathrm{Fbn})$ e da que ocorre durante o período com céu sem nuvens $(\mathrm{Fbc})$, pois a eficiência de aproveitamento da energia radiante é diferente nestas duas situações, devido às diferenças no espectro solar.

$$
\mathrm{Fb}=\mathrm{Fbn}+\mathrm{Fbc}
$$

Por sua vez, a Fbn é função da radiação solar no topo da atmosfera (Qo) corrigido por um fator de resposta fotossintética à temperatura ( $\mathrm{c} T n$ ), relativo a cada grupo de cultura e razão de insolação $(n / N)$ : 


$$
F b n=(31,7+0,219 \cdot Q o) \cdot c \operatorname{Tn} \times\left(1-\frac{n}{N}\right)
$$

A Fbc pode ser entendida analogamente à $\mathrm{Fbn}$, descrita abaixo:

$$
F b c=(107,3+0,36 \cdot Q o) \cdot c T c \times \frac{n}{N}
$$

Os fatores cTn e cTc são fatores de resposta fotossintética da cultura em relação à temperatura em dia nublado e sem nuvens, respectivamente. $O$ tipo de cultura define estes fatores, sendo que no caso do girassol temos:

a) Para períodos com temperaturas entre $16,5^{\circ} \mathrm{C}$ e $37^{\circ} \mathrm{C}$ :

$$
\begin{aligned}
& c T n=0,583+0,014 \cdot T+0,0013 \cdot T^{2}-0,000037 \cdot T^{3} \\
& c T c=-0,0425+0,035 \cdot T+0,00325 \cdot T^{2}-0,0000925 \cdot T^{3}
\end{aligned}
$$

b) Em períodos em que a temperatura estiver fora da faixa citada acima:

$$
\begin{aligned}
& c T n=-0,0425+0,035 \cdot T+0,00325 \cdot T^{2}-0,0000925 \cdot T^{3} \\
& c T c=-1,805+0,07 \cdot T+0,0065 \cdot T^{2}-0,000185 \cdot T^{3}
\end{aligned}
$$

em que T é a temperatura média ao longo do ciclo da cultura.

de Wit (1965) considerou, em seus trabalhos, uma cultura padrão com IAF igual a 5. Então para IAFs menores, em uma cultura específica, deve-se aplicar a correção proposta por Barbieri \& Tuon (1992):

$$
\mathrm{C}_{\mathrm{IAF}}=0,0186+0,37 \cdot \mathrm{IAF}-0,035 \cdot \mathrm{IAF}^{2} \quad \text { se } \mathrm{IAF}>5, \mathrm{C}_{\mathrm{IAF}}=1
$$

Durante a fotossíntese e crescimento da cultura, parte dos carboidratos são consumidos no processo de fotorespiração e parte na manutenção da matéria viva. Este consumo é fortemente dependente da temperatura, havendo uma relação direta entre temperatura e respiração. Assim a correção para a respiração $\left(\mathrm{C}_{\mathrm{R}}\right)$ é dada por:

$$
\begin{array}{ll}
\mathrm{C}_{\mathrm{R}}=0,6 & \text { se } \mathrm{T} \leq 20^{\circ} \mathrm{C} \\
\mathrm{C}_{\mathrm{R}}=0,5 & \text { se } \mathrm{T}>20^{\circ} \mathrm{C}
\end{array}
$$

Geralmente, apenas uma parte da matéria seca total é colhida, seja na forma de grão, fibra ou açúcar. A relação entre o rendimento obtido e a matéria seca total é dada pelo índice de colheita $\left(C_{C}\right)$, que no caso do presente estudo foi considerado igual a 0,25 (Barbieri \& Tuon, 1992). 
$\mathrm{O}$ valor de PP obtido pela equação 2 é dado em $\mathrm{kg}$ de matéria seca de sementes. Para se levar em consideração o peso úmido deve-se adicionar a porcentagem de umidade do produto final, que no caso do girassol está por volta de $8,0 \%$ (Ungaro, 1981).

\subsubsection{Produtividade Real (Doorenbos \& Kassam, 1979)}

A relação entre a produtividade de uma cultura e o suprimento de água pode ser entendida da seguinte forma: quando as necessidades hídricas da cultura são atendidas plenamente, a evapotranspiração real (ETr) é igual à evapotranspiração de cultura (ETc), não ocorrendo perdas na produtividade. Todavia, quando o suprimento de água é insuficiente, tem-se que ETr $<$ ETc, ocasionando uma perda na produtividade, proporcional a este déficit no suprimento hídrico.

A resposta de produtividade da cultura em relação ao suprimento de água é quantificada pelo fator de resposta da cultura (ky), o qual varia de acordo com as fases fenológicas (Tabela 2), e que relaciona a queda de rendimento relativo $\left(1-\frac{\mathrm{PR}}{\mathrm{PP}}\right)$ com o déficit de evapotranspiração relativa $\left(1-\frac{E T r}{E T c}\right)$ da seguinte forma:

$$
\left(1-\frac{\mathrm{PR}}{\mathrm{PP}}\right)=\mathrm{ky} \cdot\left(1-\frac{\mathrm{ETr}}{\mathrm{ETc}}\right)
$$

resultando que a produtividade real final (PR) é dada pelo modelo multiplicativo descrito abaixo:

$$
\mathrm{PR}=\prod_{\mathrm{i}=1}^{5}\left[1-\mathrm{ky}_{\mathrm{i}} \cdot\left(1-\frac{\mathrm{ETr}_{\mathrm{i}}}{\mathrm{ETc}_{\mathrm{i}}}\right)\right] \cdot \mathrm{PP}
$$

sendo que i corresponde às fases fenológicas consideradas na Tabela 2.

No presente trabalho, utilizou-se o programa BHCULT (Rolim et al., 1998) versão 6.2, para a planilha Excel (Windows). Este programa faz o cálculo da produtividade potencial e real pelos métodos da $\mathrm{FAO}$, já discutidos, com o cálculo de ETr proveniente do balanço hídrico, segundo Thorthwaite \& Mather (1955). O cálculo do balanço hídrico é feito com modificações propostas por Barbieri et al. (1997) para o 
cálculo com a capacidade de água disponivel (CAD) variável, para se considerar os efeitos do crescimento do sistema radicular. O método de evapotranspiração potencial utilizado foi o de Thorthwaite (1948).

Os dados iniciais a serem utilizados no programa BHCULT para a simulação nas diferentes datas de semeadura são os apresentados na Tabela 2.

Tabela 2. Dados iniciais da cultura do girassol para uso no modelo FAO

\begin{tabular}{lcccc}
\hline Fase & kc* $^{*}$ & CAD** $^{* *}$ & ky $^{*}$ & TAF** \\
\hline 1-Emergência & 0,30 & 20 & 0,0 & 0,5 \\
2- Desenvolvimento vegetativo & 0,70 & 60 & 0,3 & 2,0 \\
3- Florescimento & 1,05 & 80 & 0,5 & 3,0 \\
4- Frutificação & 0,70 & 80 & 1,0 & 2,5 \\
5- Maturação & 0,35 & 80 & 0,8 & 1,0 \\
\hline *Doorenbos \& Kassam, 1979; **Fancelli et al, 1980; ***Barni et. al., 1995.
\end{tabular}

Os dados de IAF, para cada fase da cultura, foram obtidos de Barni et al. (1995), usando os valores da variedade GR-16. Admitiu-se tal aproximação pois foi a variedade que apresentou IAF máximo para o ciclo total, mais próximo dos IAF máximos observados no experimento realizado em Monte Alegre do Sul.

No programa BHCULT, o índice térmico determina a duração do ciclo total da cultura como também a duração de cada fase ou sub-periodo. Para o ciclo total o somatório de graus-dia utilizado para o cultivar IAC-Anhandy foi igual a $1738^{\circ} \mathrm{C}$.dia, para o Contisol-621 igual a $1715^{\circ} \mathrm{C}$.dia e para o VNIIMK igual a $1850^{\circ} \mathrm{C}$.dia, com temperaturas-base iguais a $4,7^{\circ} \mathrm{C} ; 4,1^{\circ} \mathrm{C} ; 3,7^{\circ} \mathrm{C}$, respectivamente (Sentelhas et al., 1994). Para a determinação da duração das fases, foi, primeiramente, observado o indice térmico médio (entre as diferentes épocas de semeaduras) necessário para se completar cada subperíodo de cada variedade (Tabela 3 ). 
Tabela 3 - Valores Médios da soma térmica, em ${ }^{\circ} \mathrm{C}$.dia, para os cultivares IAC-Anhandy, Contisol-621 e VNIIMK, para o ciclo total e para cada subperíodo (1Estabelecimento, 2- Desenvolvimento Vegetativo, 3- Florescimento, 4Frutificação, 5- Maturação), levando-se em consideração as diferentes temperaturas-base, determinadas por Sentelhas et al. (1994).

\begin{tabular}{lcccccc}
\hline EGD médios & 1 & 2 & 3 & 4 & 5 & Cultura \\
\hline IAC-Anhandy & 125 & 196 & 651 & 388 & 352 & 1712 \\
Contisol-621 & 130 & 173 & 644 & 382 & 393 & 1723 \\
VNIIMK & 139 & 223 & 703 & 444 & 375 & 1883 \\
\hline
\end{tabular}

Com esses dados médios descritos na Tabela 3, pode-se ajustar funções que relacionam a soma térmica necessária para cada sub-período, com os valores de $\mathrm{Kc}$ (requisito para a utilização do programa). Esta função tem a forma polinomial, seguindo a proposta de Rolim et al. (1997), descrita abaixo:

$$
\mathrm{kc}=a+b \cdot \sum \mathrm{GD}+c \cdot \sum \mathrm{GD}^{2}+d \cdot \sum \mathrm{GD}^{3}+e \cdot \sum \mathrm{GD}^{4}
$$

em que os valores dos coeficientes $a, b, c, d$, e, resultantes do ajuste, são apresentados na Tabela 4.

Tabela 4 - Coeficientes da estimativa de kc em função de graus-dia (equação 13) para os cultivares IAC-Anhandy, Contisol-621 e VNIIMK.

\begin{tabular}{lccccc}
\hline & $\mathrm{a}$ & $\mathrm{b}$ & $\mathrm{c}$ & $\mathrm{d}$ & $\mathrm{e}$ \\
\hline IAC-Anhandy & $1,803 \times 10^{-2}$ & $2,714 \times 10^{-3}$ & $-1,296 \times 10^{-6}$ & $-7,427 \times 10^{-10}$ & $3,782 \times 10^{-13}$ \\
Contisol-621 & $9,72 \times 10^{-2}$ & $3,37 \times 10^{-3}$ & $-2,445 \times 10^{-6}$ & $-6,495 \times 10^{-11}$ & $2,531 \times 10^{-13}$ \\
VNIIMK & $-1 \times 10^{-2}$ & $2,383 \times 10^{-3}$ & $-9,998 \times 10^{-7}$ & $-5,413 \times 10^{-10}$ & $2,413 \times 10^{-13}$ \\
\hline
\end{tabular}

O programa BHCULT, em determinada data, calculará o valor de kc e fará uma comparação deste valor com o valor da Tabela 2, determinando a fase da cultura e os dados pertinentes ( $\mathrm{CAD}$, Ky e IAF) naquele período. Por exemplo, se o valor de kc calculado for maior ou igual a zero e menor que 0,3 a cultura estará na fase de emergência, seguindo o mesmo princípio até a fase de florescimento, quando as condições se invertem: se o valor de kc for menor ou igual a 1,05 e maior que 0,7 
teremos a fase de frutificação e assim por diante até se completar o índice térmico para o ciclo total da cultura.

As simulações de plantio foram realizadas a cada 10 dias, coletando-se os dados de duração do ciclo total da cultura, produtividade potencial e real de grãos e a quebra relativa de produtividade, para a posterior comparação com os dados do modelo DSSAT/OILCROP-SUN.

\subsubsection{DSSAT / OILCROP-SUN}

O modelo orientado a processos OILCROP-SUN, desenvolvido por Villalobos et al. (1996), simula o efeito da temperatura, radiação solar e disponibilidade de água no crescimento e no desenvolvimento de girassol. Para tanto, o modelo simula a biomassa e conteúdo de nitrogênio dos órgãos (raízes, caule, folhas e capítulo), o índice de área foliar e o balanço de água e nitrogênio no solo em escala diária.

O modelo é compatível com o sistema DSSAT (IBSNAT,1989) e, portanto, os formatos de entrada de dados são aqueles especificados para este sistema: climáticos (temperaturas mínima e máxima, radiação solar e chuva), características físico-químicas e conteúdos iniciais de água e nitrogênio no solo.

Simplificadamente, o modelo calcula taxas potenciais, ou ótimas, dos processos que ocorrem na planta, que são depois penalizadas por variáveis escalares para quantificar os efeitos de fatores limitantes, como o estresse hídrico e de nitrogênio. A lei dos mínimos é aplicada para determinar o mais limitante dos fatores que controlam o crescimento da cultura e dos seus órgãos, a cada dia.

A taxa de geração de nova biomassa da cultura no modelo pode ser limitada tanto pela temperatura do ar como pelos balanços hídrico e de nitrogênio. Ela pode ser limitada, também, pelo potencial de crescimento e disponibilidade de nova biomassa para cada órgão. Os efeitos da temperatura na taxa de geração de nova biomassa, como também nas taxas de aparecimento e expansão foliar e eficiência do uso da radiação, são quantificadas por curvas de respostas escalares, detalhadas por Villalobos et al. (1996). 
O sistema DSSAT calcula o balanço hídrico estimando a evapotranspiração potencial pelo método de Priestley \& Taylor (1972) e a transpiração da planta, a evaporação do solo e os fluxos de água em um perfil uni-dimensional de solo dividido em várias camadas, conforme os trabalhos de Jones \& Ritchie (1990) e Ritchie et al. (1990).

A variável usada para estimar o grau de estresse hídrico da cultura em um dia, é a razão entre a taxa potencial de absorção de água e a demanda pela transpiração. A taxa potencial de absorção de água depende da distribuição da água que pode ser extraída do solo, da profundidade e da densidade do sistema radicular (SR).

Outro fator importante que decresce as taxas potenciais nos processos da planta é o balanço de nitrogênio. O balanço de nitrogênio usado no sistema DSSAT, detalhado por Godwin \& Jones (1991), leva em consideração os processos de movimento do nitrato e uréia no perfil, transformações de nitrogênio no solo (nitrificação da amônia, mineralização da matéria orgânica, denitrificação, hidrólise da uréia e imobilização), efeitos da aplicação de fertilizantes, concentração e absorção de nitrogênio pelas plantas e pelos grãos.

\subsubsection{Fenologia}

O modelo considera três fases no desenvolvimento da cultura: semeadura à emergência, emergência à primeira antese e primeira antese à maturidade fisiológica. $\mathrm{Na}$ segunda e terceira fases, foram consideradas subfases que representam estádios importantes no desenvolvimento da cultura (Tabela 3).

Tabela 5 - Fases e sub-fases usados no modelo OILCROP-SUN.

\begin{tabular}{|c|c|c|c|}
\hline \multirow[b]{2}{*}{ Fases } & \multicolumn{2}{|r|}{ Subfases } & \multirow[b]{2}{*}{ Fim } \\
\hline & Código & Inicio & \\
\hline semeadura $\Leftrightarrow$ emergencia & $A$ & semeadura & $\rightarrow$ emergencia \\
\hline \multirow[t]{4}{*}{ emergência $\leftrightharpoons$ primeira antese } & 8 & emergència & $\rightarrow$ fim da fase juvenil \\
\hline & $\mathrm{C}$ & fim da fase juvenil & $\rightarrow$ iniciaçăo floral \\
\hline & D & iniciaçāo floral & $\rightarrow$ fim da iniciação floral \\
\hline & $E$ & fim da iniciação floral & $\rightarrow$ primeira antese \\
\hline \multirow{3}{*}{$\begin{array}{r}\text { primeira antese } \diamond \text { maturidade } \\
\text { fisiológica }\end{array}$} & $\mathrm{F}$ & primeira antese & $\rightarrow$ inicio do preenchimento dos grãos \\
\hline & G & inicio do preenchimento dos grãos & $\rightarrow$ inicio da deposição de óleo \\
\hline & $H$ & inicio da deposiçāo de óleo & $\rightarrow$ maturidade fisiológica \\
\hline
\end{tabular}


Partindo do pressuposto que o conteúdo de água na profundidade de semeadura é adequado, foi assumido que a duração da subfase semeadura - emergência $\left(t_{1}\right)$ é dependente da temperatura (Angus et al. 1981) e da profundidade de semeadura (Radford, 1977). A equação abaixo é usada para descrever estes efeitos:

$$
\mathrm{t}_{1}=\frac{\mathrm{PA} \times \mathrm{PB} \times \mathrm{SDEPTH}}{\mathrm{T}-\mathrm{Tb}}
$$

em que: $t_{1}$ é o tempo da semeadura à emergência (dias); SDEPTH é a profundidade de semeadura $(\mathrm{cm})$; T é a temperatura média do $\operatorname{ar}\left({ }^{\circ} \mathrm{C}\right)$; PA é o índice térmico $\left({ }^{\circ} \mathrm{C}\right.$.dia) da subfase semeadura - emergência (ou seja, o início da elongação do hipocótilo); e PB é o índice térmico requerido por centímetro de elongação do hipocótilo $\left({ }^{\circ} \mathrm{C}\right.$. dia.cm $\left.{ }^{-1}\right)$. Temperaturas importantes para o cálculo de índices térmicos em todas as subrotinas do modelo são aquelas estimadas por Villalobos \& Ritchie (1992): Temperatura base $(\mathrm{Tb})=$ $4^{\circ} \mathrm{C}$; ótima $($ TOPT $)=28^{\circ} \mathrm{C}$ e máxima $($ TMAX $)=40^{\circ} \mathrm{C}$.

Para a equação 14 , são utilizados valores ótimos de PA, igual a $66^{\circ} \mathrm{C}$.dia, e para $\mathrm{PB}$, igual a $11,9^{\circ} \mathrm{C} \cdot$ dia.cm ${ }^{-1}$, decorrentes de experimentos em câmaras de crescimento com variação de temperatura de $11,2^{\circ} \mathrm{C}$ a $20,2^{\circ} \mathrm{C}$ com sementes de seis cultivares semeadas em profundidades entre 2,5 a $7,5 \mathrm{~cm}$ (Villalobos et al., 1996). O modelo OILCROP-SUN não permite mudanças nesses valores (PA, PB, Tb, TOPT, TMAX).

A duração da subfase $B\left(t_{2}\right)$ é dependente do índice térmico específico (P1) que caracteriza a fase juvenil (subfase B) (Marc \& Palmer, 1978, 1981), sendo descrita por:

$$
\mathrm{t}_{2}=\frac{\mathrm{P} 1}{\mathrm{TT}_{2}}
$$

sendo P1 a duração da fase juvenil em unidades térmicas $\left({ }^{\circ} \mathrm{C}\right.$.dia) específica para o cultivar e TT o índice térmico médio diário $\left({ }^{\circ} \mathrm{C}\right.$.dia.dia $\left.{ }^{-1}\right)$ na subfase.

A duração da subfase $C\left(t_{3}\right)$, sensível ao fotoperíodo, somada ao tempo necessário para que mudanças morfológicas se tornem detectáveis na gema vegetativa apical, é dada por:

$$
\mathrm{t}_{3}=3+[(15-\mathrm{H}) \times \mathrm{P} 2] \quad \text { para } \mathrm{H} \leq 15
$$

em que: $\mathrm{H}$ é o fotoperíodo, em horas, no início da subfase; e P2 $\left(\right.$ dia. $\left.^{-1}{ }^{-1}\right)$ é o índice de sensibilidade ao fotoperíodo específico para o cultivar. A forma desta equação reflete o 
pressuposto de que a maioria dos genótipos de girassol exibe resposta a dias longos na iniciação floral (Rawson \& Hindmarsh, 1982) e que o processo de indução é insensível à temperatura (Marc e Palmer, 1978, 1981). O intercepto da equação 16 foi derivado de dados de Marc \& Palmer (1981) e Rawson \& Hindmarsh (1982) para Sunfola 68-2, e foi assumido ser válido para todos os cultivares. Na falta de informações foi fixado um limite superior de 15 horas para o comprimento do fotoperíodo efetivo.

A duração das subfases $D+E\left(t_{4}\right)$ é função da temperatura e é afetada pela fase juvenil:

$$
\mathrm{t}_{4}=\frac{2 \mathrm{P} 1}{\mathrm{TT}_{4}}
$$

em que $\mathrm{TT}_{4}$ é o índice térmico médio diário na subfase.

A inclusão de P1 na equação 17 reflete o efeito da fase juvenil nos subperíodos D + E em relação ao número de primórdios foliares acumulados no ápice (Yegappan et al., 1980). O valor de dois multiplicando P1 na equação 17 foi derivada dos dados de Gimeno et al. (1989) e de Sadras \& Villalobos (1993).

A equação 17 ignora possiveis efeitos fotoperiódicos na duração da subfase D (Marc \& Palmer, 1981; Rawson \& Hindmarsh, 1982).

No modelo, a duração da fase primeira antese - maturidade fisiológica $\left(\mathrm{t}_{5}\right) \mathrm{e}$ de suas subfases $(\mathrm{F}, \mathrm{G}$ e $\mathrm{H})$ são controladas diretamente pela temperatura e podem variar entre os cultivares (Trapani et al., 1988) e os seus efeitos podem ser descritos por:

$$
\mathrm{t}_{5}=\frac{\mathrm{P} 5}{\mathrm{TT}_{5}}
$$

sendo P5 é o índice térmico específico para o cultivar que define a duração do preenchimento dos grãos $\left({ }^{\circ} \mathrm{C}\right.$.dia) e $\mathrm{TT}_{5}$ o índice térmico diário como descrito anteriormente.

Análises de dados de diversos experimentos, mostraram que o peso máximo de pericarpo foi conseguido próximo de $270{ }^{\circ} \mathrm{C}$.dia depois da primeira antese (FA), o crescimento da amêndoa começou $170^{\circ} \mathrm{C}$.dia após a FA e a deposição de óleo começou $230^{\circ} \mathrm{C}$.dia depois da FA. Estes valores foram usados no modelo. Existem evidências conflituosas no efeito de seca na duração do subperíodo de preenchimento de grãos 
(Anderson et al. 1978; Whitfield et al. 1989). Os possíveis efeitos relacionados à seca em ts não são considerados no modelo.

\subsubsection{Aparecimento e expansão foliar}

A expansão foliar potencial por planta, isto é, o incremento diário da área foliar esperada por uma planta crescendo em condições de ótima temperatura, com adequado suprimento de água, nutrientes, radiação e sem competição, depende da taxa potencial de expansão e do número atual de folhas.

O número atual de folhas depende da taxa de aparecimento de folhas e da duração da expansão foliar. No girassol, a taxa de aparecimento de folhas é controlada significativamente pela temperatura, com o modelo usando os seguintes valores: 43 ${ }^{\circ} \mathrm{C}$.dia para a $1^{\mathrm{a}}$ até a $6^{\mathrm{a}}$ folhas, $23{ }^{\circ} \mathrm{C}$.dia para a $7^{\mathrm{a}}$ folha e acima (Villalobos \& Ritchie, 1992). O índice térmico, para a duração da expansão de cada folha, é fixado em 350 ${ }^{\circ} \mathrm{C}$.dia, uma estimativa proposta pelos dados de Rawson \& Dunstone (1986).

A taxa potencial de expansão foliar da planta é dependente do potencial de expansão de cada folha que, por sua vez, varia com o número total de folhas que aparecem naquele nível de inserção no caule, e com o efeito do tamanho das folhas basais.

O valor inicial da área foliar (superfície cotiledonar) por planta na emergência é fixada em $3 \mathrm{~cm}^{2}$, crescendo em uma taxa de $2 \mathrm{~cm}^{2}$. planta ${ }^{-1} \cdot \mathrm{d}^{-1}$ até o aparecimento da primeira folha, $43^{\circ} \mathrm{C}$.dia após a emergência.

\subsubsection{Senescência foliar}

A senescência foliar, sem estresse hídrico, foi considerada ser controlada pelo sombreamento (Cock et al., 1979) durante a pré-antese e pelo conteúdo de nitrogênio nas folhas (Sinclair \& de Witt, 1976) na pós-antese. A indução da senescência é iniciada quando o índice de área foliar (LAI) excede 1,2. Um atraso de 12 dias controla a perda 
atual das folhas e a taxa de senescência (SENRATE) se torna proporcional à taxa de aumento da área foliar no início do período de atraso $\left(\Delta \mathrm{LAI}_{(\mathrm{t}-12)}\right)$, então:

$$
\text { SENRATE }=-0,0182+0,4147 \times \Delta \mathrm{LAI}_{(\mathrm{t}-12)}
$$

Esta aproximação descreve o progresso da senescência foliar na pré-antese em culturas irrigadas e fertilizadas adequadamente que atingiram altos índices de área foliar antes da antese (Giménez, 1985).

\subsubsection{Profundidade e densidade do sistema radicular}

A profundidade do sistema radicular (SR) na germinação é considerada igual à profundidade de semeadura, e a taxa potencial do avanço das extremidades do SR, em camadas do solo com suficiente água e sem nenhum outro impedimento para o crescimento da raiz, é fixado em $2 \mathrm{~mm} \cdot{ }^{\circ} \mathrm{C}^{-1} \cdot \mathrm{dia}^{-1}$ (na $\mathrm{Tb}=4^{\circ} \mathrm{C}$ ). Esta estimativa é baseada em medidas do avanço da frente de extração de água feito por Alvarez del Toro (1987) e taxas de avanço do SR feito por Sadras et al. (1989). O modelo leva em consideração o efeito da limitação hídrica no desenvolvimento da planta; a taxa de avanço das extremidades do SR é limitada pelo conteúdo de água se esta estiver abaixo de um valor específico (Jones e Kiniry, 1986). O incremento diário do comprimento do SR dependende, também, de nova partição de biomassa em relação às raízes finas. É usado um comprimento fixo de raizes finas disponíveis para o incremento $\left(1,7.10^{4}\right.$ $\mathrm{cm} \cdot \mathrm{g}^{-1}$ ), baseado em estimativas de comprimento de raízes (Connor \& Jones, 1985) e biomassa (Hall et al., 1990).

Depois da antese, o modelo assume que parte do SR é perdido para o solo em uma taxa diária de $0,5 \%$ da biomassa presente em cada camada do solo.

\subsubsection{Interceptação de radiação solar e acúmulo de biomassa}

No modelo, a interceptação da radiação solar é estimada como uma função exponencial em relação ao IAF (Monsi \& Saeki, 1953), usando um coeficiente de 
extinção (k) que varia com o IAF (Rawson et al., 1984; Trapani et al., 1992), descrito abaixo:

$$
\mathrm{k}=\frac{\ln \{1-1,72 \times[1-\operatorname{EXP}\{0,863 \times[1-\operatorname{EXP}(-0,86 \times \mathrm{IAF})]\})]\}}{\mathrm{IAF}}
$$

A radiação solar interceptada diariamente é convertida em um novo incremento de biomassa pelo uso de um coeficiente que descreve a eficiência do uso da radiação (RUE, g de biomassa $\mathrm{MJ}^{-1} \mathrm{PAR}$ ). O modelo considera as mudanças do RUE devido à ontogenia da cultura (Trapani et al., 1992) associadas com mudanças no IAF.

Antes da antese, o modelo assume que RUE aumenta exponencialmente de 1,4 $(\mathrm{IAF} \cong 0)$ a $3(\mathrm{IAF}=4)$. Logo após a antese, o RUE declina rapidamente (Steer et al., 1993). Um valor de 1,3 é assumido para o RUE na subfase antese-início do preenchimento dos grãos (Trapani et al., 1992). A remobilização do nitrogênio foliar para o grão é a causa mais provável da queda do RUE durante o preenchimento dos

grãos, que começa algum tempo depois da antese. Quando a amêndoa começa a crescer o valor de 0,33 para o RUE é usado para indicar o início da subfase G. Este valor é resultante do trabalho de Trapani et al. (1992).

\subsubsection{Partição da Biomassa}

No OILCROP-SUN o crescimento das raízes finas, folhas, caule (inclusive pecíolos), capítulo (receptáculo e partes florais somente após antese), pericarpo e amêndoas são simulados.

Na emergência, assume-se que cada "seedling" tem 0,02 g de raízes, 0,01 g de caule e $0,03 \mathrm{~g}$ de folhas (cotilédones).

Cada dia, o novo incremento de biomassa, calculado em função da radiação solar interceptada como citado anteriormente, sofre partição entre os órgão que estão naquele momento crescendo, utilizando-se dos coeficientes de partição (PC), que é a taxa de incremento diário de biomassa de um órgão dividida pelo incremento diário de biomassa da cultura, que são específicos aos órgãos e para os estádios fenológicos (Trapani et al., 1994). 


\subsubsection{Determinação da produção de grãos}

Foi assumido que a produção de grãos é o produto do número e do peso destes na maturidade fisiológica. O número de grãos por capítulo é estimado a partir do coeficiente genético específico G2 (número potencial de grãos por capítulo, medido em plantas sob condições edafo-climáticas ótimas e de baixa densidade de população). Este número potencial de grãos sofre redução devido às condições ambientais durante os estágios iniciais da formação do capítulo até o início do crescimento da amêndoa. Villalobos et al. (1994) mostraram que o número potencial de grãos por capítulo em culturas irrigadas, com 0,5 plantas $\mathrm{m}^{-2}$, variou de 520 a 3700 .

Experimentos envolvendo estresse por falta de água (Hall et al., 1985) e de nitrogênio (Steer et al., 1984), raleamento (Miller \& Roath, 1982), sombreamento (Chimenti \& Hall, 1992) e desfoliação (Schneiter et al., 1987) demonstraram que o número de grãos produzidos pode ser alterado a partir de um período anterior à antese. No modelo, este periodo vai de $180^{\circ} \mathrm{C}$.dia até $230^{\circ} \mathrm{C}$.dia antes da primeira antese no qual o número atual de grãos por planta é estimado com base na taxa média diária de incremento de biomassa.

Em relação ao peso dos grãos, o modelo OILCROP-SUN utiliza um coeficiente específico do cultivar G3 para simular a taxa de crescimento dos grãos, através da taxa potencial de crescimento da amêndoa em mg. $\mathrm{d}^{-1}$. Deve-se considerar o peso do grão completo, ou seja, pericarpo e amêndoa, e que ele varia entre os genótipos de girassol (Hall et al., 1985; Steer \& Hocking, 1984; Trapani et al., 1988; Villalobos et al., 1994). Esta variação é atribuída às diferenças na duração e/ou na taxa de enchimento dos grãos.

Os valores de G3 para os cultivares podem ser estimados medindo-se a taxa linear de incremento de massa da amêndoa em baixa densidade de plantas desenvolvidas sob condições ótimas. A taxa de crescimento do pericarpo até o grão inteiro, em condições ótimas de crescimento, é estável $\left(0,23 \mathrm{mg} \mathrm{dia}^{-1}\right)$ em uma grande faixa de densidade populacional (Villalobos et al., 1996).

Os valores de G2 e G3 utilizados no presente trabalho foram 2800 e 1,7 respectivamente, para todos os cultivares (Villalobos et al., 1994). 
A taxa potencial de crescimento do pericarpo é calculada em função dos valores de G3. É assumido um valor inicial de $2 \mathrm{mg}$ por pericarpo na antese. O crescimento atual dos componentes do grão ocorre em taxas que são dependentes da disponibilidade de biomassa, da temperatura e da disponibilidade de água. O modelo também produz estimativas do acúmulo de óleo no grão, assumindo uma taxa linear de incremento após o início do acúmulo de óleo.

\subsubsection{Balanço de nitrogênio na cultura}

A absorção de nitrogênio pela cultura é modulada pela disponibilidade de nitrogênio no solo, densidade do SR no perfil e demanda de nitrogênio pela cultura. $O$ modelo segue a aproximação descrita por Godwin \& Jones (1991).

No modelo, a concentração de nitrogênio em cada órgão pode variar entre um limite superior (NCRIT) e inferior (NMIN) e varia com a ontogenia da cultura (Angus \& Moncur, 1985; Penning de Vries, 1982).

Se a concentração cai abaixo de NMIN, considera-se que a cultura está em algum grau de estresse por falta de nitrogênio, ocorrendo um cessamento do crescimento dos órgãos. Se a concentração estiver entre NMIN e NCRIT a planta estará mantendo o seu nível de biomassa sem nenhum estresse. Por fim, se a concentração estiver acima de NCRIT, haverá um incremento diário de biomassa decorrente desta disponibilidade de nitrogênio. Os níveis de nitrogênio nos "seedlings" são fixadas em 4,6\% (raízes), 6,2\% (folhas) e 4,4\% (no caule).

A demanda por nitrogênio para o crescimento dos grãos é modulada em função da concentração de nitrogênio da parte aérea, detalhado em Villalobos et al. (1996). O requerimento de nitrogênio pela amêndoa pode variar no máximo entre $2,3 \%$ a 4,7\% da biomassa da própria amêndoa. Esta restrição evita que o modelo leve à uma súbita redução do nitrogênio foliar (superestimando a taxa de senescência foliar). 


\subsubsection{Calibração do Modelo OILCROP-SUN para os cultivares estudados}

Os coeficientes genéticos calibrados foram: coeficiente do período juvenil ( $\mathrm{P} 1$, ${ }^{\circ} \mathrm{C}$.dia, para temperatura-base igual a $4^{\circ} \mathrm{C}$ ), correspondente à duração da fase juvenil; coeficiente fotoperiódico $\left(\mathrm{P} 2\right.$, dia.hora $\left.{ }^{-1}\right)$, referente ao atraso no desenvolvimento da cultura decorrente de um fotoperíodo menor que 15 horas; e o coeficiente da duração do preenchimento dos grãos $\left(\mathrm{P} 5,{ }^{\circ} \mathrm{C}\right.$.dia), que corresponde à duração da antese até a maturidade fisiológica.

Os demais coeficientes foram: número máximo de grãos por capítulo (G2, medido em plantas com condições ótimas de crescimento) igual a 2800; taxa de crescimento potencial da amêndoa $\left(\mathrm{G} 3, \mathrm{mg} \mathrm{dia}^{-1}\right)$ igual a 1,7 ; e conteúdo máximo de óleo na amêndoa $(\mathrm{O} 1, \%)$ igual a 65 , igualmente para os três cultivares (Ungaro ${ }^{2}$, Villalobos et al., 1994).

Para a calibração dos coeficientes genéticos (P1, P2 e P5), primeiramente foi necessário encontrar os valores de $t_{2}$ (emergência - fim do periodo juvenil) e $t_{3}$ (fim do período juvenil - início da iniciação floral) para cada época de semeadura, porque não foi feita uma observação a campo para distinguir estas duas subfases. $\mathrm{Na}$ determinação da duração das subfases $t_{2}$ e $t_{3}$ utilizou-se os seguintes procedimentos: a partir da equação 18 , tem-se os valores de $\mathrm{TT}_{5}$ e tem-se a duração desta subfase $\left(\mathrm{t}_{5}\right)$, então o valor de P5 é conseguido. O mesmo procedimento é utilizado para encontrar o valor de P1 nas subfases $\mathrm{D}+\mathrm{E}$ por meio da equação 17. Com o valor de $\mathrm{P} 1$ e $\mathrm{TT}_{2}$, pôde-se calcular o valor de $t_{2}$, com o uso da equação 15 . Subtraindo-se a duração da subfase $B\left(t_{2}\right)$ da emergência-iniciação floral $(B+C)$ têm-se o valor da subfase $C\left(t_{3}\right)$. Com o valor de $t_{3}$ e $\mathrm{H}$ consegue-se o valor de P2 pelo uso da equação 16.

\footnotetext{
${ }^{2}$ UNGARO, M. R. G., comunicação pessoal, 1999.
} 
A partir destes procedimentos conseguiu-se os valores de $t_{2}, t 3$ e os valores ótimos de P1, P2 e P5 para cada época de semeadura. Estes valores ótimos foram descartados pois o sistema DSSAT não comporta a utilização de vários valores para um mesmo coeficiente, sendo necessário, então, a calibração para a determinação dos valores ideais para quaisquer datas de semeaduras.

Por fim, a calibração dos coeficientes genéticos foi realizada na planilha Excel 97 (Windows), com a introdução das equações do submodelo de fenologia do OILCROPSUN. Na planilha, foram confeccionadas listas ou matrizes para se testar vários valores de um mesmo coeficiente e verificar o efeito deste valor na duração de determinada fase. As durações das fases provenientes de dados medidos (Anexo 1) e simulados foram ajustadas da seguinte forma: primeiramente buscou-se a minimização da soma dos quadrados dos erros (ERRO, \%), a partir disto o valor de cada coeficiente genético foi mudado buscando-se uma minimização do coeficiente linear (a), uma aproximação do coeficiente angular (b) ao valor 1 e a maximização de $\mathrm{r}^{2}$.

A calibração foi realizada levando-se em consideração todas as datas de semeadura nos anos de 1988 e 1989 em Monte Alegre do Sul, SP (Anexo 1).

De forma geral, sempre as subfases consideradas são dependentes das subfases anteriores a ela, por isso, na determinação dos coeficientes genéticos a metodologia usada foi a de diminuir os graus de liberdade, calibrando-se primeiramente a profundidade de semeadura (SDEPTH), os coeficientes P1 e P2 (conjuntamente, pois eles são interdependentes) e finalmente o coeficiente P5, pois este último é dependente dos dois primeiros.

Com os testes de vários valores e combinações dos coeficientes, foi possivel, a determinação dos valores ideais para cada coeficiente genético, para cada cultivar.

\subsection{Comparação dos modelos}

A comparação dos modelos foi feita para diferentes cidades dos Estados de São Paulo e do Paraná, utilizando-se dados de temperatura média, máxima e mínima $\left({ }^{\circ} \mathrm{C}\right)$, insolação (hora) e precipitação (mm). Além desses, o modelo DSSAT/OILCROP-SUN 
utiliza, também, dados relativos ao tipo de solo das localidades (Anexo 2). As cidades utilizadas foram, Piracicaba, Ribeirão Preto, Manduri no Estado de São Paulo, Ponta Grossa e Paranavaí no Estado do Paraná (Tabela 6).

Para a execução do programa DSSAT/OILCROP-SUN estipulou-se condições iniciais que foram comuns em todas as datas semeadura. Primeiramente, o espaçamento entre linhas foi de $50 \mathrm{~cm}$, com uma densidade populacional de 10 plantas. $\mathrm{m}^{-2}$. Para os cálculos da produtividade potencial foram estipuladas irrigações automáticas sempre que a umidade do perfil chegou a 50\% da capacidade de campo. Já no caso dos cálculos da produtividade real, o fornecimento de água foi somente pela chuva, condicionado, portanto, pelas condições climáticas da região, sendo também considerado que, na semeadura o solo teria a quantidade ideal de nitrogênio para a cultura (recomenda-se uma quantidade de $10 \mathrm{~kg}$ de N.ha' ${ }^{-1}$ IAC, 1998), o mesmo ocorrendo durante o seu crescimento.

Tabela 6 - Localidades utilizadas nas simulações dos modelos FAO e DSSAT/OILCROP-SUN

\begin{tabular}{lccc}
\hline & Latitude () & Longitude (\%) & Altitude (m) \\
\hline Piracicaba & $-22,71$ & $-47,63$ & 490 \\
Ribeirão Preto & $-21,18$ & $-47,80$ & 521 \\
Manduri & $-23,17$ & $-49,33$ & 589 \\
Ponta Grossa & $-25,22$ & $-50,01$ & 880 \\
Paranavaí & $-23,08$ & $-52,43$ & 480 \\
\hline
\end{tabular}

A comparação dos dados simulados pelos modelos FAO e DSSAT/OILCROPSUN foi feita avaliando-se a duração do ciclo total, Produtividade Potencial (PP), Produtividade Real (PR) e Quebra Relativa de Produtividade (Q).

Para cada uma destas avaliações foram usados métodos de descrição paramétrica dos dados como a média absoluta, desvio padrão e coeficiente de variação, nas diferentes datas de semeaduras em todos os anos considerados em cada localidade. Posteriormente, foi calculado, com os dados médios absolutos, a diferença média 
absoluta (DMA), máxima (DMAX) e mínima (DMIN) em relação a todas as datas de semeaduras, dado por:

$$
\begin{aligned}
& D M A=\sum_{i=1}^{n}\left|E_{F_{A O}}-E_{D_{S S A T}}\right| / n \\
& D M A X=\left|E_{\text {DAO }_{i}}-E_{\text {DSSAT }_{i}}\right|_{\text {MAX }} \\
& D M N=\left|E_{\text {FAO }_{i}}-E_{\text {DSSAT }_{i}}\right|_{\text {MIN }}
\end{aligned}
$$

sendo que i varia de 1 a 36 indicando as datas de semeaduras decendiais durante o ano médio; E representa as estimativas de PP, PR e Q; e n é o total de anos analisados

A seguir, também com os dados médios de PP, PR e Q, simulados pelos modelos FAO e DSSAT/OILCROP-SUN, foram feitas regressões lineares simples para se verificar a correspondência entre os dois modelos.

Por fim, foram feitas regressões lineares simples com os dados médios de PP, PR e Q, simulados pelos modelos FAO e DSSAT/OILCROP-SUN, para a determinação do grau de proximidade entre estes modelos. 


\section{RESULTADOS E DISCUSSÃO}

\subsection{Calibração do modelo DSSAT/OILCROP-SUN para os cultivares em Monte Alegre do Sul, SP}

\subsubsection{Cultivar IAC-Anhandy}

Primeiramente, para o cultivar IAC-Anhandy, calibrou-se a profundidade de semeadura (SDEPTH) que tem influência direta na duração da subfase A (equação 14). Para tanto, foi elaborada uma matriz com os possíveis valores de SDEPTH, começando com 2 até $10 \mathrm{~cm}$, com intervalos de $0,5 \mathrm{~cm}$. Com a introdução de cada um destes valores na equação 14, foi possível a determinação da soma dos quadrados dos erros (ERRO), o coeficiente linear (a) e o coeficiente angular (b) entre os dados simulados e os medidos com todas as datas de semeaduras entre os anos de 1988 e 1989 em Monte Alegre do Sul (Anexo 1). A variação do valor de ERRO, a e b, em decorrência dos vários valores de SDEPTH, podem ser visualizadas na Figura 3. 


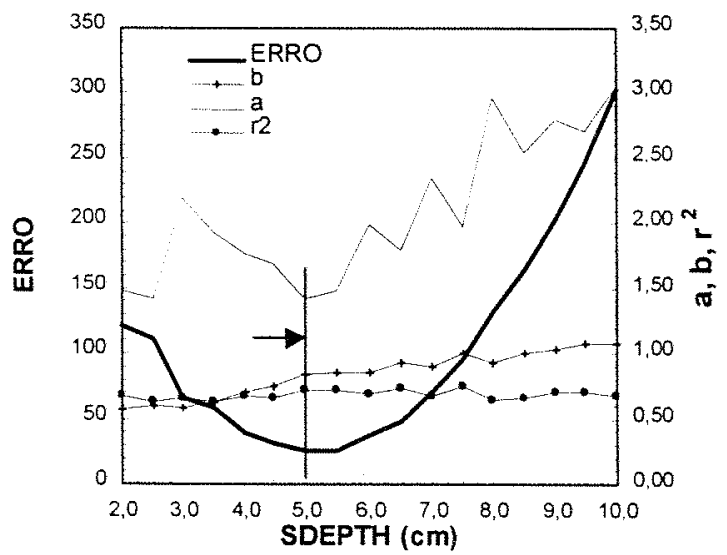

Figura 3 - Determinação da profundidade de semeadura ideal em relação à duração da subfase semeadura - emergência, para o cultivar IAC-Anhandy, em Monte Alegre do Sul, SP.

Observou-se, então, que a profundidade de $5 \mathrm{~cm}$ foi a ideal, pois foi o valor que apresentou o menor ERRO, tornou o $\mathrm{r}^{2}$ e o $\mathbf{b}$ mais próximo de 1 , e ainda, minimizou o valor de a. $\mathrm{O}$ ajuste final desta profundidade de semeadura e os parâmetros estatísticos decorrentes, são mostrados na Figura 4.

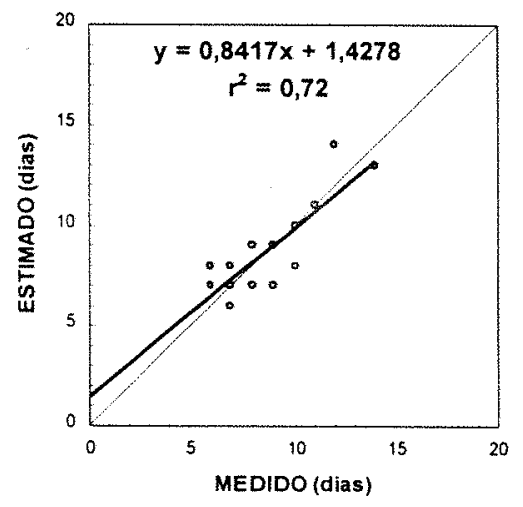

Figura 4 - Resultado final da calibração da profundidade de semeadura (SDEPTH), para o cultivar IAC-Anhandy, em Monte Alegre do Sul, SP.

$\mathrm{O}$ coeficiente do periodo juvenil $\left(\mathrm{P} 1,{ }^{\circ} \mathrm{C}\right.$.dia) tem influência direta nas subfases B e $(D+E)$ (equação 15 e 17), todavia, a subfase $C$, que ocorre entre as duas anteriores, é influenciada pelo coeficiente fotoperiódico (P2, dia.hora ${ }^{-1}$ ) (equação 16). Desse modo, as calibrações dos coeficientes P1 e P2 foram feitas conjuntamente para a posterior 
comparação da duração das subfases $\mathrm{B}, \mathrm{C}$ e $(\mathrm{D}+\mathrm{E})$, que corresponde à fase emergência primeira antese (Tabela 5). Os valores de $\mathrm{P} 1$ variaram de 130 a $450^{\circ} \mathrm{C}$.dia a cada $5^{\circ} \mathrm{C}$.dia e os valores de $\mathrm{P} 2\left(\right.$ dia.hora $\left.^{-1}\right)$ variaram de 0,1 até 1 , com um incremento de 0,1 , e de 1 a 8 com um incremento de 0,5 , totalizando 1561 combinações.

Primeiramente, analisaram-se as combinações que forneceram os menores ERRO (Figura 5).

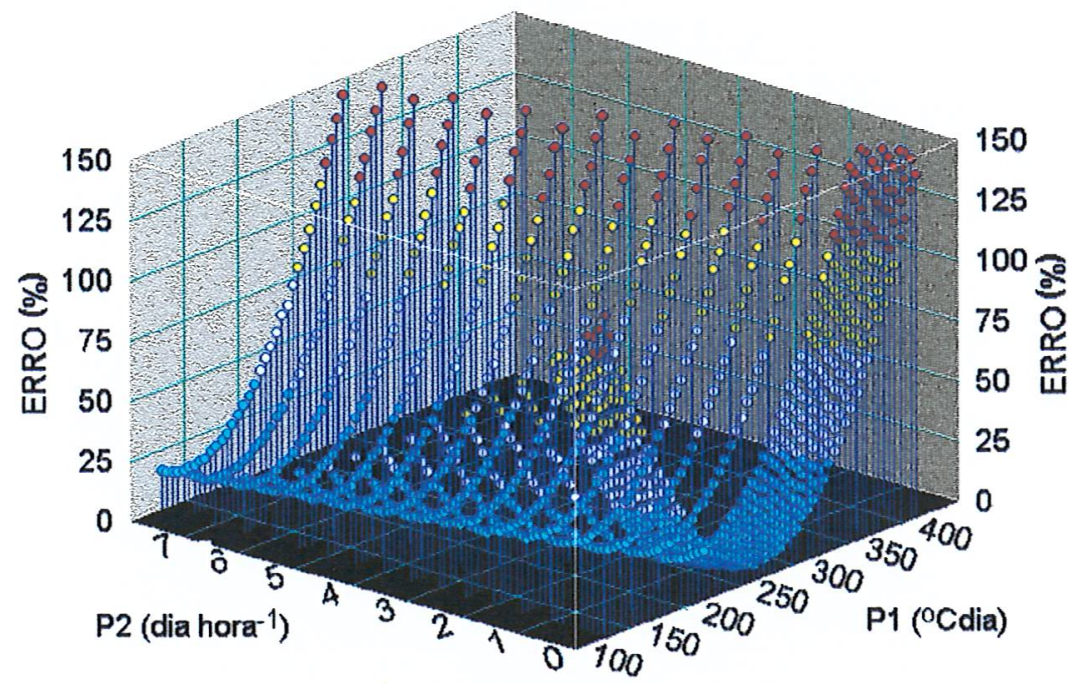

Figura 5 - ERRO decorrente de diferentes valores de $\mathrm{P} 1$ e P2, em relação à determinação da fase emergência - primeira antese, do cultivar IAC-Anhandy, em Monte Alegre do Sul, SP.

Pode-se observar que, quanto maior P1 e P2, maiores são os valores de ERRO. Para $\mathrm{P} 2$ pequenos (entre 0 e 1) o valor ideal de P1 é por volta de 250 a $300{ }^{\circ} \mathrm{C}$.dia; entretanto, o valor ideal de P1 é reduzido quando se aumenta o valor de P2.

Avaliando-se os outros parâmetros estatísticos, observa-se que a é minimizado quando se diminui os valores de P1 e P2 (Figura 6), indicando que os valores de P1 e P2 devem ser pequenos para a calibração do cultivar IAC-Anhandy. 


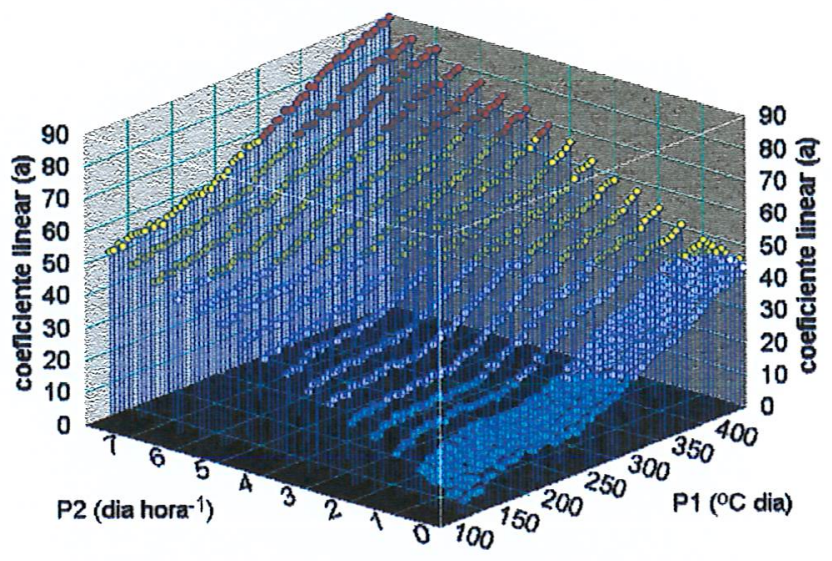

Figura 6 - Coeficiente linear (a) decorrente de diferentes valores de P1 e P2, em relação à determinação da fase emergência - primeira antese, do cultivar IAC-Anhandy, em Monte Alegre do Sul, SP.

$\mathrm{O}$ valor de b é maximizado com a diminuição de P2 e com o aumento de P1 (Figura 7), indicando que P1 deve ser elevado e que P2 deve ter valor baixo para que se consiga um b próximo a 1 .

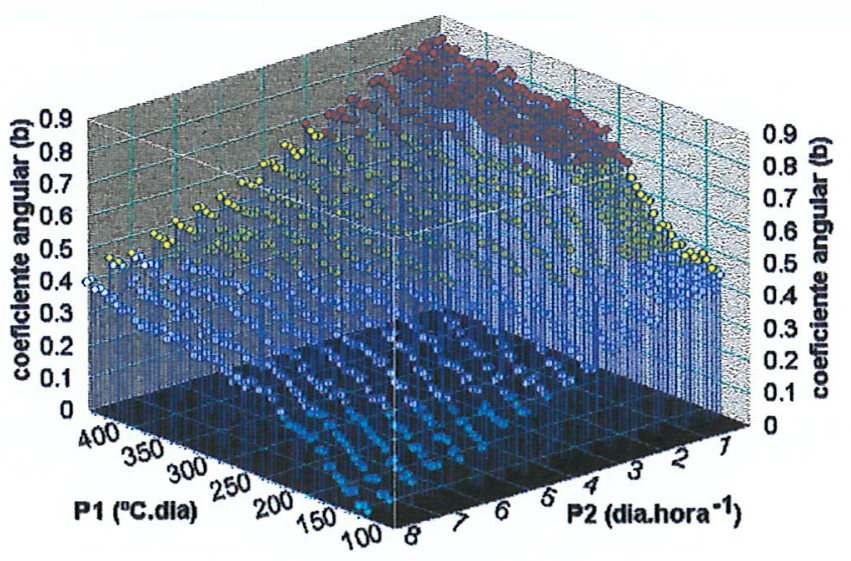

Figura 7 - Coeficiente angular (b) decorrente de diferentes valores de P1 e P2, em relação à determinação da fase emergência - primeira antese, do cultivar IAC-Anhandy, em Monte Alegre do Sul, SP. 
Observou-se, também, que os valores de $\mathrm{r}^{2}$ podem-se tornar, no máximo, próximos à 0,7 com a diminuição de $\mathrm{P} 2$ e $\mathrm{P} 1$ conjuntamente. Pela Figura 8 , pode-se notar que o $\mathrm{r}^{2}$ é mais sensível à diminuição de $\mathrm{P} 2$ do que de $\mathrm{P} 1$, indicando que o coeficiente fotoperiódico (P2) tem uma grande influência na determinação da duração da fase emergência - primeira antese $(\mathrm{B}+\mathrm{C}+\mathrm{D}+\mathrm{E})$ no modelo DSSAT/OILCROP-SUN.

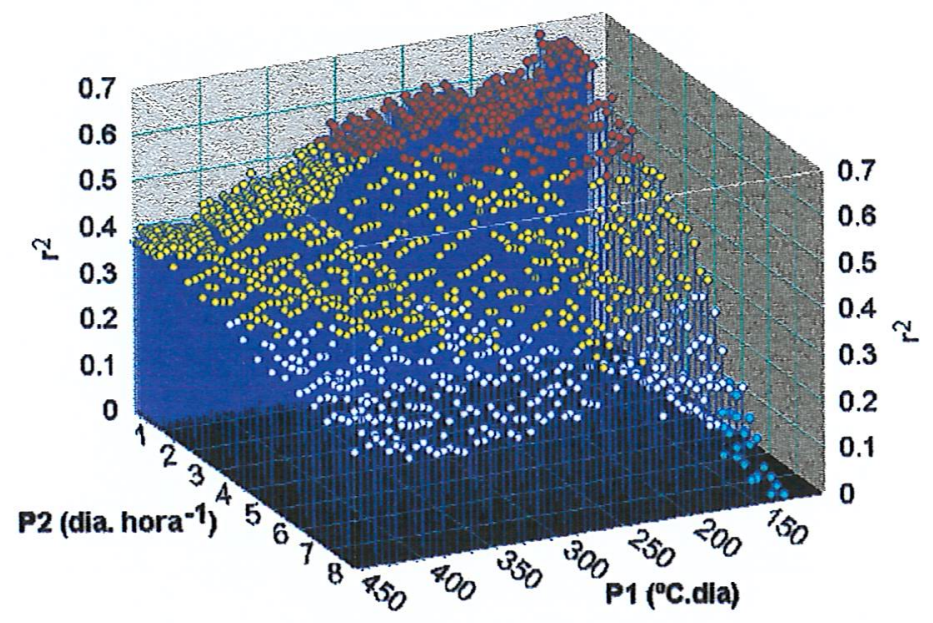

Figura 8 - Coeficiente de correlação $\left(\mathrm{r}^{2}\right)$ decorrentes de diferentes valores de P1 e P2, em relação à determinação da fase emergência - primeira antese, do cultivar IAC-Anhandy, em Monte Alegre do Sul, SP.

Então, a partir destas observações, considerou-se que os valores ideais de P1 e P2 seriam $265^{\circ} \mathrm{C}$.dia e 0,3 dia hora ${ }^{-1}$, respectivamente. $\mathrm{O}$ resultado final do ajuste destes coeficientes é mostrado na Figura 9, com os respectivos valores dos parâmetros estatísticos. 


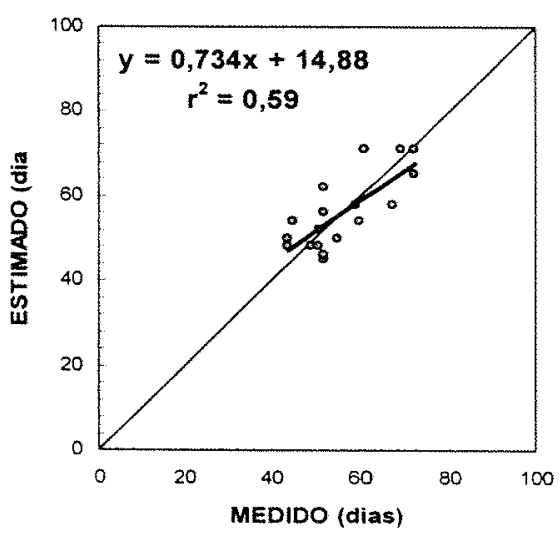

Figura 9 - Resultado final da calibração dos coeficiente P1 e P2, em relação à duração da fase emergência - primeira antese, para o cultivar IAC-Anhandy, em Monte Alegre do Sul, SP.

Por fim, o coeficiente $\mathrm{P} 5$, que determina a duração da fase primeira antesematuridade fisiológica (subfases F, G e H, equação 18), foi calibrado em função do ciclo total da cultura. A matriz com os possíveis valores de P5 variou de 300 até $1000{ }^{\circ} \mathrm{C}$.dia, com um incremento de $5{ }^{\circ} \mathrm{C}$.dia, totalizando 141 valores testados.

Pelos resultados apresentados na Figura 10 pode-se observar que quanto maior o valor de P5, maior o a, b e menor o $\mathrm{r}^{2}$. A minimização do ERRO ocorreu entre 740 e 795 ${ }^{\circ} \mathrm{C}$.dia.

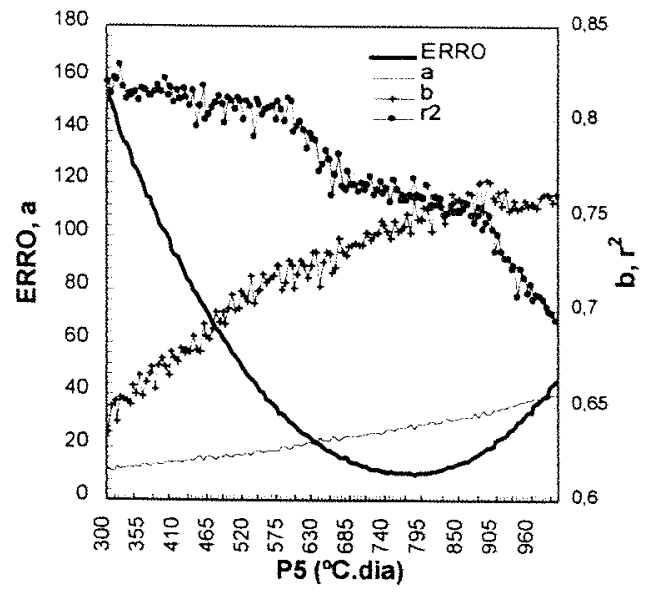

Figura 10 - Calibração do coeficiente de duração do preenchimento dos grãos (P5), feito em relação à duração do ciclo total da cultura do girassol, cultivar IAC-Anhandy, em Monte Alegre do Sul, SP. 
Levando-se em consideração todos os parâmetros estatísticos, foi considerado que o valor ideal de P5 seria $560{ }^{\circ} \mathrm{C}$.dia. $\mathrm{O}$ ajuste final entre os dados medidos e estimados e os referidos parâmetros estatísticos são apresentados na Figura 11.

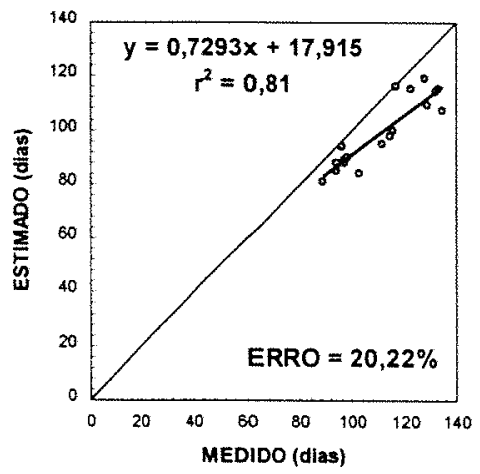

Figura 11 - Resultado Final da calibração do coeficiente P5, em relação à duração do ciclo total da cultura, para o cultivar IAC-Anhandy, em Monte Alegre do Sul, SP.

\subsubsection{Cultivares Contisol-621 e VNIIMK}

O mesmo procedimento apresentado para a calibração dos coeficientes genéticos do cultivar IAC-Anhandy foi utilizado para os cultivares Contisol-621 e VNIIMK.

A profundidade de semeadura ideal, para os cultivares Contisol-621 e VNIIMK, foi igual a $5 \mathrm{~cm}$, semelhante à do cultivar IAC-Anhandy. Os resultados são apresentados, em sua forma final, na Figura 12. 

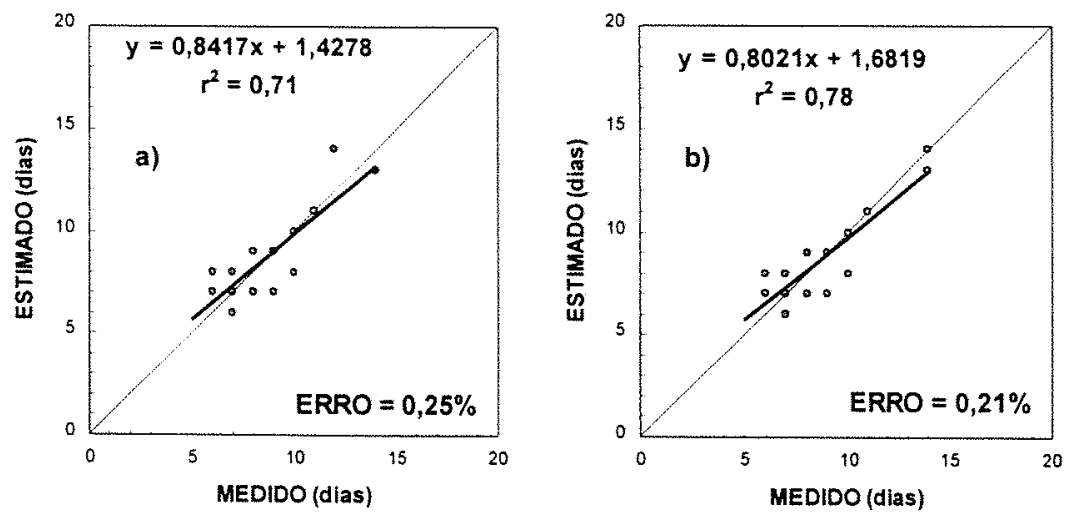

Figura 12 - Calibração da profundidade de semeadura (SDEPTH) para os cultivares Contisol-621 (a) e VNIIMK (b), feito em relação à duração da fase semeadura- emergència (A), em Monte Alegre do Sul, SP.

Tabela 7 - Valores calibrados dos coeficientes genéticos P1 (coeficiente da duração do periodo juvenil), P2 (coeficiente fotoperiódico) e P5 (coeficiente da duração da fase primeira antese - maturidade fisiológica) para o modelo DSSAT/OILCROP-SUN dos culivares, IAC-Anhandy, Contisol-621 e VNIIMK.

\begin{tabular}{|c|c|c|c|}
\hline Cultivares & $\overline{\left.\mathrm{P} 1 \text { ( }{ }^{\circ} \mathrm{Cdia}\right)}$ & P2 (dia hora-1) & P5 ( $\left.{ }^{\circ} \mathrm{Cdia}\right)$ \\
\hline IAC-Anhandy & 265 & 0,3 & 780 \\
\hline Contisol-621 & 235 & 1 & 560 \\
\hline VNIIMK & 260 & 1 & 560 \\
\hline
\end{tabular}

A correspondência entre os dados medidos e os estimados pelos coeficientes da Tabela 7, para os cultivares Contisol-621 e VNIIMK, é apresentado nas Figuras 14 e 15, respectivamente. 

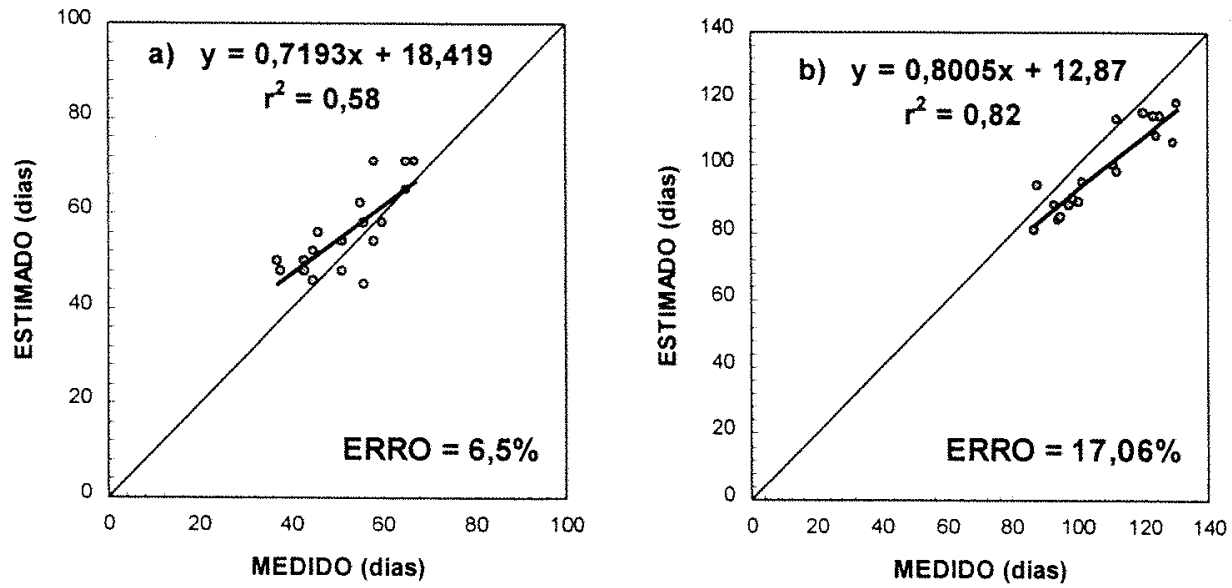

Figura 13 - Resultado final da calibração dos coeficientes: P1 e P2 (em relação à duração da fase emergência - primeira antese) (a), P5 (em relação à duração do ciclo total da cultura) (b), para o cultivar Contisol-621, em Monte Alegre do Sul, SP.
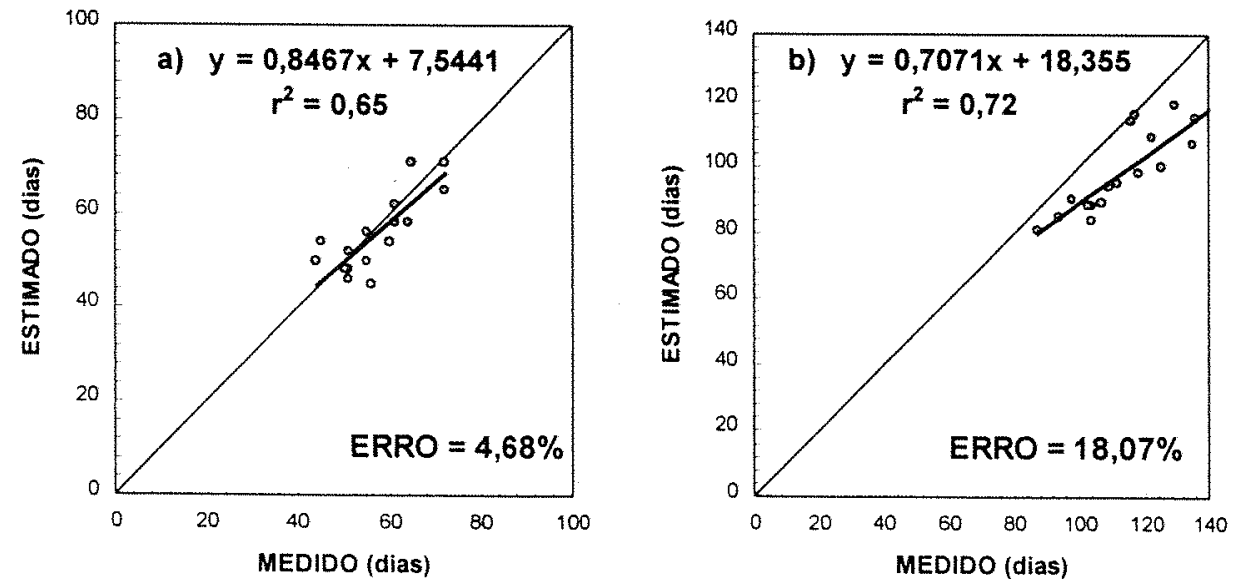

Figura 14 - Resultado final da calibração dos coeficientes: P1 e P2 (em relação à duração da fase emergência - primeira antese) (a), P5 (em relação à duração do ciclo total da cultura) (b), para o cultivar VNIIMK, em Monte Alegre do Sul, SP.

Os resultados obtidos para os coeficientes P1, P2 e P5 estão dentro da faixa dos sugeridos pelo sistema DSSAT (Tsuji et al., 1994); cujos valores de P1 devem ficar entre 210 e $450^{\circ} \mathrm{C}$.dia, de P2 entre 0,15 e 12 dia.hora $^{-1}$ e de P5 entre 550 e $750{ }^{\circ} \mathrm{C}$.dia. 
Além disso, os resultados obtidos no presente estudo estão relativamente próximos daqueles encontrados por Villalobos et al. (1996) para os cultivares SH-3000, 894 e Sungro, nos quais os valores de $\mathrm{P} 1$ foram 245,274 e $295^{\circ} \mathrm{C}$.dia e os valores de $\mathrm{P} 2$ foram 3,74, 9,33 e 12,32 dia.hora ${ }^{-1}$ respectivamente. Para o coeficiente P5 também foram encontrados resultados semelhantes ao apresentado por Gimenez (1985), que mostrou que para o cultivar Florasol esse valor é de $600{ }^{\circ} \mathrm{C}$.dia.

\subsection{Comparação dos Modelos DSSAT /OILCROP-SUN e FAO para as localidades no Estado de São Paulo e no Paraná}

Utilizando-se dados de três localidades paulistas e duas paranaenses, processouse a comparação entre os resultados de duração do ciclo, produtividade potencial, produtividade real e quebra relativa de produtividade, obtidos pelos modelos para os três cultivares, que são apresentados a seguir.

\subsubsection{Duração do ciclo total}

Observou-se que os modelos FAO e DSSAT simularam resultados muito próximos em relação à duração do ciclo total médio dos cultivares para todas as cidades, nas diferentes datas de semeadura, evidenciando um bom ajuste dos coeficientes genéticos calibrados (Figura 15 e 16). Foi observado, também, que a duração do ciclo da cultura variou conforme a data de semeadura, de 90 a 110 dias, em datas de semeadura de novembro até março e de 120 a 150 dias nas semeaduras dos demais meses do ano.

Nas localidades do Estado de São Paulo (Figura 15) a duração do ciclo total de todos os cultivares teve no mínimo 90 dias, na maioria das cidades e, um valor máximo de 130 dias nas cidades de Piracicaba e Manduri. Em Ribeirão Preto, devido às altas temperaturas, os cultivares apresentaram no máximo 117 dias.

Nas localidades do Estado do Paraná (Figura 16), a duração do ciclo total, em relação a todos os cultivares, teve o mínimo de 85 dias em Paranavaí, e em Ponta Grossa por volta de 100 dias. Em Ponta Grossa, a cidade com menores temperaturas, o ciclo da 
cultura se estendeu até um máximo de 150 dias, enquanto que em Paranavaí o ciclo atingiu no máximo 120 dias.
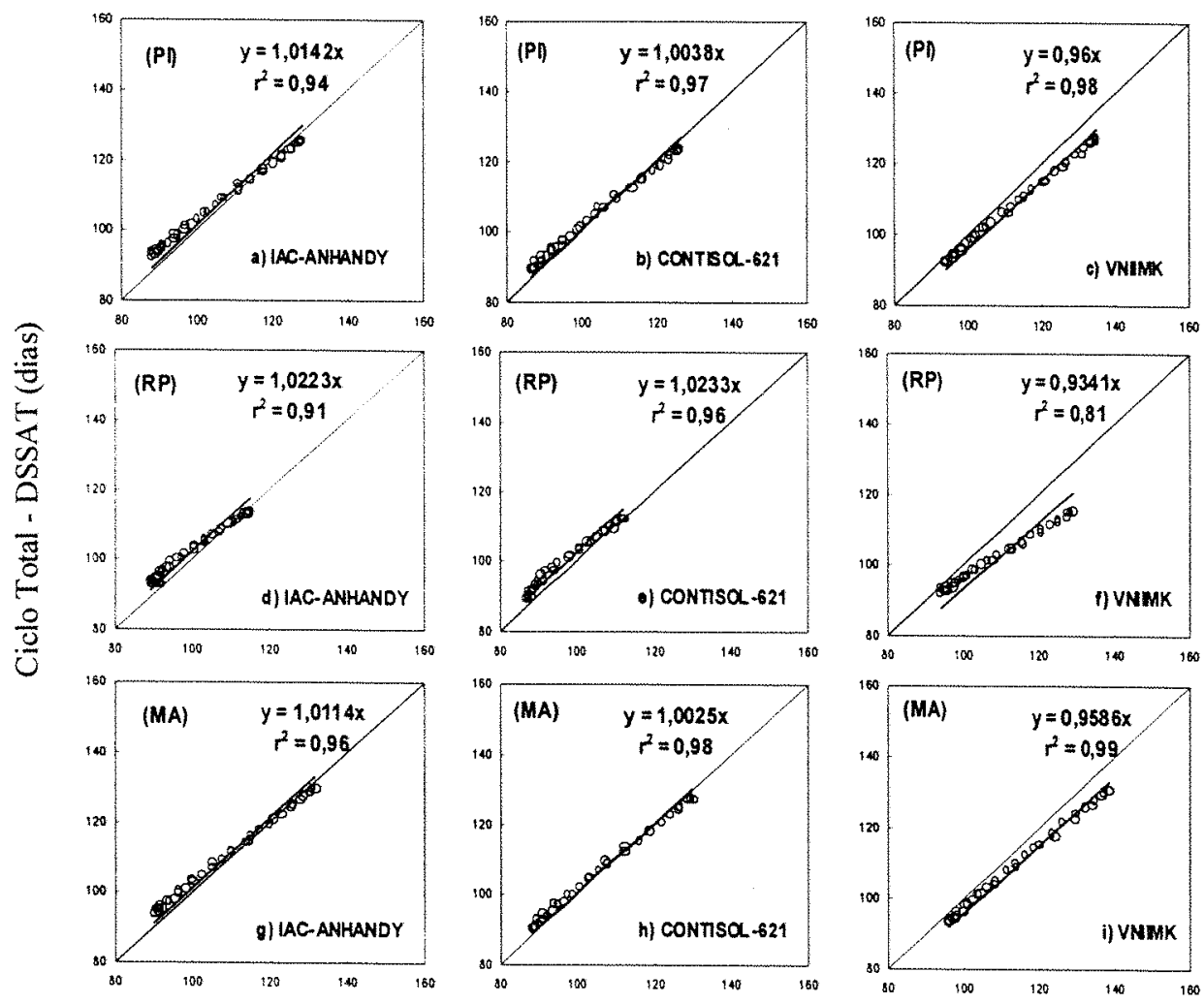

Ciclo Total - FAO (dias)

Figura 15 - Relação do número de dias do ciclo total médio, determinado pelos modelos FAO e DSSAT, para os cultivares de girassol, IAC-Anhandy, Contisol-621 e VNIIMK, nas localidades de Piracicaba (PI), Ribeirão Preto (RP) e Manduri (MA), no Estado de São Paulo.

Independentemente do Estado, nas situações em que o $\mathrm{r}^{2}$ foi menor que 0,94 , existe a possibilidade do modelo FAO ter sido diferente do DSSAT por este último levar em consideração, além da temperatura, o fotoperíodo, que influencia a duração da subfase $C$ (fim da fase juvenil - iniciação floral). Este mesmo fato explica alguns pontos discrepantes na Figura 16, pois o ciclo total dos cultivares simulados pelo modelo 
DSSAT podem ter sido reduzidos pela ação do fotoperíodo, como descrito na equação 16.
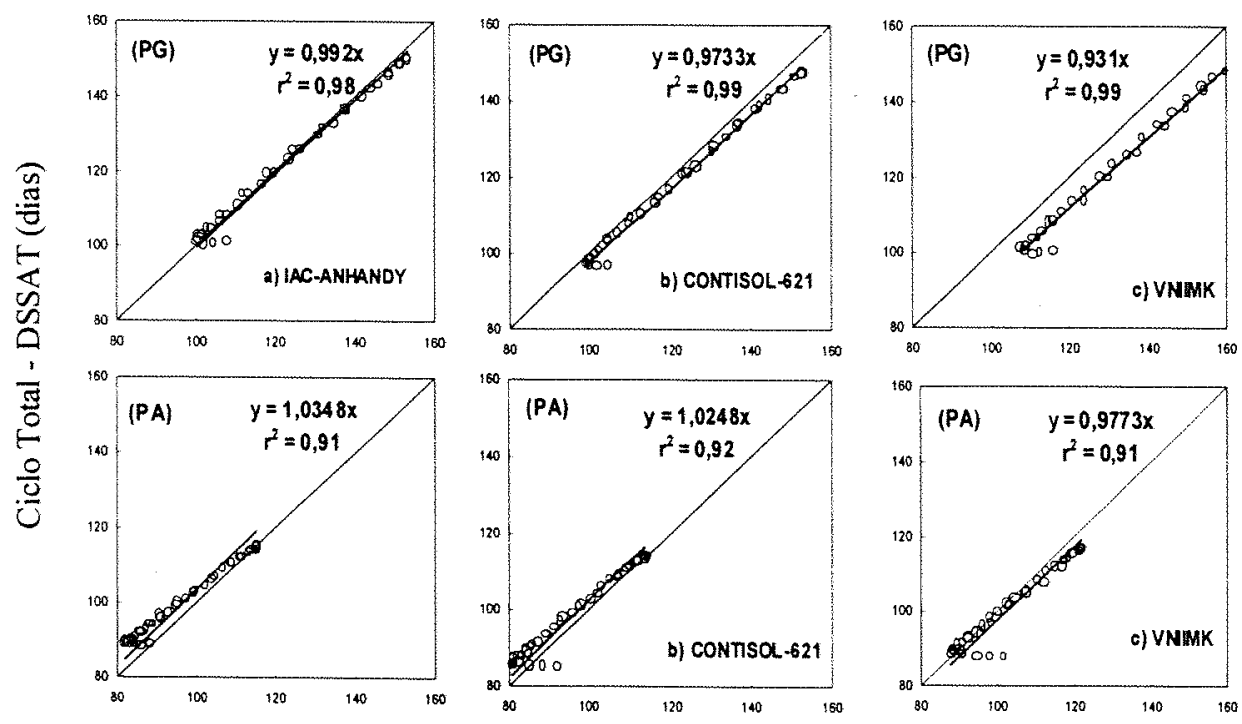

Ciclo Total - FAO (dias)

Figura 16 - Relação do número de dias do ciclo total médio determinados pelos modelos FAO e DSSAT para os cultivares de girassol IAC-Anhandy, Contisol-621 e VNIIMK nas localidades de Ponta Grossa (PG) e Paranavaí (PA), no Estado do Paraná.

Apesar da boa aproximação entre os dois modelos, pode-se verificar que, para o cultivar VNIIMK, o modelo FAO superestimou os valores do ciclo total em relação ao DSSAT. O contrário aconteceu para o cultivar IAC-Anhandy, excluindo-se a cidade de Ponta Grossa, onde os resultados de um modelo se aproximaram do outro. Esse aumento da estimativa do ciclo total por parte do modelo FAO para o cultivar VNIIMK leva a um aumento na produtividade, pelo fato da cultura ter mais tempo no período do florescimento até a maturação.

Esses resultados estão em concordância com a Contibrasil (1981) que afirma que a cultura semeada entre outubro a fevereiro tem por volta de 88 a 161 dias, dependendo do cultivar, desde os mais precoces até os mais tardios, respectivamente. Os resultados também foram semelhantes a Matsuoka et al. (1999) que, pela avaliação de 13 
cultivares, constataram que o ciclo médio dos mesmos foi de 110 dias em semeaduras em dezembro na cidade de Araras, SP.

No Estado do Paraná, os resultados dos modelos também se aproximaram de dados observados, como por exemplo, pela EMBRAPA (1984), que cita que os cultivares IAC-Anhandy e Contisol, semeados entre fevereiro a abril em Londrina, tiveram em média 125 a 131 dias no ciclo total, repectivamente. Enquanto que os modelos FAO e DSSAT em Paranavaí, a cidade mais próxima, simularam no máximo 117 dias para os dois cultivares, subestimando, então, de 8 a 14 dias o ciclo total dos cultivares.

\subsubsection{Produtividade Potencial}

Analisando-se a Produtividade Potencial (PP) média nas diferentes datas de semeaduras para todos os cultivares, observa-se que as variações do modelo FAO foram diferentes das obtidas com o modelo usado pelo DSSAT (Figuras 17 e 18) para todas as cidades, com exceção de Ponta Grossa, onde houve um melhor ajuste entre elas.

Essas diferenças ocorridas entre os modelos se deveram principalmente às variações do modelo FAO, pois este forneceu as maiores PPs, entre 3.500 a $4.000 \mathrm{~kg}$.ha

' nas cidades de Piracicaba e Manduri, em semeaduras entre abril e fim de maio. Já em Ribeirão Preto e Paranavaí não houve uma variação considerável da PP, ficando por volta de 3.000 a $3.500 \mathrm{~kg} \cdot \mathrm{ha}^{-1}$ e, por fim, em Ponta Grossa, as maiores PPs foram de 4.000 a $4.500 \mathrm{~kg} \cdot \mathrm{ha}^{-1}$ em semeaduras também entre abril e fim de maio. O DSSAT, por sua vez, forneceu PPs máximas por volta de 4.000 a $4.500 \mathrm{~kg} \cdot \mathrm{ha}^{-1} \mathrm{em}$ semeaduras entre julho e fim de agosto em todas as cidades. 


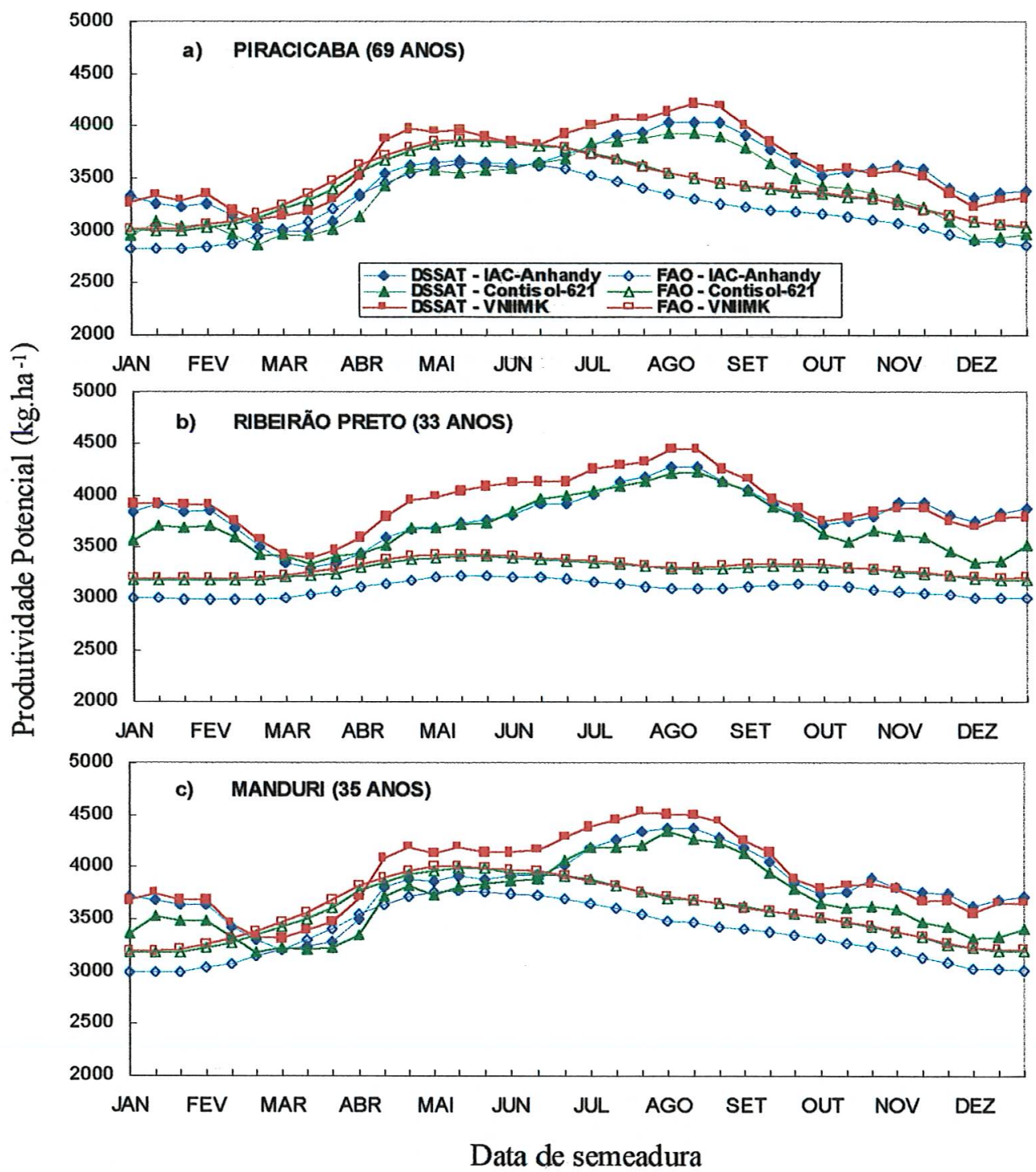

Figura 17 - Produtividade Potencial (PP) média nas diferentes datas de semeadura para os cultivares IAC-Anhandy, Contisol-621 e VNIIMK simuladas pelos modelos FAO e DSSAT, nas localidades de Piracicaba (a), de Ribeirão Preto (b) e de Manduri (c), no Estado de São Paulo. 


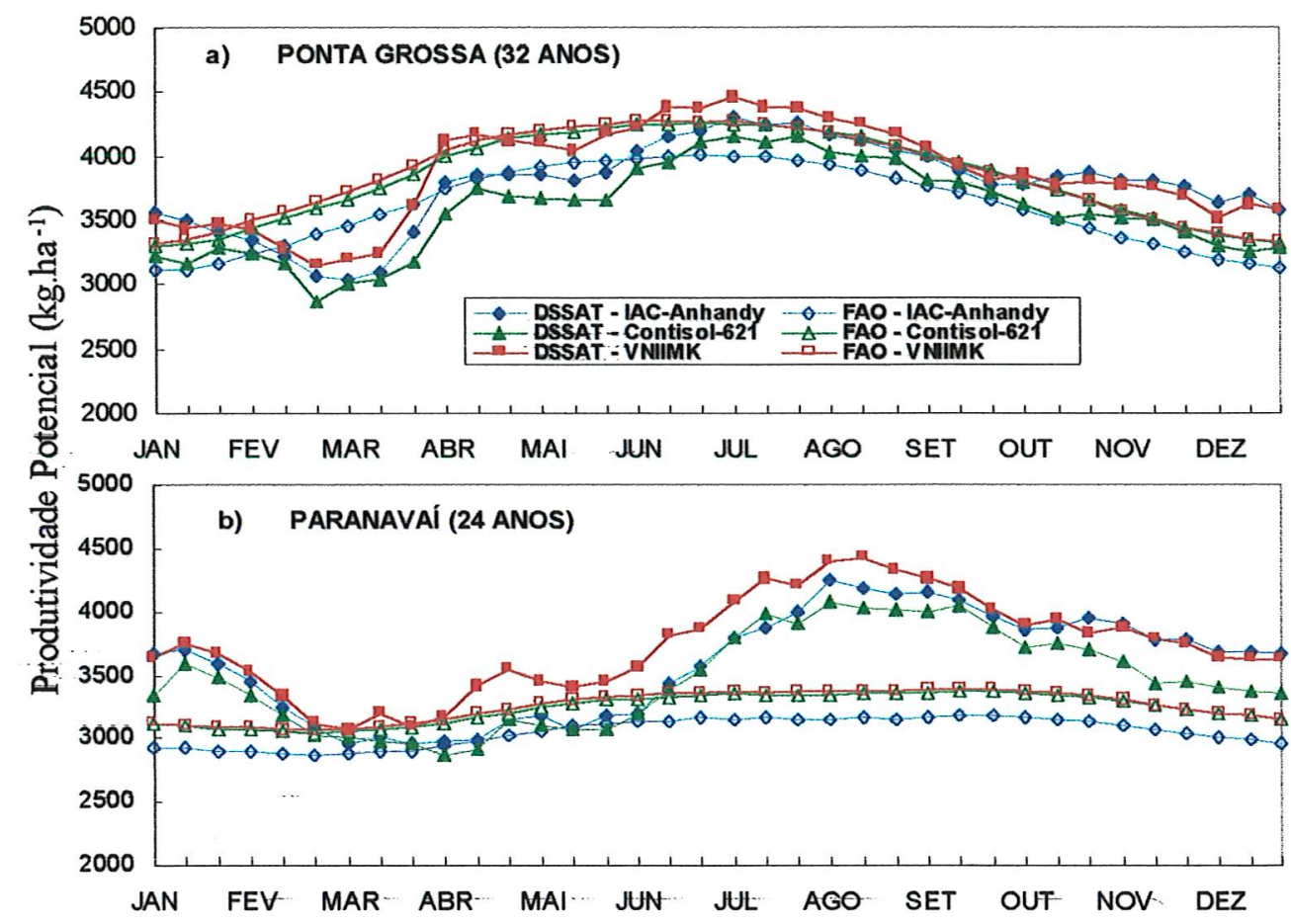

Data de semeadura

Figura 18 - Produtividade Potencial (PP) média nas diferentes datas de semeadura para os cultivares IAC-Anhandy, Contisol-621 e VNIIMK, simuladas pelos modelos FAO e DSSAT, nas localidädës de Pònta Grossa (a) e de Paranavaí (b), no Estado do Paraná.

Esses resultados estão de acordo com experimentos realizados pela EMBRAPA (1983), que concluiu ser possível para o girassol chegar até $6.000 \mathrm{~kg} \cdot \mathrm{ha}^{-1}$ nos Estados de São Paulo, Paraná e Mato Grosso do Sul, sob condições irrigadas.

Apesar do modelo DSSAT apresentar baixa variação das estimativas de PP em relação às diferentes cidades, ele mostrou-se mais sensível que o modelo FAO por apresentar uma maior variabilidade ao longo das datas de semeadura. Este fato pode ser visualizado nas Figuras 17 e 18, estabelecendo-se 4 períodos distintos; primeiramente nas datas de semeadura entre o início de outubro e o início de fevereiro, o modelo simulou valores intermediários de PP, decorrentes de estresse térmico que afeta todo o ciclo da cultura, apesar da boa disponibilidade de radiação global (Figura 19.b). A 
precipitação nesse período foi alta, o que provocou uma baixa insolação, promovendo também uma queda na PP devido à diminuição da taxa fotossintética dos cultivares. Este fato foi também confirmado por Ungaro (1986) que constatou que o excesso de chuva e dias nublados durante o florescimento levaram à diminuição da produtividade do cultivar IAC-Anhandy.

Com a queda acentuada da temperatura e da radiação a partir de março, as semeaduras do $2^{\circ}$ decêndio de fevereiro até o fim de março, resultaram nas menores simulações de PP em relação às outras datas de semeadura feitas pelo modelo DSSAT. Isto deve-se ao fato de que as fases de florescimento e de frutificação coincidem com os períodos mais frios ou mesmo sujeitos às geadas. Além disso, Pelegrini (1985) constatou que a produtividade do girassol também poderá ficar prejudicada se temperaturas frias ocorrerem no período que a cultura estiver no estágio de 6 a 8 folhas.

O terceiro período, que compreende semeaduras entre 10 de abril até 10 de junho, caracterizou-se por uma estabilização de PP por volta de 3.500 a $4.000 \mathrm{~kg}_{\text {.ha }}{ }^{-1}$, já que nessas datas de semeaduras, o ciclo total da cultura é maior em função do maior número de dias com temperaturas mais amenas. Além disso, o fotoperíodo atua no sentido de antecipar a antese, reduzindo o sub-período emergência-antese e aumentando o período entre a floração e maturação dos grãos, aumentando assim a PP.

Por fim, as maiores PP ocorreram nas semeaduras entre julho e fim de agosto, decorrentes do aumento da área foliar simulada pelo DSSAT em função das temperaturas sempre crescentes durante todo o ciclo da cultura. 

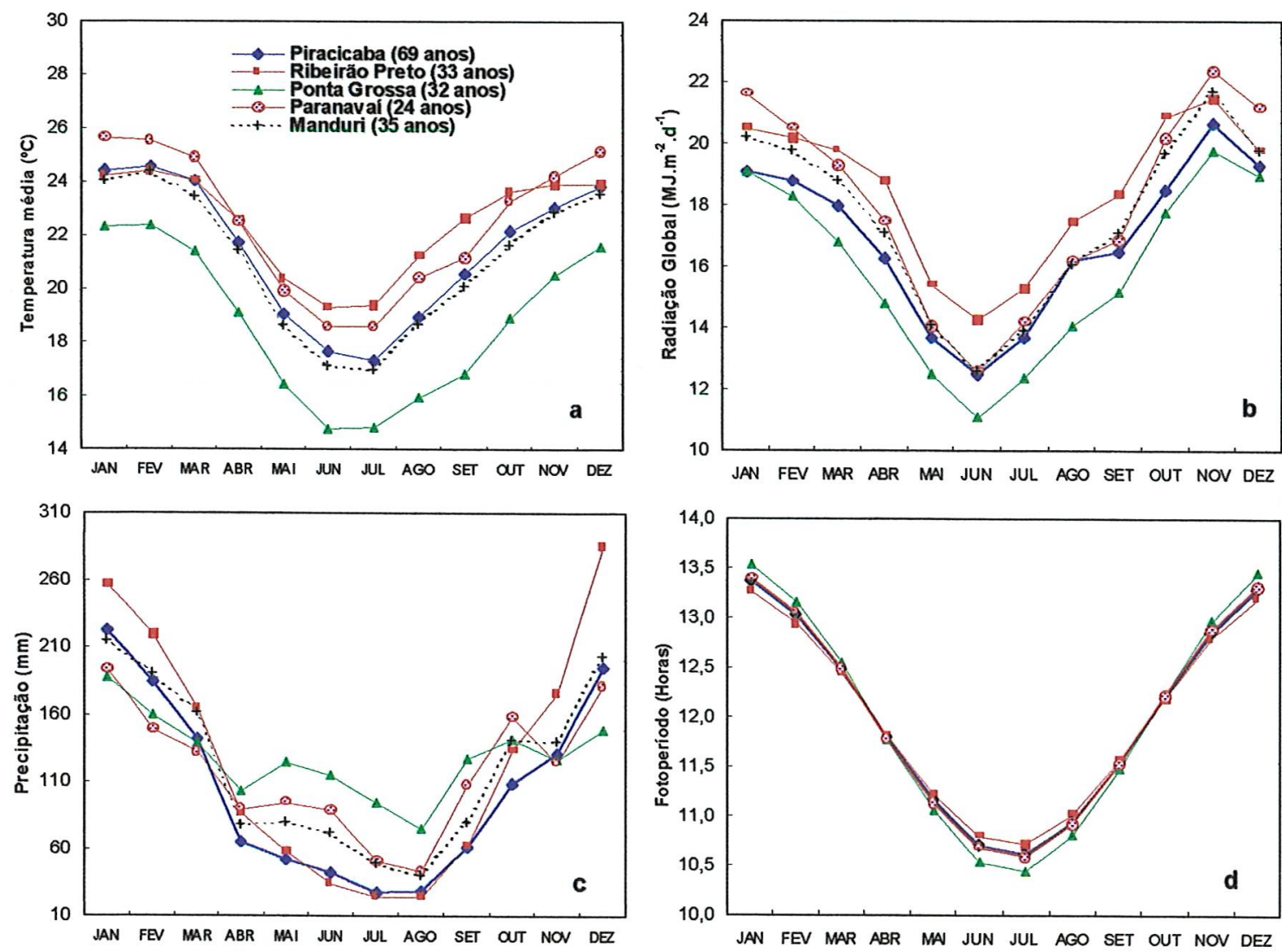

Figura 19 - Temperatura do ar (a), radiação solar global (b), precipitação (c) e fotoperíodo (d) mensais para as localidades de Piracicaba, de Ribeirão Preto, e de Manduri, no Estado de São Paulo, e de Ponta Grossa e de Paranavaí, no Estado do Paraná.

Por sua vez, o modelo FAO apresentou uma menor variabilidade nas simulações de PP nas diferentes datas de semeaduras em comparação ao DSSAT (Figuras 17 e 18). Primeiramente, observa-se que o modelo apresentou relação inversa entre a PP e a temperatura média das cidades (Tabela 8), ou seja, nas localidades de maiores temperaturas como Ribeirão Preto e Paranavaí, a PP apresentou valores menores. Por outro lado, nas localidades de menores temperaturas como Piracicaba, Manduri e Ponta Grossa, foram estimadas nesta sequência, maiores PP. Tal relação não foi observada nos resultados provenientes do modelo DSSAT. 
Tabela 8 - Produtividade Potencial média dos cultivares IAC-Anhandy, Contisol-621 e VNIIMK, nas localidades de Piracicaba, Ribeirão Preto e Manduri, no Estado de São Paulo,e de Ponta Grossa e Paranavaí, no Estado do Paraná, simuladas pelo modelo FAO e DSSAT.

\begin{tabular}{|c|c|c|c|c|c|c|c|c|c|}
\hline \multirow{3}{*}{ Local } & \multirow{3}{*}{$\begin{array}{l}\text { Temperatura } \\
\text { média } \\
\left({ }^{\circ} \mathrm{C}\right)\end{array}$} & \multicolumn{8}{|c|}{ Produtividade Potencial Media (kg ha') } \\
\hline & & \multicolumn{4}{|c|}{ FAO } & \multicolumn{4}{|c|}{ DSSAT } \\
\hline & & IAC-Anhandy & Contisol-621 & VNIIMK & MÉDIA & IAC-Anhandy & Contisol-621 & VNIIMK & MÉDIA \\
\hline Paranavai & 22,5 & $3 \longdiv { 4 7 }$ & 3337 & 3354 & 3279 & 3583 & 3462 & 3722 & 3589 \\
\hline Ribeirão Preto & 22,4 & 3362 & 3445 & 3453 & 3420 & 3813 & 3712 & 3921 & 3815 \\
\hline Piracicaba & 21,5 & 3348 & 3554 & 3572 & 3491 & 3533 & 3377 & 3642 & 3517 \\
\hline Manduri & 21,1 & 3440 & 3533 & 3541 & 3505 & 3819 & 3689 & 3925 & 3811 \\
\hline Ponta Grossa & 18,8 & 3712 & 3952 & 3973 & 3879 & 3768 & 3576 & 3861 & 3735 \\
\hline
\end{tabular}

Essa relação inversa entre a PP e a temperatura média pode ter as seguintes causas: o modelo FAO considera que os cultivares atingem o ponto de saturação fotossintéfica em valores baixos de temperatura, ou seja, nas cidades mais quentes os cultivares tendem a diminuir a fotossintese bruta em decorrência de uma temperatura maior do que a ideal. Outra possibilidade é que a taxa de manutenção da cultura, que é função da temperatura e da biomassa total da planta, representada pelo coeficiente de respiração $\left(C_{R}\right)$, pode estar sendo superestimada nos meses mais frios (entre maio e agosto) e subestimada nos meses mais quentes. Por exemplo, nos períodos frios $\left(\mathrm{T}<20^{\circ} \mathrm{C}\right)$ o valor de $\mathrm{C}_{\mathrm{R}}$ preconizado é de 0,6 , significando que $60 \%$ da fotossíntese bruta é disponibilizada para o acúmulo de biomassa da cultura; entretanto, este valor pode estar muito alto pois sabe-se que, em épocas de baixa temperatura, a planta tende a diminuir sua taxa de crescimento. Por fim, o modelo FAO pode estar subestimando a PP nas localidades mais quentes pela diminuição do número de dias do ciclo total da cultura.

Observa-se que o modelo FAO simulou baixas produtividades em semeaduras entre novembro e janeiro em todas as cidades, em decorrência dos possíveis problemas acima mencionados, além da baixa insolação causada pela alta quantidade de precipitação, que provoca a queda da taxa fotossintética (Figuras 17 e 18).

As semeaduras em março já obtiveram PPs maiores devido à diminuição da temperatura, saindo dos níveis de estresse. Entretanto, as PPs não foram ainda as 
máximas devido à ocorrência de baixas temperaturas, que podem ter afetado as fases de florescimento e frutificação, diminuindo a produção de aquênios.

Semeaduras no início de maio ao final de julho, apresentaram as máximas PPs simuladas pelo modelo FAO. Nestas datas de semeadura, a cultura tem, em média 4 meses, ou seja, ela tem mais tempo para o florescimento, frutificação e maturação e, nos meses que correspondem ao ciclo total da cultura, tem-se temperaturas mais adequadas, promovendo também o aumento da produtividade. Outro fator que propiciou o aumento da PP nessas datas de semeadura, foi a maior insolação disponível, em função da menor precipitação nos meses de junho a agosto, aumentando a fotossintese bruta dos cultivares, o que aumenta, por sua vez, o acúmulo de biomassa.

Observou-se que as datas de semeadura entre julho e fim de agosto foram as de maiores diferenças entre os modelos FAO e DSSAT. Isto decorreu de um maior índice de área foliar simulada pelo DSSAT (que chegou a $5 \mathrm{~m}^{2} \cdot \mathrm{m}^{-2}$ ), enquanto que no modelo FAO a área foliar máxima foi igual a 3 , proveniente de dados experimentais.

Analizando-se as Figuras 20 e 21, onde são apresentadas as frequências da Produtividade Potencial da cultura do girassol, relativas a todos os dados simulados, nota-se que os valores de maior frequência ocorreram entre 3000 a $4000 \mathrm{~kg}^{-h a^{-1}}$ nas localidades de Piracicaba, Ribeirão Preto e Paranavaí, e entre 3500 a $4500 \mathrm{~kg}^{-h^{-1}} \mathrm{em}$ Manduri e Ponta Grossa, para os dois modelos. Observa-se, ainda, que o modelo DSSAT simulou maior número de produtividades até $3000 \mathrm{~kg} \cdot \mathrm{ha}^{-1}$ do que o modelo $\mathrm{FAO}$ e que este, por sua vez, suplantou o modelo DSSAT nas frequências de PP entre 3000 a 4500 kg. ha ${ }^{-1}$. 


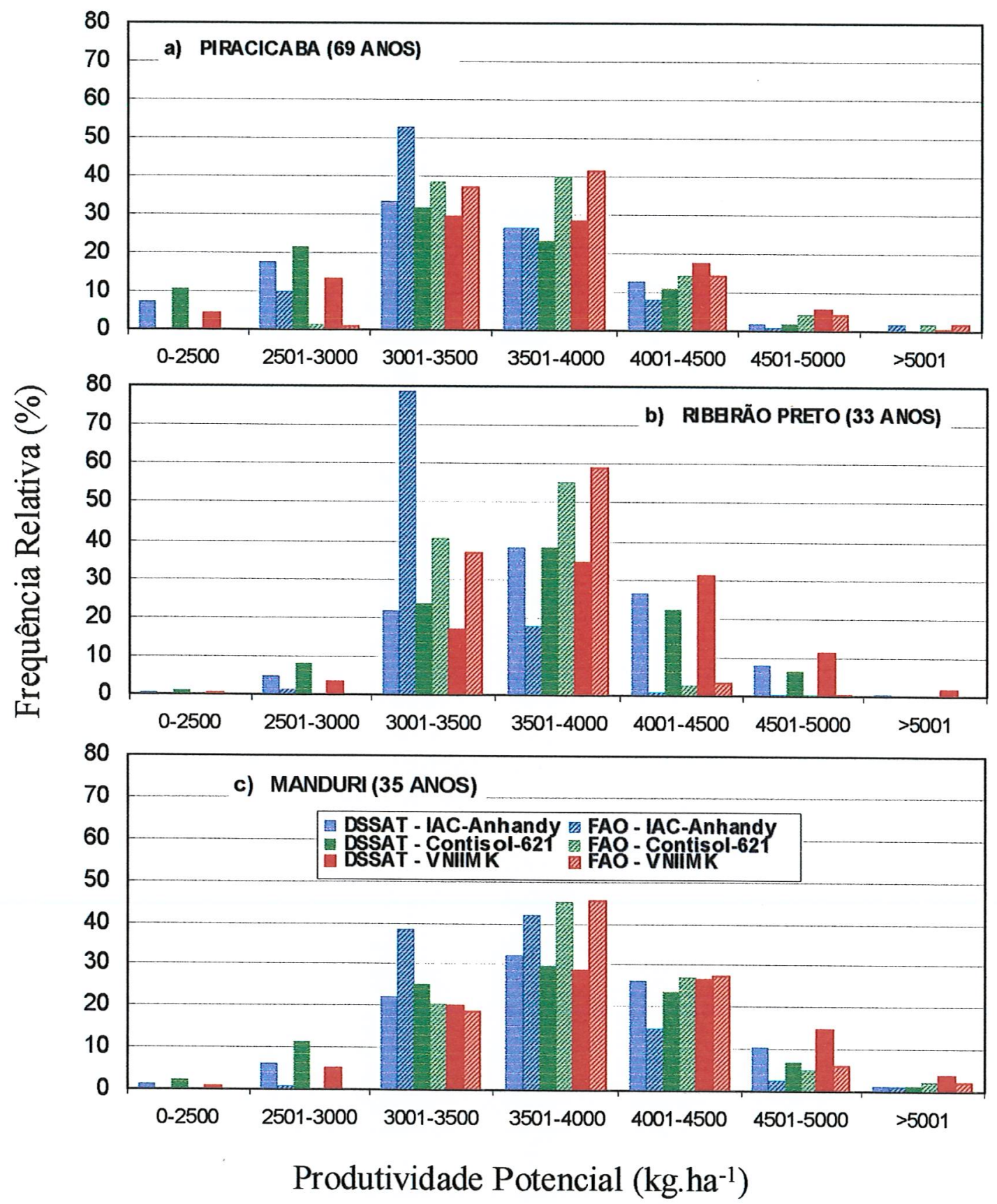

Figura 20 - Frequência Relativa de Produtividades Potenciais (PP) simuladas pelos modelos FAO e DSSAT para todas as datas de semeadura analisadas, para os cultivares IAC-Anhandy, Contisol-621 e VNIIMK, nas localidades de Piracicaba (a), de Ribeirão Preto (b) e de Manduri (c), no Estado de São Paulo. 


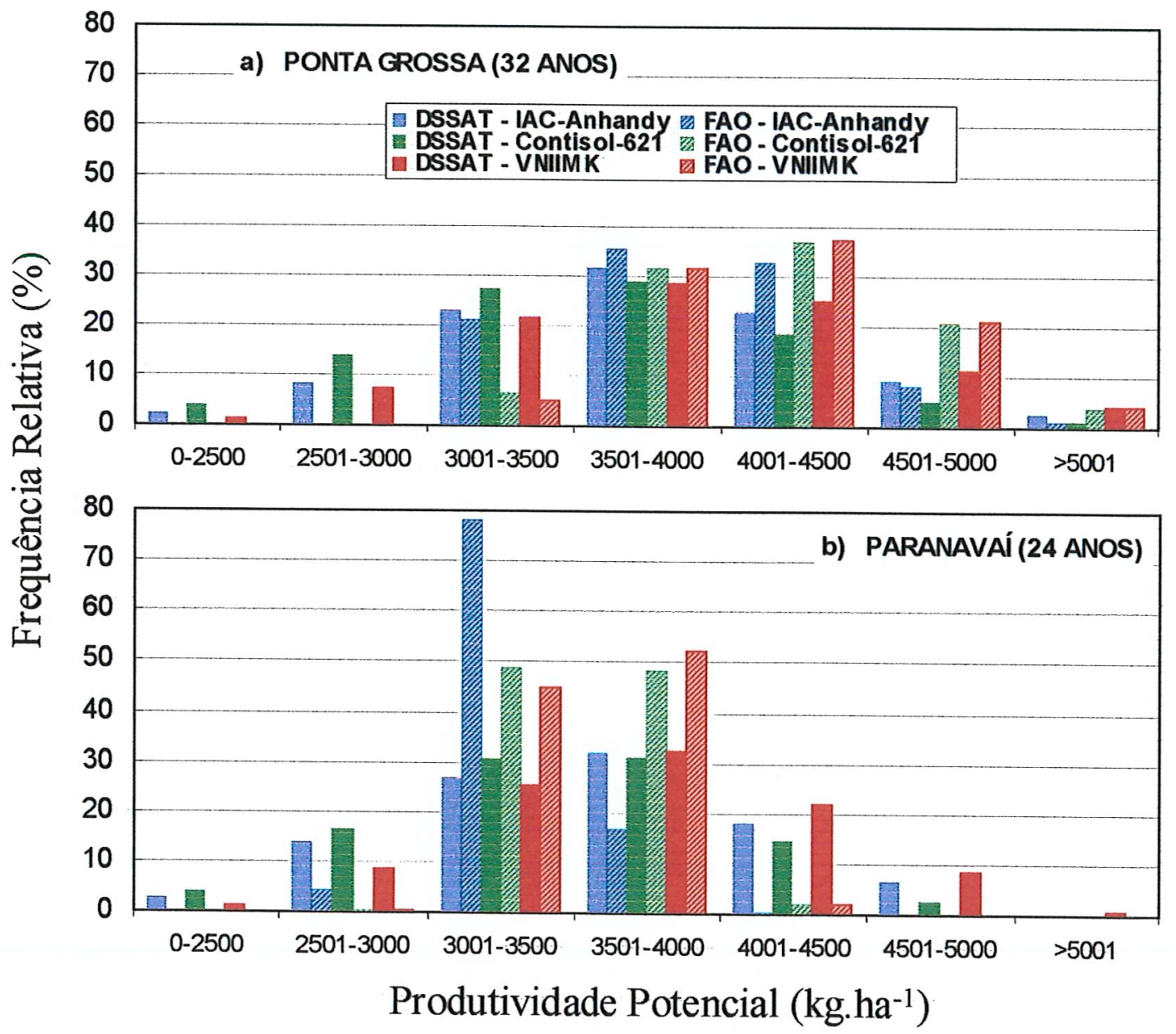

Figura 21 - Frequência Relativa Produtividades Potenciais (PP) simuladas pelos modelos FAO e DSSAT para todas as datas de semeaduras analisadas, para os cultivares IACAnhandy, Contisol-621 e VNIIMK, nas localidade de Ponta Grossa (a) e de Paranavaí (b), no Estado do Paraná.

De forma geral, pode-se notar que nas cidades mais quentes, como Ribeirão Preto e Paranavaí, houve uma concentração de PPs entre 3.000 a $4.000 \mathrm{~kg} \cdot \mathrm{ha}^{-1}$ simuladas pelo modelo FAO (Figuras 20.b e 21.b). Por outro lado, nas cidades mais frias, o modelo ampliou os valores de PP para além de $4.000 \mathrm{~kg} \cdot \mathrm{ha}^{-1}$, indicando o efeito do aumento do ciclo total na PP. Já o modelo DSSAT apresentou sempre maior distribuição dos valores 
de PP em relação ao modelo FAO, indicando ser um modelo mais robusto por utilizar mais dados nas suas simulações, o que evita mudanças repentinas nos valores de PP.

Para quantificação das diferenças entre a PP simulada pelos dois modelos, foi calculado a diferença média absoluta, máxima e mínima entre todos os valores simulados (Tabela 9).

Tabela 9 - Diferença média absoluta, máxima e mínima entre os valores de Produtividade Potencial simulados pelos modelos FAO e DSSAT, para as localidades analisadas.

\begin{tabular}{llccccc}
\hline LOCAL & Diferença & $\begin{array}{c}\text { TAC-Anhandy } \\
\text { P.P. } \\
\left(\mathrm{kg} \mathrm{ha}^{-1}\right)\end{array}$ & $\begin{array}{c}\text { Contisol-621 } \\
\text { P.P. } \\
\left(\mathrm{kg} \mathrm{ha}^{-1}\right)\end{array}$ & $\begin{array}{c}\text { VIIMK } \\
\text { P.P. } \\
\left(\mathrm{kg} \mathrm{ha}^{-1}\right)\end{array}$ & $\begin{array}{c}\text { GERAL } \\
\text { P.P. } \\
\left(\mathrm{kg} \mathrm{ha}^{-1}\right)\end{array}$ \\
\hline Piracicaba & Média Absoluta & 339 & 192 & 259 & 263 \\
& Máxima & 780 & 444 & 728 & 780 \\
& Minima & 13 & 18 & 3 & 3 \\
\hline Ribeirão & Média Absoluta & 452 & 203 & 357 & 337 \\
Preto & Máxima & 913 & 653 & 853 & 2419 \\
& Mínima & 3 & 3 & 27 & 3 \\
\hline Manduri & Média Absoluta & 466 & 254 & 186 & 302 \\
& Máxima & 908 & 643 & 541 & 908 \\
& Mínima & 6 & 53 & 4 & 4 \\
\hline Ponta & Média Absoluta & 262 & 255 & 164 & 227 \\
Grossa & Máxima & 535 & 727 & 579 & 727 \\
& Minima & 22 & 5 & 15 & 5 \\
\hline Paranavai & Média Absoluta & 537 & 315 & 474 & 442 \\
& Máxima & 1093 & 743 & 1060 & 1093 \\
& Minima & 21 & 20 & 6 & 6 \\
\hline GERAL & Média Absoluta & 411 & 244 & 288 & 314 \\
& Máxima & 1093 & 743 & 1060 & 2419 \\
& Minima & 3 & 3 & 3 & 3 \\
\hline
\end{tabular}

A Tabela 9 mostra que a maior diferença média absoluta entre a PP, estimada pelo modelo FAO e pelo DSSAT, ocorreu em Paranavaí, para o cultivar IAC-Anhandy. A PP do cultivar Contisol-621 resultou na menor diferença média absoluta entre os dois modelos na maioria das cidades. Por fim, analisando-se a diferença média absoluta e a diferença máxima, Ponta Grossa foi onde os valores provenientes do modelo FAO se aproximaram mais do DSSAT, seguida por Piracicaba, Manduri, Ribeirão Preto e Paranavaí.

Isso mostra que, quando o modelo FAO simulou baixas PP devido às altas temperaturas médias das cidades, as diferenças entre os modelos FAO e DSSAT foram 
maiores. Por sua vez, nas cidades onde as temperaturas são mais amenas (Piracicaba, Manduri e Ponta Grossa) os valores simulados de PP pelo modelo FAO foram maiores, levando a uma menor diferença entre os modelos.

Devido a essas diferenças de PP média nas diferentes datas de semeaduras, não existiu concordância consistente entre as estimativas feitas pelos modelos FAO e DSSAT como pode ser observado nas Figuras 22 e 23. Apesar disso, pelos motivos já descritos, pode-se afirmar que ambos os modelos mostraram que, em datas de semeaduras entre abril e fim de agosto (Figuras 17 e 18), culturas irrigadas de girassol obterão maiores produtividades nas cidades analisadas.
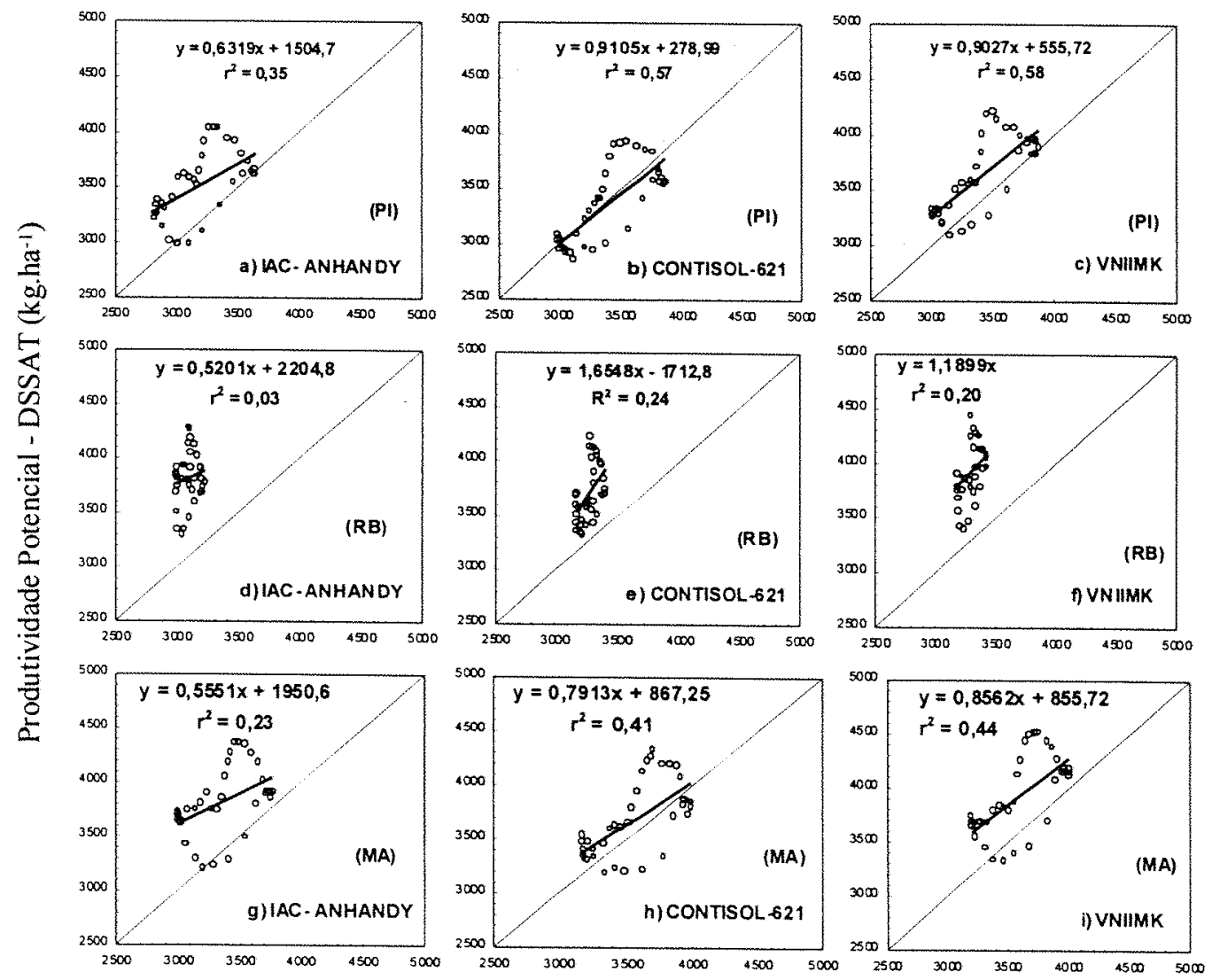

Produtividade Potencial - FAO (kg. ha-1)

Figura 22 - Relação entre as Produtividades Potenciais (PP) médias simuladas pelos modelos FAO e DSSAT para os cultivares IAC-Anhandy, Contisol-621 e VNIIMK para Piracicaba (PI), Ribeirão Preto (RP) e Manduri (MA), no Estado de São Paulo. 

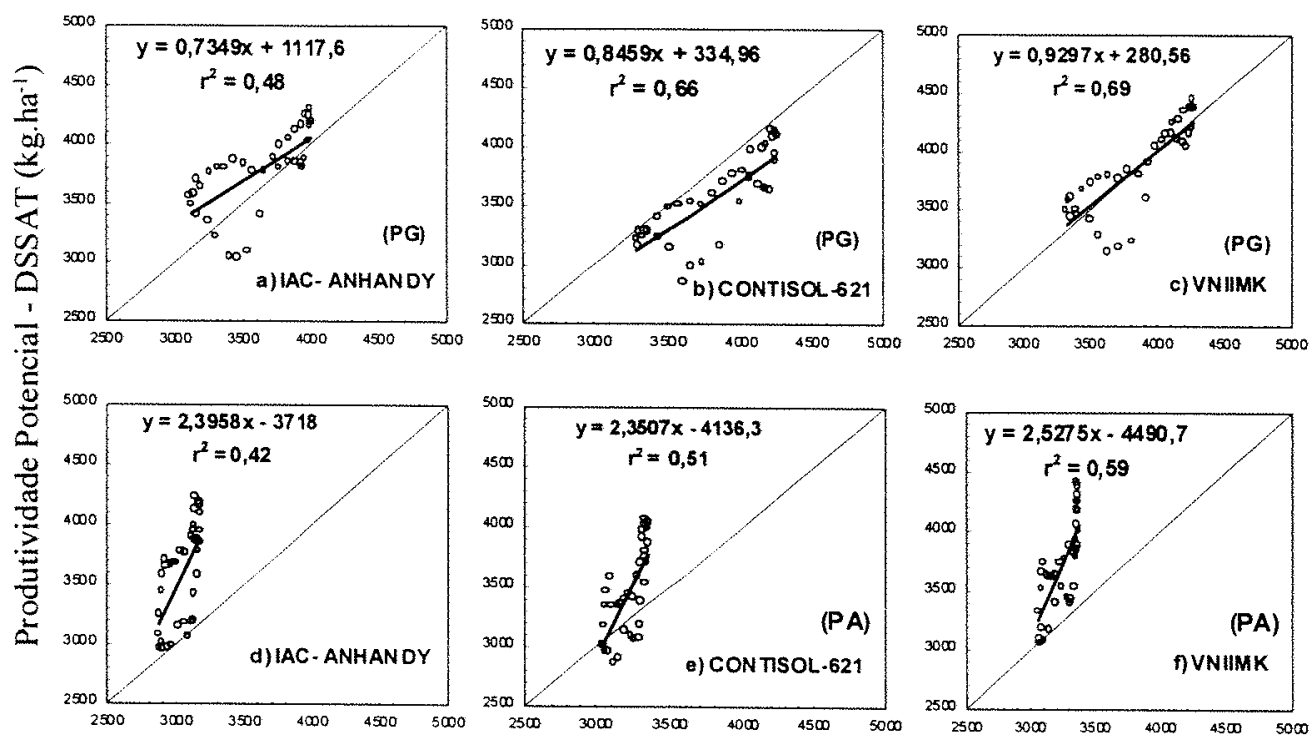

Produtividade Potencial - FAO (kg. ha $\left.{ }^{-1}\right)$

Figura 23 - Relação entre as Produtividades Potenciais (PP) médias, simuladas pelo modelo FAO e DSSAT, para os cultivares IAC-Anhandy, Contisol-621 e VNIIMK, para Ponta Grossa (PG) e Paranavai (PA), no Estado do Paraná.

\subsubsection{Produtividade Real}

Analisando-se a Produtividade Real (PR) média nas diferentes datas de semeaduras, observa-se que as variações do modelo FAO foram semelhantes as do DSSAT, com exceção de Paranavaí, como pode ser visualizado nas Figuras 24 e 25.

No entanto, o modelo DSSAT apresentou estimativas com maior variação nas diferentes datas de semeadura em comparação ao modelo FAO, mostrando sua maior sensibilidade às condições ambientais. Essa sensibilidade do modelo DSSAT também pode ser confirmada pelos altos coeficientes de variação (Anexo 2) indicando variabilidade nas estimativas nos diferentes anos. 


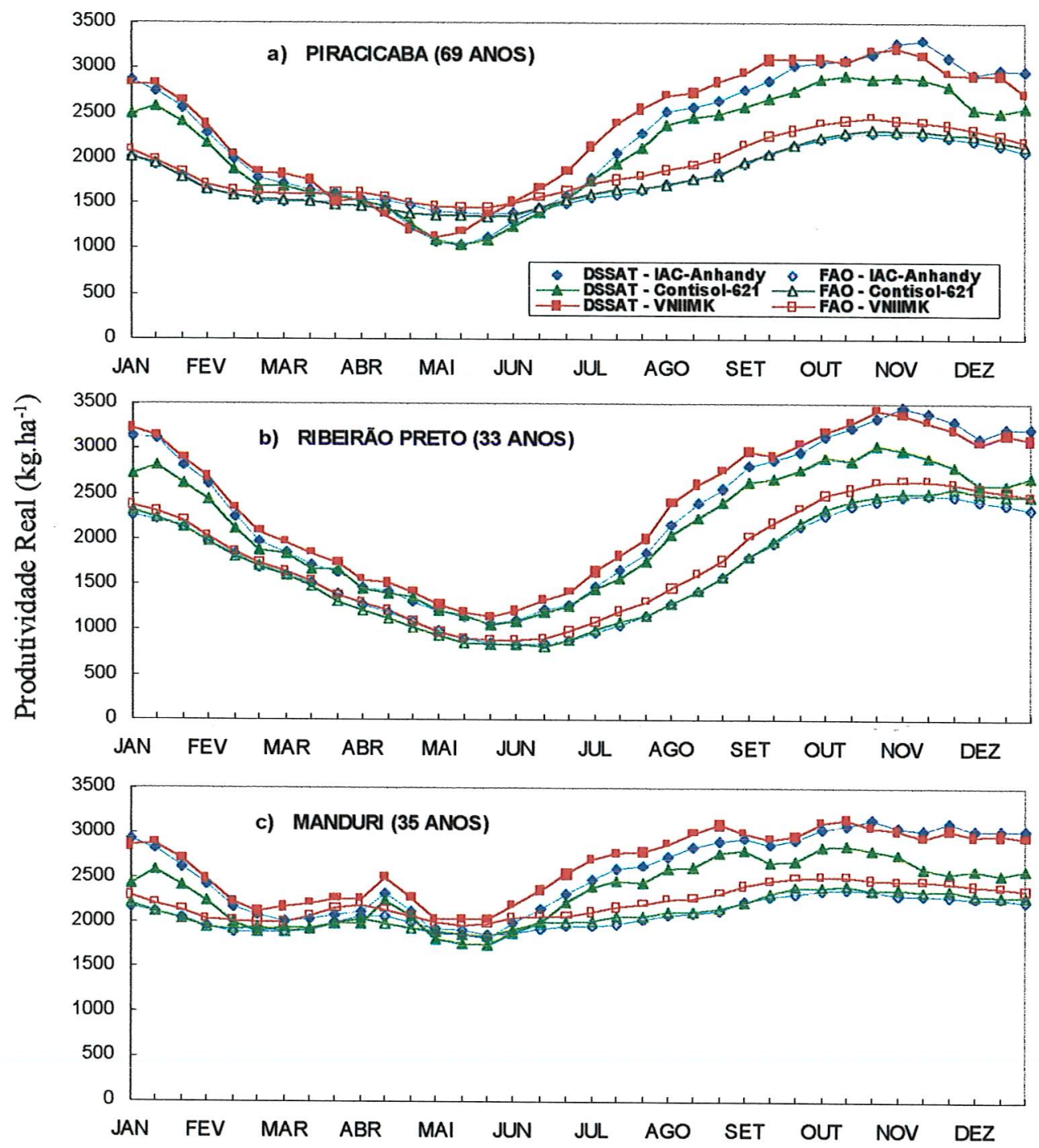

Data de semeadura

Figura 24 - Produtividade Real (PR) média, nas diferentes datas de semeadura, para os cultivares IAC-Anhandy, Contisol-621 e VNIIMK, simuladas pelos modelos FAO e DSSAT, nas localidades de Piracicaba (a), de Ribeirão Preto (b) e de Manduri (c), no Estado de São Paulo. 


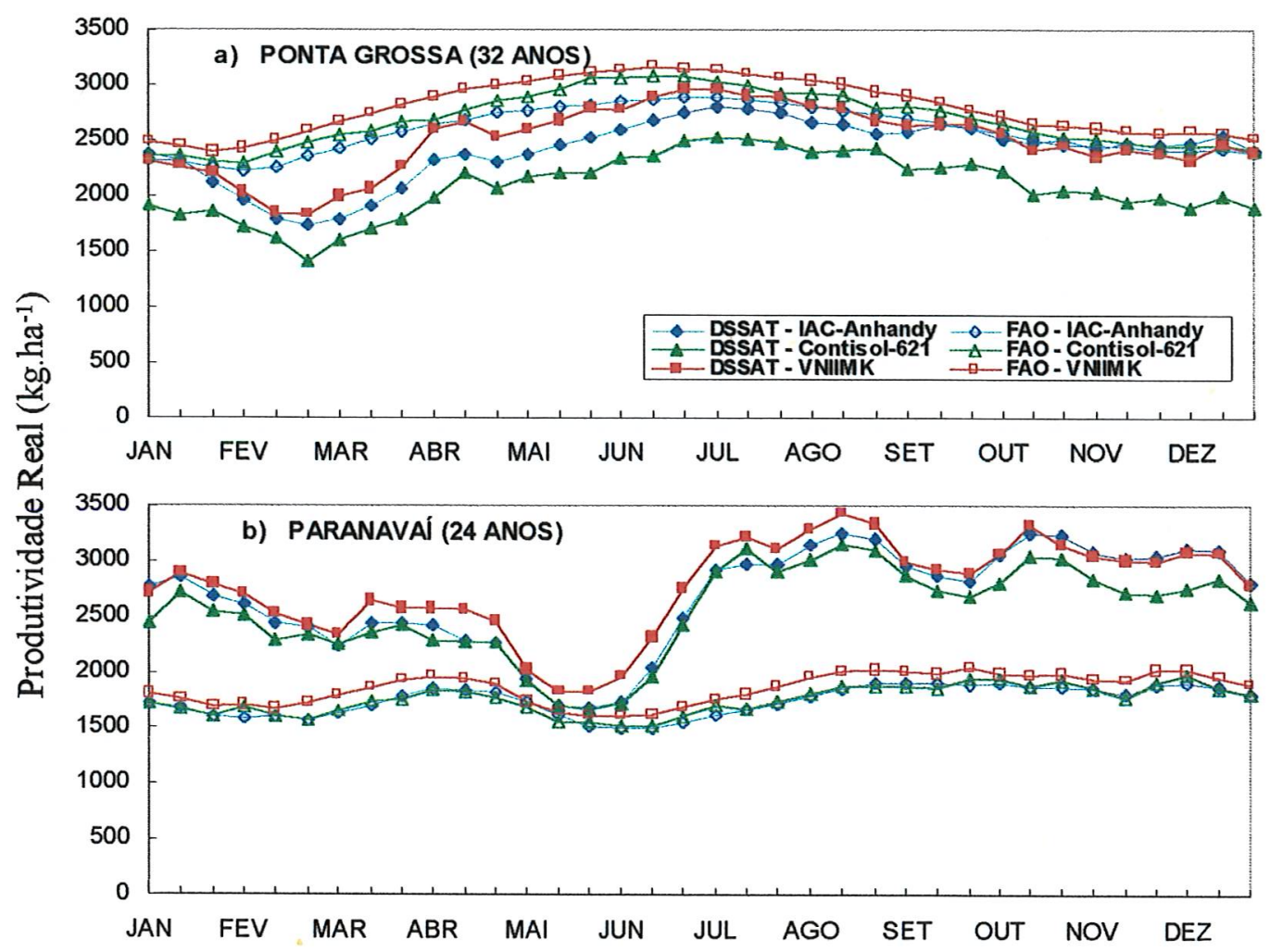

Data de semeadura

Figura 25 - Produtividade Real (PR) média nas diferentes datas de semeadura para os cultivares IAC-Anhandy, Contisol-621 e VNIIMK simuladas pelos modelos FAO e DSSAT, nas localidades de Ponta Grossa (a) e de Paranavaí (b), no Estado do Paraná.

O modelo DSSAT, normalmente, obteve maiores valores de PR em relação ao modelo FAO, excluindo-se a cidade de Ponta Grossa. Nesta cidade o modelo FAO simulou maiores valores de PR devido a um excedente hídrico que ocorreu em média durante o ano todo (Figura 26.d), ao alto valor de PP e por fim, devido ao aumento do ciclo da cultura decorrente da baixa temperatura (Figura 16.a).

Observou-se que, nas localidades paulistas as PR entre 20 de setembro e 20 de janeiro, simuladas pelo modelo DSSAT, estiveram entre $2500 \mathrm{~kg}^{-\mathrm{ha}^{-1}}$ e $3.500 \mathrm{~kg} \cdot \mathrm{ha}^{-1}$ enquanto que o modelo FAO, nas mesmas datas, obteve valores entre 1.500 e 2.500 $\mathrm{kg} \cdot \mathrm{ha}^{-1}$. Já nas datas de semeadura entre março e fim de agosto, os modelos DSSAT e FAO obtiveram conjuntamente PR aproximadamente entre $1.000 \mathrm{~kg}^{-\mathrm{ha}^{-1}} \mathrm{e} 2.000 \mathrm{~kg} \cdot \mathrm{ha}^{-1}$. 
Os resultados simulados pelos dois modelos foram próximos daqueles encontrados na literatura. Por exemplo, em relação ao cultivar IAC-Anhandy, EMBRAPA (1983) mostrou que semeaduras em 1 de fevereiro em Avaré, SP, resultaram, em média, $2.278 \mathrm{~kg} \cdot \mathrm{ha}^{-1}$, enquanto que na localidade mais próxima, Manduri, os modelos FAO e DSSAT indicaram1.900 e $2.400 \mathrm{~kg}^{-\mathrm{ha}^{-1}}$, respectivamente.

Em relação ao cultivar Contisol-621, em semeaduras em 1 de fevereiro na localidade de Manduri, os modelos FAO e DSSAT simularam PRs médias iguais a 1.900 e $2.250 \mathrm{~kg} \cdot \mathrm{ha}^{-1}$, respectivamente, enquanto que na localidade mais próxima Avaré, SP, EMBRAPA (1983) obteve PR igual a $2.603 \mathrm{~kg} \cdot \mathrm{ha}^{-1}$. O mesmo autor, com semeaduras em 20 de novembro em Campinas, obteve uma produtividade de $2.030 \mathrm{~kg}^{-\mathrm{ha}^{-1}}$. Nesta mesma época de semeadura, na cidade mais próxima, Piracicaba, os modelos FAO e DSSAT simularam PRs de 2.100 e $2.700 \mathrm{~kg} \cdot \mathrm{ha}^{-1}$. Os modelos, nesta situação, superestimaram a PR talvez por não levarem em consideração o efeito de ataque de doenças como a Mancha de Alternária, comum no mês de dezembro, por encontrar condições climáticas favoráveis como o alto número de dias com chuva (Sentelhas et. al. 1996).

Como pode ser observado na Figura 25, Paranavaí foi a localidade onde houve as maiores diferenças entre os modelos. Entretanto, experimentos realizados por Pelegrini (1985) demonstraram que o modelo FAO simulou bem os dados medidos. O autor obteve, em semeaduras em 30 de outubro, em Londrina, próximo a Paranavaí, uma PR igual a 1.902 e $2.083 \mathrm{~kg}^{-h^{-1}}$ para os cultivares IAC-Anhandy e Contisol, respectivamente, enquanto que os modelos FAO e DSSAT obtiveram PRs, por volta de 1.700 e $3.000 \mathrm{~kg} \cdot \mathrm{ha}^{-1}$, respectivamente, para os dois cultivares. 

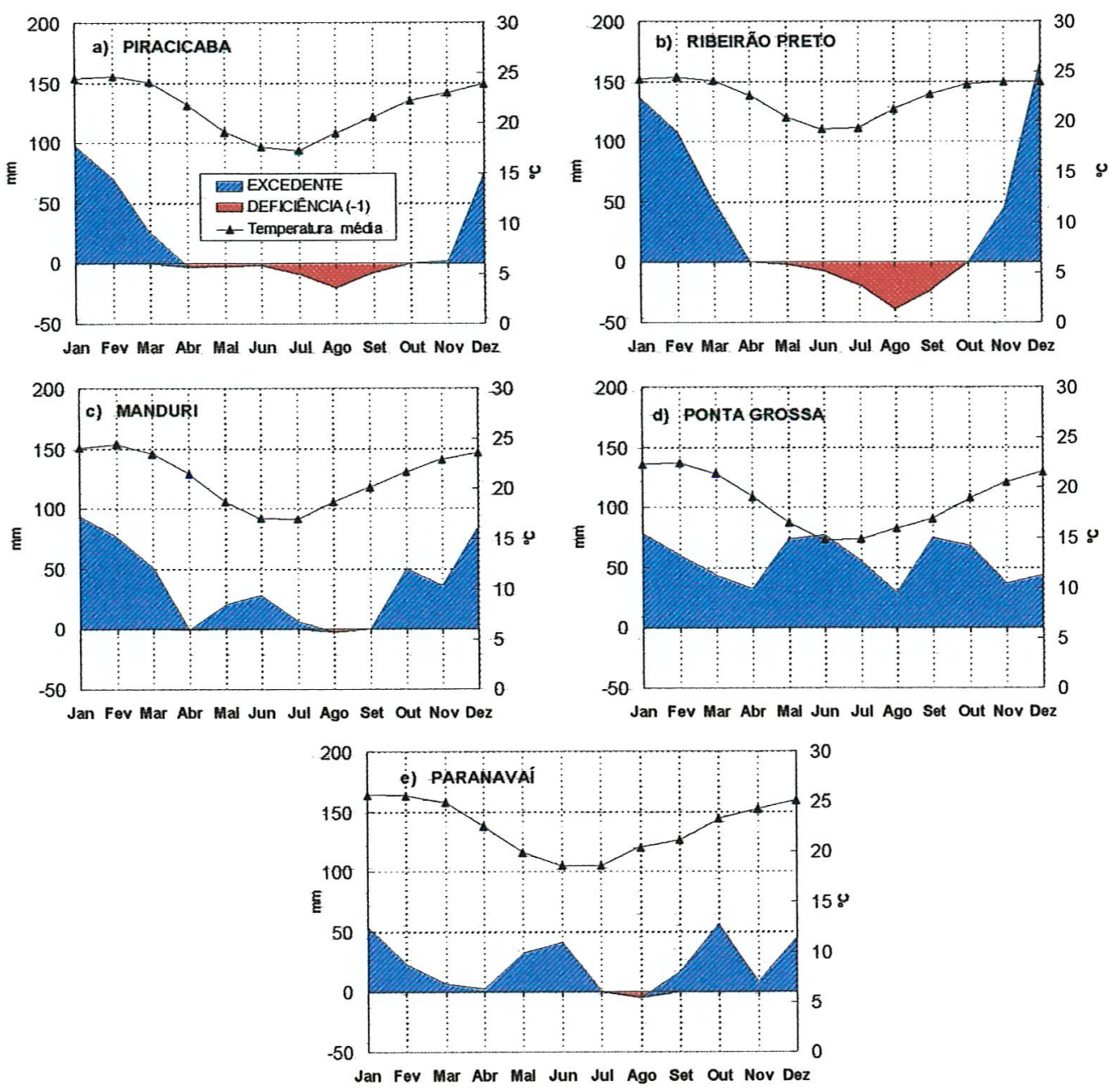

Figura 26 - Extratos dos balanços hídricos climatológicos normais mensais, segundo Thorthwaite \& Mather (1955), para CAD igual a $50 \mathrm{~mm}$, das localidades de Piracicaba (a), de Ribeirão Preto (b), e de Manduri (c), no Estado de São Paulo, e de Ponta Grossa (d) e de Paranavaí (e), no Estado do Paraná.

Os valores mais baixos de PRs, encontrados pelos dois modelos, ocorreram em semeaduras entre maio e junho (Figura 24 e 25), devido ao déficit hídrico no solo durante todo o ciclo da cultura, nas cidades de Piracicaba e Ribeirão Preto (Figura 26.a e 26.b). Nas cidades de Manduri e Paranavaí, as mais baixas PRs também ocorreram entre maio e junho, devido à baixa $\mathrm{PP}$ e ao défícit hídrico em agosto, que atingiu a fase de floração, com efeitos na redução da produtividade pela diminuição da formação de aquênios (Figura 26.c e 26.e). 
Em todas as localidades, as maiores PRs simuladas pelos modelos FAO e DSSAT ocorreram em datas de semeadura entre setembro e fim de janeiro pois, apesar do déficit hídrico no início da cultura, a fase de florescimento ocorre quando existe elevada disponibilidade hídrica no solo. A exceção foi Ponta Grossa, que obteve sua maior PR em semeaduras entre junho e agosto devido à maior produtividade potencial neste período (Figura 18.a) e ao elevado armazenamento de água no solo em todo o ciclo da cultura (Figura 26.e). No entanto, nessa localidade, o excesso hídrico durante praticamente o ano todo pode representar aspecto negativo especialmente com relação à ocorrência de doenças fúngicas como o mancha de alternária.

Mais detalhadamente, em relação ao modelo DSSAT, observa-se que, nas datas de semeadura entre 20 de fevereiro e fim de março, houve queda na PR, nas cidades de Manduri, Ponta Grossa e Paranavaí, (Figuras 24.c, 25) decorrente da menor produtividade potencial (Figuras 17.c, 18), pois não houve déficit hídrico durante o período da cultura (Figura 26.c, 26.d e 26.e).

Então, resumidamente, exceto para Ponta Grossa, semeaduras a partir de novembro até o fim de fevereiro, terão as maiores PRs. Estes resultados estão de acordo com os obtidos por Pelegrini (1985) que indicam que no Oeste do Paraná e em São Paulo, as semeaduras deverão ser feitas até o final de fevereiro no máximo, pois esta prática evita que as fases do florescimento e da maturação, mais sensíveis às baixas temperaturas, ocorram em épocas sujeitas a geadas. Entretanto, no Estado de São Paulo, semeaduras entre outubro a dezembro, são evitadas pela alta taxa de infecção de doenças como a Mancha de Alternária (Sentelhas et al. 1996), que não é levado em consideração pelos modelos. Por outro lado, semeaduras no fim de fevereiro também devem ser evitadas, pois já terão redução significativa de produtividade. Este fato foi confirmado por Ungaro (1986), que constatou que as semeaduras de fim de fevereiro tendem a produzir menos, pela diminuição na disponibilidade hídrica, geralmente entre abril e maio.

Pela análise da Figura 27 e 28 , onde são apresentadas as frequências de Produtividade Real (PR) de sementes de todos os dados simulados, observa-se que os valores simulados de maior frequência pelos dois modelos, ocorreram, de forma geral, 
entre 2000 a 3000 kg.ha ${ }^{-1}$ em Manduri. Em Ribeirão Preto, as frequências foram bem distribuídas, ocorrendo valores entre 500 a $3000 \mathrm{~kg} \cdot \mathrm{ha}^{-1}$, aproximadamente iguais para os dois modelos, apesar do modelo FAO simular maior frequência até $500 \mathrm{~kg} \cdot \mathrm{ha}^{-1}$ do que o DSSAT e este, por sua vez, apresentar mais datas de semeaduras com produtividades maiores que $3000 \mathrm{~kg} \cdot \mathrm{ha}^{-1}$. Nas outras localidades, observou-se diferenças em Ponta Grossa, onde o modelo FAO simulou as maiores frequências entre 2500 a $3500 \mathrm{~kg} \cdot \mathrm{ha}^{-1}$ e o modelo DSSAT entre 1500 a $3000 \mathrm{~kg} \cdot \mathrm{ha}^{-1}$, em Paranavaí onde as maiores frequências de PR pelo modelo FAO foram entre 1500 a $2500 \mathrm{~kg} \cdot \mathrm{ha}^{-1}$ e pelo DSSAT a partir de $2500 \mathrm{~kg} \cdot \mathrm{ha}^{-1}$, em Piracicaba, onde ocorreu uma maior diferença pois, o modelo DSSAT simulou produtividades reais com maior frequência entre 500 a 1000 $\mathrm{kg} \cdot \mathrm{ha}^{-1}$ e o modelo FAO entre 2000 a $3000 \mathrm{~kg} \cdot \mathrm{ha}^{-1}$. 

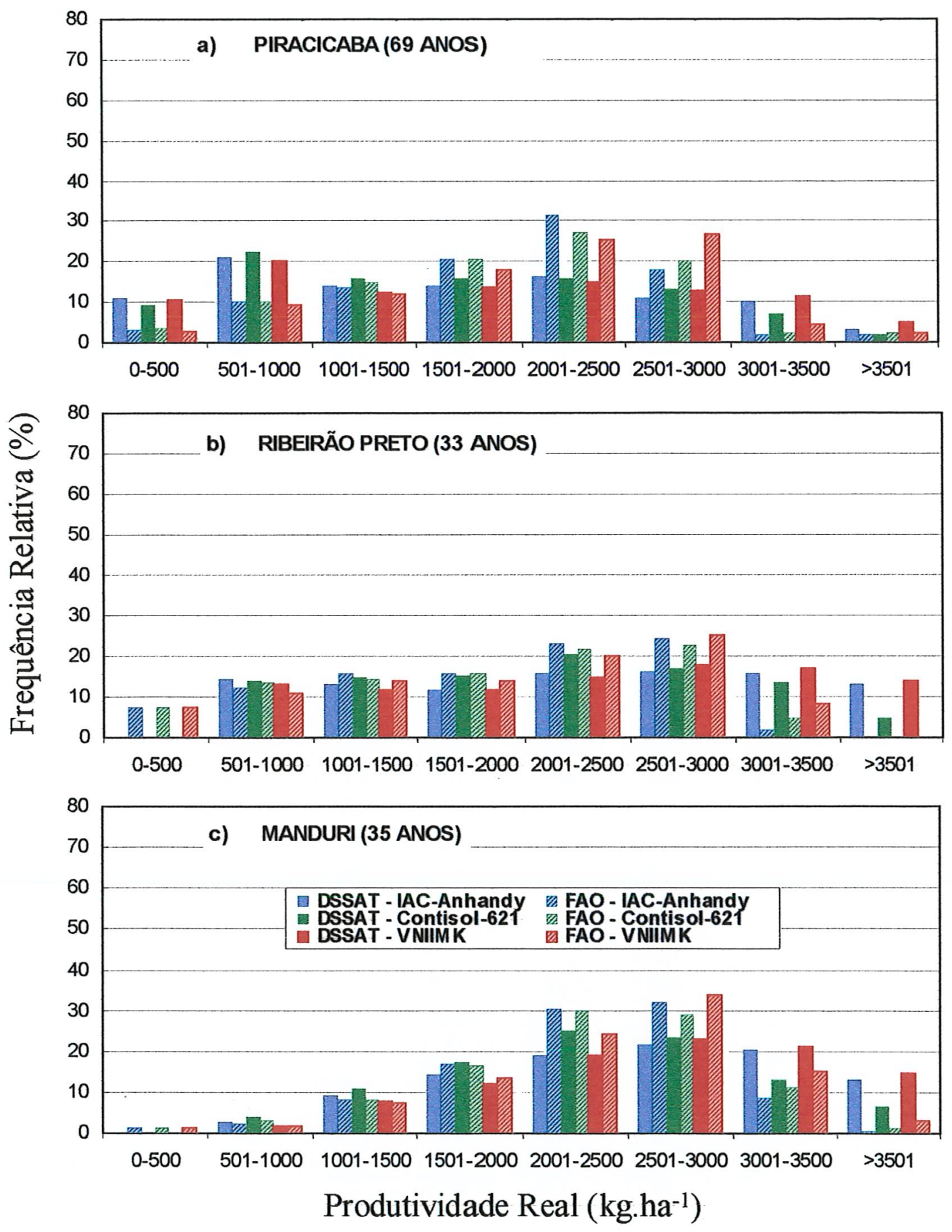

Figura 27 - Frequência Relativa das Produtividades Reais (PR) simuladas pelos modelos FAO e DSSAT para todas as datas de semeadura analisadas nas localidades de Piracicaba (a), de Ribeirão Preto (b) e de Manduri (c), no Estado de São Paulo. 


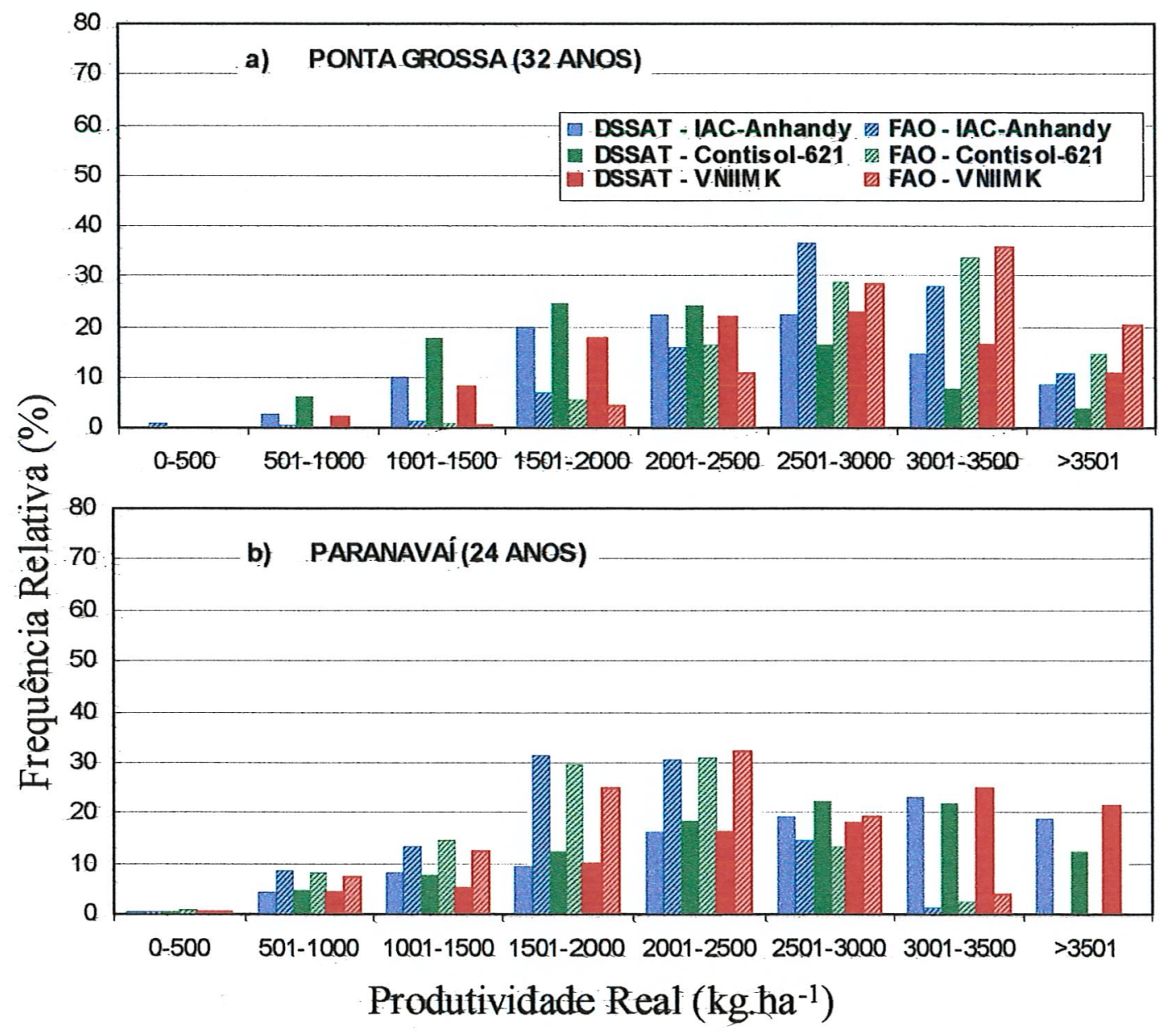

Figura 28 - Frequências Relativa das Produtividades Reais (PR) simuladas pelos modelos FAO e DSSAT para todas as datas de semeadura analisadas nas localidades de Ponta Grossa (a) e de Paranavaí (b), no Estado do Paraná.

De forma geral, pode-se dizer que os valores das PRs foram melhores distribuídos nas localidades onde a estação seca é bem definida durante o inverno, como nos casos de Piracicaba e Ribeirão Preto. Esta estação seca levou à diminuiçãa dos valores das PRs pelos dois modelos, fazendo com que as estimativas feitas pelo modelo FAO se aproximassem daquelas obtidas pelo modelo DSSAT. Por sua vez, quando houve boa distribuição das chuvas ao longo do ano, como nas cidades de Manduri, Ponta Grossa e Paranavaí, as frequências ficaram mais coneentradas entre 1500 a $3000 \mathrm{~kg} \cdot \mathrm{ha}^{-1}$, ocorrendo maiores diferenças nas estimativas entre os modelos. Essas diferenças, além 
dos motivos já citados, foram também devidas às variações nas estimativas da evapotranspiração potencial e real, pois os modelos FAO e DSSAT estimam a ETP por diferentes métodos. O DSSAT utiliza o método de Priestley \& Taylor (1972) e o modelo FAO, no presente trabalho, utiliza o método de Thornthwaite (1948). Apesar de Camargo \& Sentelhas (1997), nas condições do Estado de São Paulo, demonstrarem que os dois métodos foram muito semelhantes na escala mensal, esses métodos levam a diferentes estimativas de ETP na escala diária, principalmente nas cidades com baixas temperaturas onde existe a diminuição das estimativas feitas pelo modelo de Thornthwaite (1948).

Para uma melhor visualização das diferenças entre os valores de PR, simuladas pelos modelos FAO e DSSAT, foi realizado o cálculo da diferença média absoluta, máxima e mínima com os dados simulados de todos os anos em todas as localidades (Tabela 10).

Tabela 10 - Diferença média absoluta, máxima e mínima entre os valores de Produtividade Real simulados pelos modelos FAO e DSSAT para as localidades analisadas.

\begin{tabular}{|c|c|c|c|c|c|}
\hline LOCAL & Diferença & $\begin{array}{c}\text { TAC-Anhandy } \\
\text { P.R. } \\
\left(\mathrm{kg} \mathrm{ha}^{-1}\right)\end{array}$ & $\begin{array}{c}\text { Contisol-62 } \\
\text { P.R. } \\
\left(\mathrm{kg} \mathrm{ha}^{-1}\right)\end{array}$ & $\begin{array}{c}\text { VNIIMK } \\
\text { P.R. } \\
\left(\mathrm{kg} \mathrm{ha}^{-1}\right)\end{array}$ & $\begin{array}{c}\text { GERAL } \\
\text { P.R. } \\
\left(\mathrm{kg} \mathrm{ha}^{-1}\right)\end{array}$ \\
\hline \multirow[t]{3}{*}{ Pाracicaba } & Thedia Absoluta & 404 & 280 & 404 & 362 \\
\hline & Máxima & 665 & 542 & 665 & 665 \\
\hline & Minima & 21 & 8 & 21 & 8 \\
\hline Ribeirāo & Thedia Absoluta & 438 & 312 & 397 & 382 \\
\hline \multirow[t]{2}{*}{ Preto } & Máxima & 1119 & 953 & 1136 & 3208 \\
\hline & Minima & 5 & 2 & 8 & 2 \\
\hline \multirow[t]{3}{*}{ Manduri } & Media Absoluta & 734 & 198 & 270 & 407 \\
\hline & Máxima & 1458 & 457 & 566 & 1458 \\
\hline & Minima & 170 & 13 & 12 & 12 \\
\hline Ponta & Media Absoluta & 408 & 842 & 546 & 598 \\
\hline \multirow[t]{2}{*}{ Grossa } & Máxima & 857 & 1281 & 973 & 1281 \\
\hline & Minima & 91 & 608 & 328 & 91 \\
\hline \multirow[t]{3}{*}{ Paranavai } & Media Absoluta & 780 & 650 & 754 & 728 \\
\hline & Máxima & 1223 & 1297 & 1250 & 1297 \\
\hline & Minima & 36 & 21 & 50 & 21 \\
\hline \multirow[t]{3}{*}{ GERAL } & Media Absoluta & 553 & 456 & 474 & 494 \\
\hline & Máxima & 1458 & 1297 & 1250 & 3208 \\
\hline & Minima & 5 & 2 & 8 & 2 \\
\hline
\end{tabular}

As menores diferenças ocorreram em Piracicaba e Ribeirão Preto em decorrência da estação seca no meio do ano (Figura 26.a e 26.b), que levou à diminuição das 
estimativas de PR pelo modelo DSSAT, aproximando-o do FAO. Já nas localidades de Manduri e Ponta Grossa, onde a estação seca não é bem definida (Figuras 26.c, 26.d), as diferenças entre os modelos foram intermediárias devido ao distanciamento das estimativas entre julho e fim de janeiro em Manduri e entre fevereiro e fim de março em Ponta Grossa. Por fim, em Paranavaí, ocorreu a maior diferença entre os modelos, as altas temperaturas levaram à uma baixa variação da PR simulada pelo modelo FAO em comparação ao DSSAT.

Entretanto, apesar dessas diferenças, pode-se observar que existiu boa relação entre os modelos FAO e DSSAT na estimativa da PR (Figura 29 e 20).

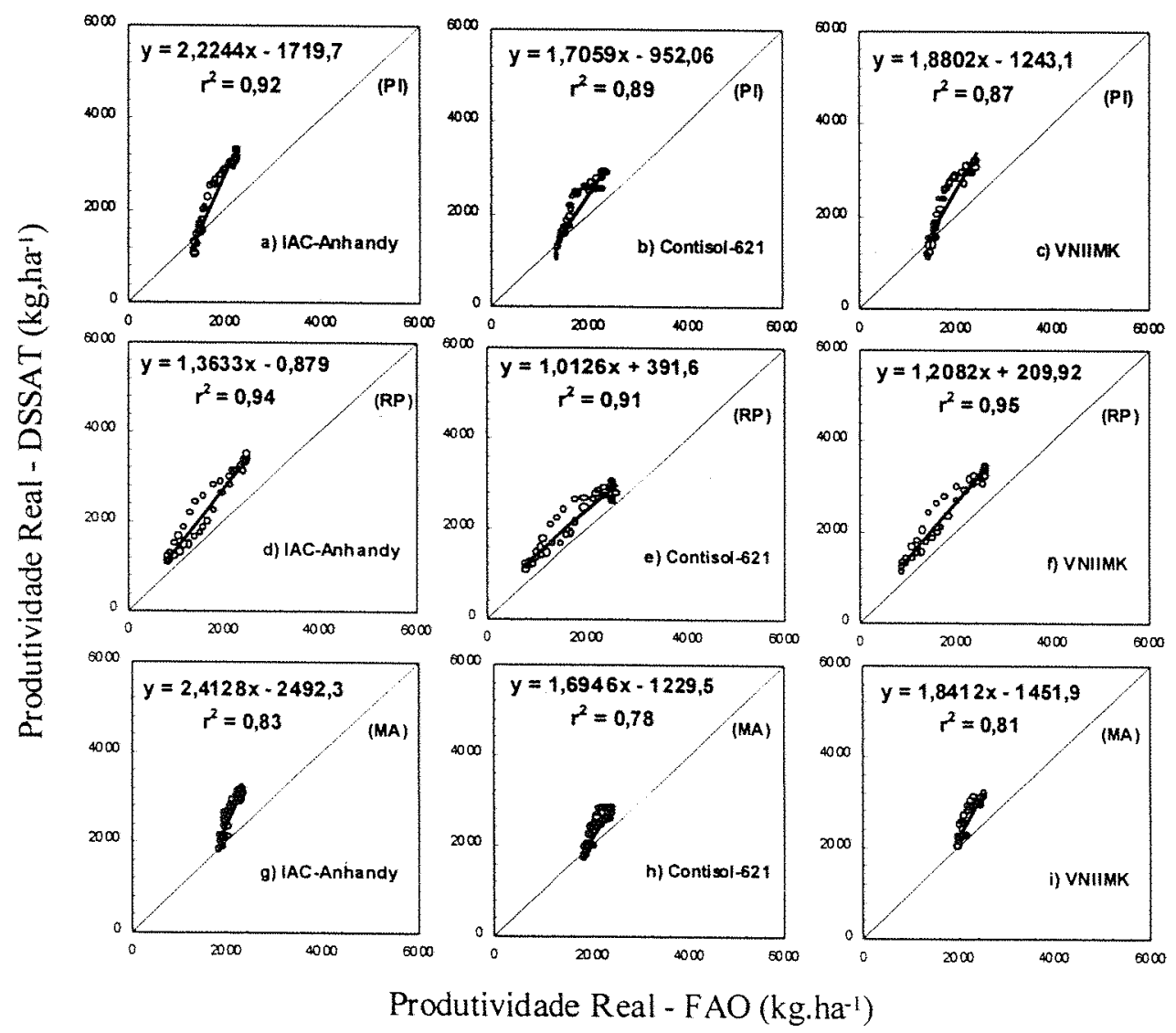

Figura 29 - Relação entre as Produtividades Reais (PR) médias simuladas pelo modelos FAO e DSSAT para os cultivares IAC-Anhandy, Contisol e VNIIMK para Piracicaba (PI), Ribeirão Preto (RB) e Manduri (MA), no Estado de São Paulo 

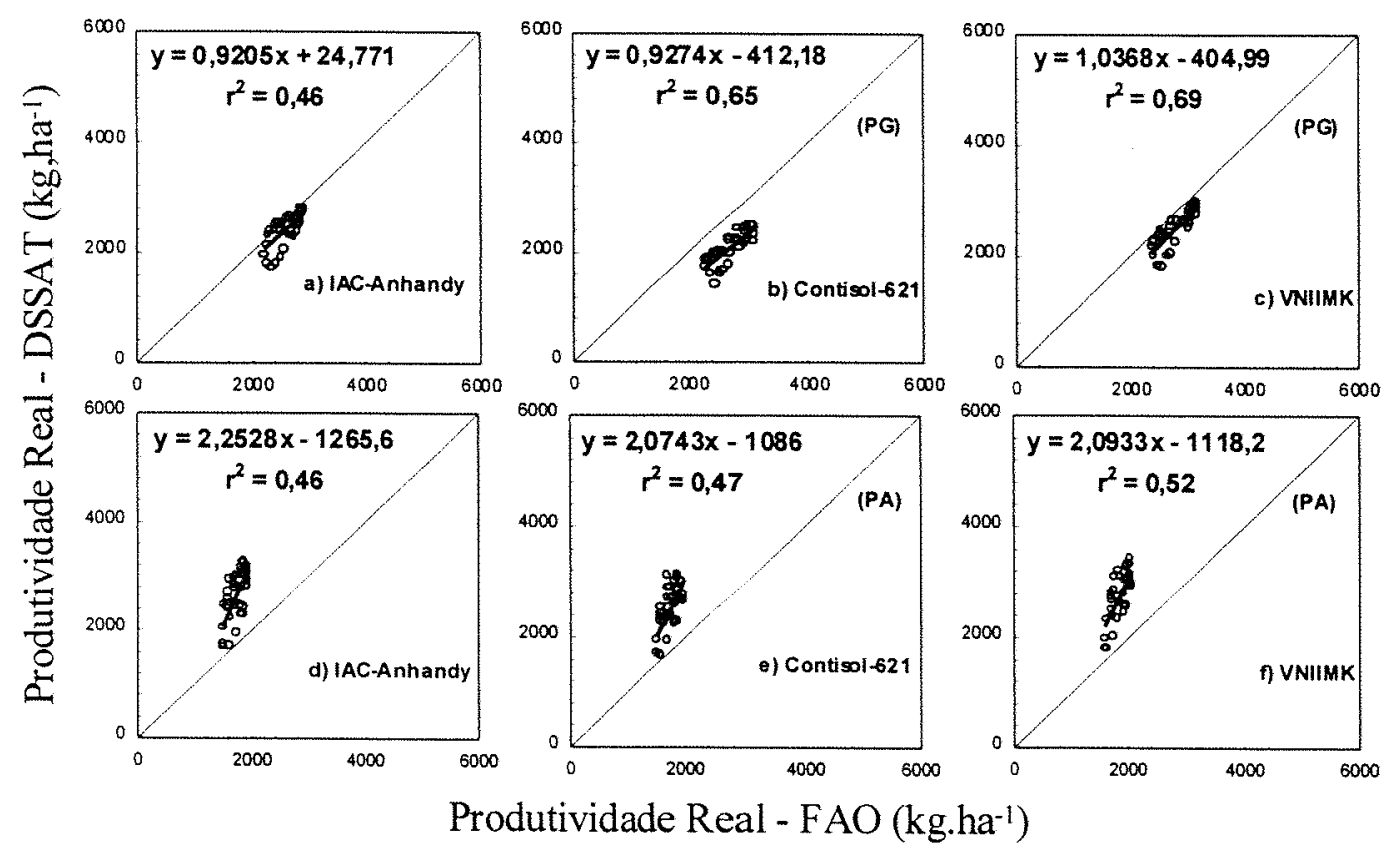

Figura 30 - Relação entre as Produtividades Reais (PR) médias simuladas pelos modelos FAO e DSSAT para os cultivares IAC-Anhandy, Contisol e VNIIMK para Ponta Grossa (PG) e Paranavaí (PA), no Estado do Paraná.

De forma geral, observa-se que o modelo DSSAT apresentou maior variação nas simulações de PR em relação ao modelo FAO e que nas cidades do Estado de São Paulo houve boa relação entre os dois modelos nas estimativas, com um $\mathrm{r}^{2}$ mínimo de 0,78 para o cultivar Contisol-621 em Manduri. Entretanto, para as cidades do Estado do Paraná, a relação entre os modelos diminuiu sendo que, o ${ }^{2}$ mínimo foi o de 0,46 para as duas cidades em relação ao cultivar IAC-Anhandy. 


\subsubsection{Quebra Relativa de Produtividade}

Como pode ser observado na Figura 31, as variações da Quebra Relativa de Produtividade $(\mathrm{Q})$ média simuladas nas diferentes datas de semeaduras pelos modelos FAO e DSSAT, foram semelhantes em todas as cidades do Estado de São Paulo, indicando que as melhores épocas de semeaduras ficam entre outubro e fim de janeiro, para todos os cultivares.

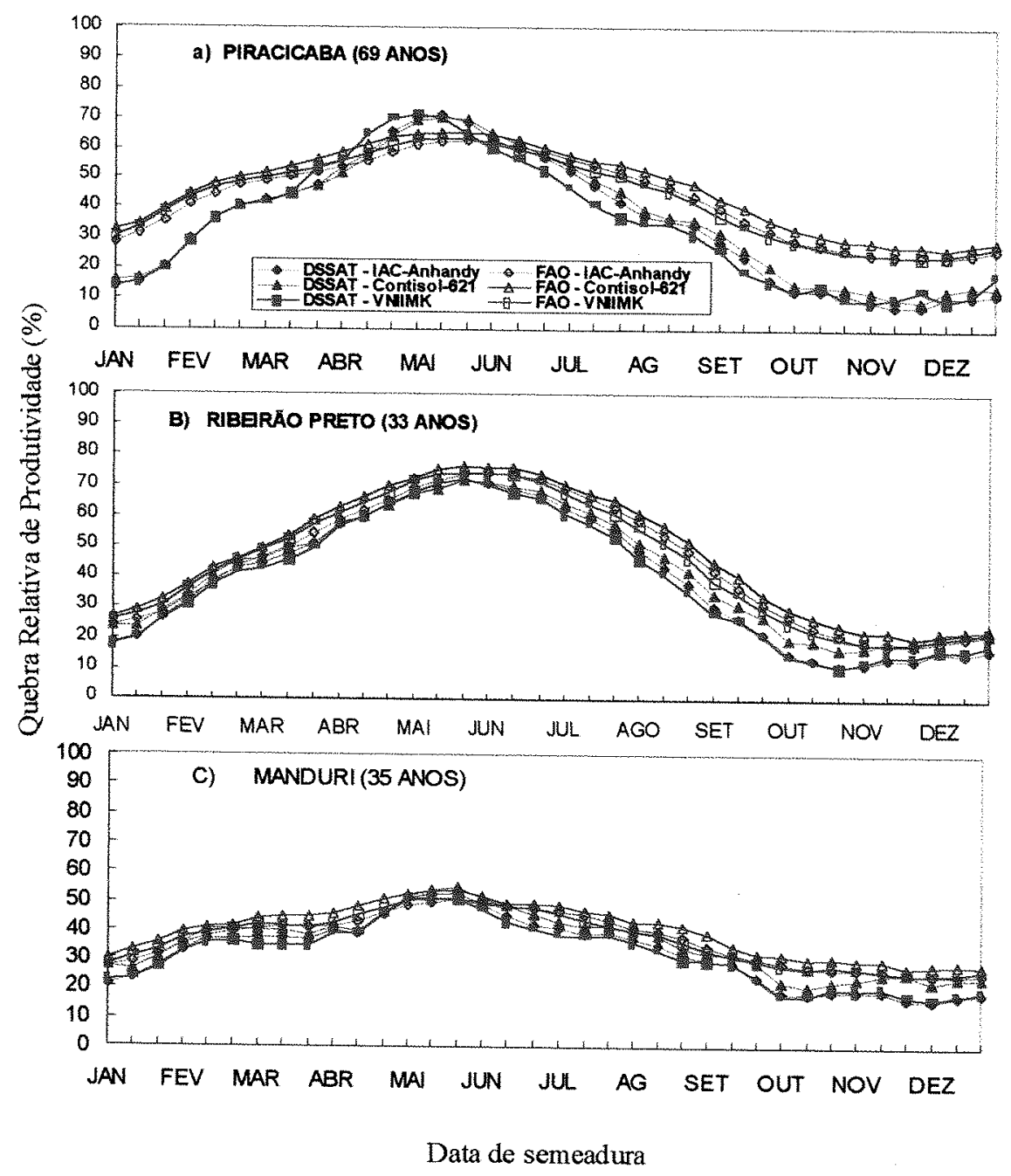

Figura 31 - Quebra Relativa de Produtividade média nas diferentes datas de semeadura, para os cultivares IAC- Anhandy, Contisol-621 e VNIIMK, simulada pelos modelos FAO e DSSAT, nas cidades de Piracicaba (a), Ribeirão Preto (b) e Manduri (c), no Estado de São Paulo 
Nessas datas de semeadura o modelo FAO obteve por volta de $25 \%$ de Q em todas as cidades, enquanto que o DSSAT apresentou entre 5 e $15 \%, 10$ e $20 \%$ e 15 e $25 \%$ para as cidades de Piracicaba, Ribeirão Preto e Manduri, respectivamente.

As épocas de maiores $Q$ foram entre maio e fim de junho, chegando a $60 \% \mathrm{em}$ Piracicaba, 50\% em Manduri e 75\% em Ribeirão Preto, simuladas pelos dois modelos. Entretanto, vale lembrar que Q maiores que 50\% preconizadas pelo modelo $\mathrm{FAO}$ não são exatas porque o fator de resposta da cultura à seca $(\mathrm{ky})$, perde sua precisão a partir de 50\%. Entretando, apesar desta limitação, o modelo obteve resultados muito semelhantes ao DSSAT, que não apresenta tal limitação.

Observa-se que na cidade de Ribeirão Preto a $\mathrm{Q}$ foi maior do que nas outras cidades porque já em 10 de março houve uma Q igual a $50 \%$, sendo maior que este valor até 01 de setembro. Estes resultados são decorrentes do período prolongado de estiagem desse local (Figura 26.b) que diminui a PR, e também à baixa PP em função das altas temperaturas.

Esses resultados estão de acordo com experimentos de campo realizados por EMBRAPA (1983), Campbell \& Athayde (1988) e Ungaro (1997) que mostram que semeaduras posteriores ao fim de fevereiro sofrem redução de produtividade devido ao déficit hídrico e também pela ocorrência de geadas no Estado de São Paulo que atingem a cultura nas fases do florescimento e frutificação.

Nas cidades do Estado do Paraná, observa-se pela Figura 32, que as variações de $Q$ foram semelhantes entre os modelos FAO e DSSAT nas diferentes datas de semeadura para todos os cultivares, apesar dos valores encontrados pelos modelos serem diferentes. 


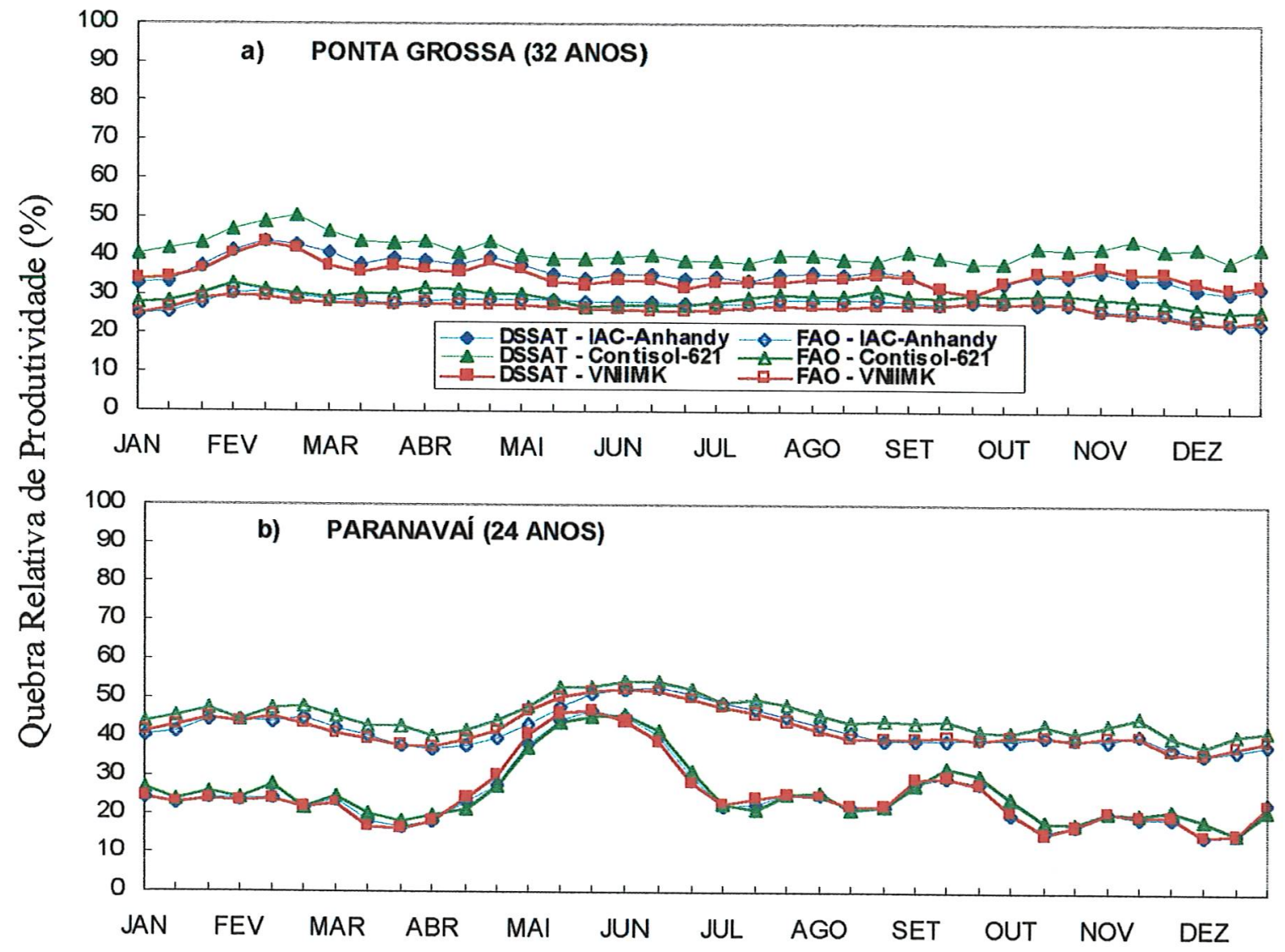

Data de semeadura

Figura 32 - Quebra Relativa de Produtividade média nas diferentes datas de semeadura para os cultivares IAC- Anhandy, Contisol-621 e VNIIMK simulada pelos modelos FAO e DSSAT, nas cidades de Ponta Grossa (a) e Paranavaí (b), no Estado do Paraná.

Em Ponta Grossa, devido à ocorrência de excedente hídrico durante praticamente todo o ano, as Q simuladas pelos modelos FAO e DSSAT foram relativamente constantes sendo em média igual a $30 \%$, para o primeiro modelo, e entre 30 e $40 \%$, para o segundo. Os valores das Q simuladas pelo modelo FAO foram maiores que os do DSSAT pelo fato do primeiro apresentar maiores valores de PP em função do aumento 
do ciclo da cultura e pelo modelo considerar que a temperatura nessa cidade ser mais próxima do ideal para a cultura.

Em Paranavaí, também devido ao excedente hídrico durante quase todas os meses do ano, não houve variação nos valores das $Q$, sendo que o modelo FAO apresentou em média Q igual a $45 \%$ e o modelo DSSAT por volta de 20 a $30 \%$. Como normalmente ocorre um pequeno déficit hídrico em agosto (Figura 26.e), há aumento da $Q$ nas semeaduras entre maio e metade de junho, chegando a valores entre 40 e $50 \%$ pelos dois modelos. Devido às altas temperaturas, o modelo FAO obteve menores PR, ocasionando um aumento das $\mathrm{Q}$ em relação ao DSSAT, como pode ser visualizado na Figura 25.b.

Pode-se observar mais detalhadamente pelas Figuras 33 e 34 em relação a todos os dados simulados e para os três cultivares, que o modelo DSSAT simulou mais $\mathrm{Q}$ até $10 \%$ que o modelo $\mathrm{FAO}$, indicando sua maior sensibilidade às pequenas mudanças no ambiente. Por outro lado, ocorreu muitas $\mathrm{Q}$ maiores que $51 \%$ simuladas pelo dois modelos, diretamente relacionadas a duração do período de estiagem em cada localidade.

Além disso, observa-se que no Estado de São Paulo os modelos FAO e DSSAT foram semelhantes por apresentarem relativamente as mesmas frequências de ocorrência de $Q$ entre 11 e $50 \%$.

Já no Estado do Paraná, essa aproximação não pode ser verificada pois em Ponta Grossa, devido às baixas temperaturas, o modelo FAO concentrou suas estimativas de $\mathrm{Q}$ entre 11 e $30 \%$, enquanto que, o DSSAT chegou a atingir valores superiores a $51 \%$. Na cidade de Paranavaí, o modelo FAO apresentou maiores frequências de $\mathrm{Q}$ em valores maiores que $51 \%$, enquanto que, o DSSAT resultou em valores até $10 \%$, para todos os cultivares. 

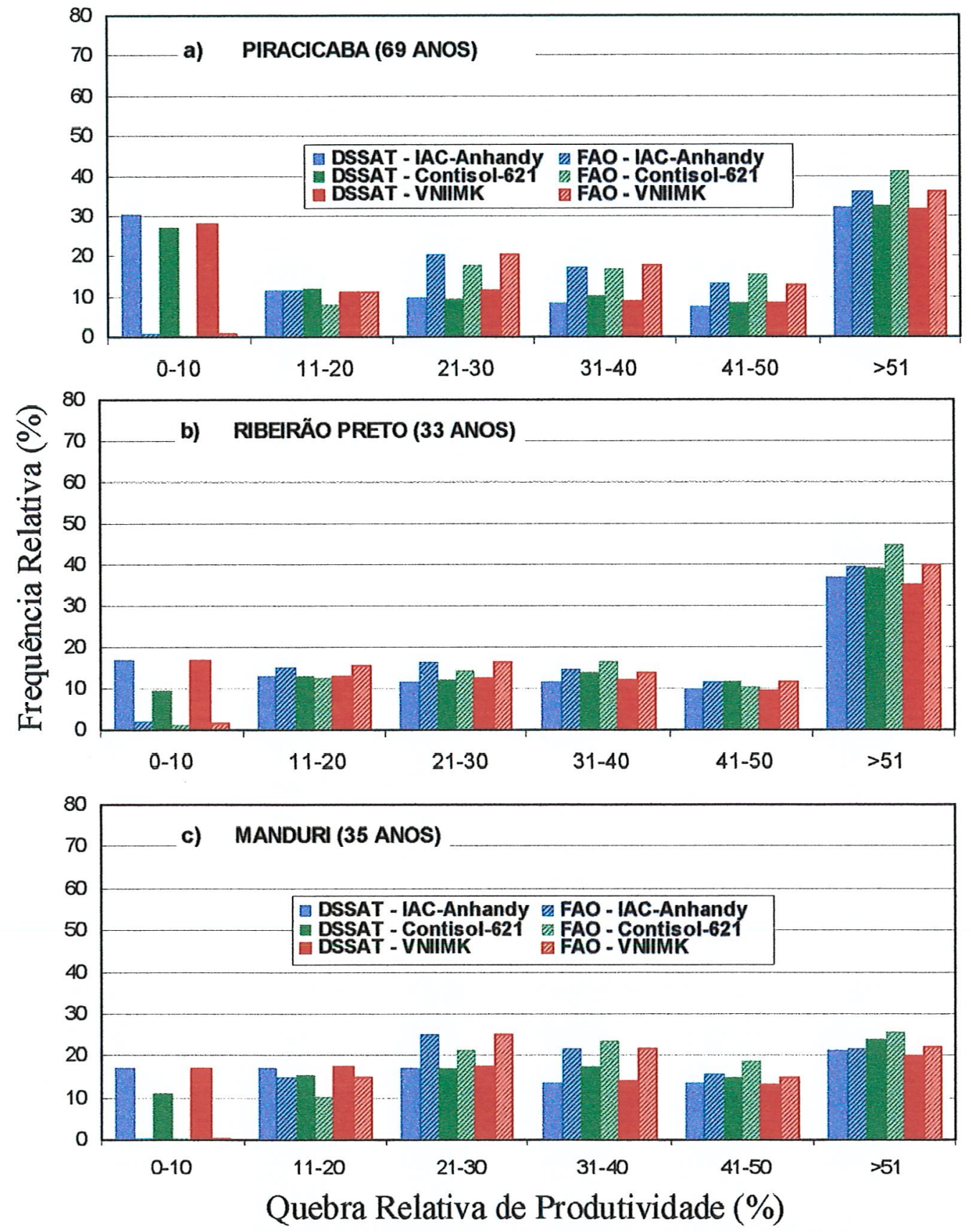

Figura 33 - Frequências Relativa da Quebra Relativa de Produtividade simulada pelo modelo FAO e DSSAT para todas as datas de semeadura analisadas, para os cultivares IAC-Anhandy, Contisol-621 e VNIIMK, nas cidades de Piracicaba (a), Ribeirão Preto (b) e Manduri (c), no Estado de São Paulo 


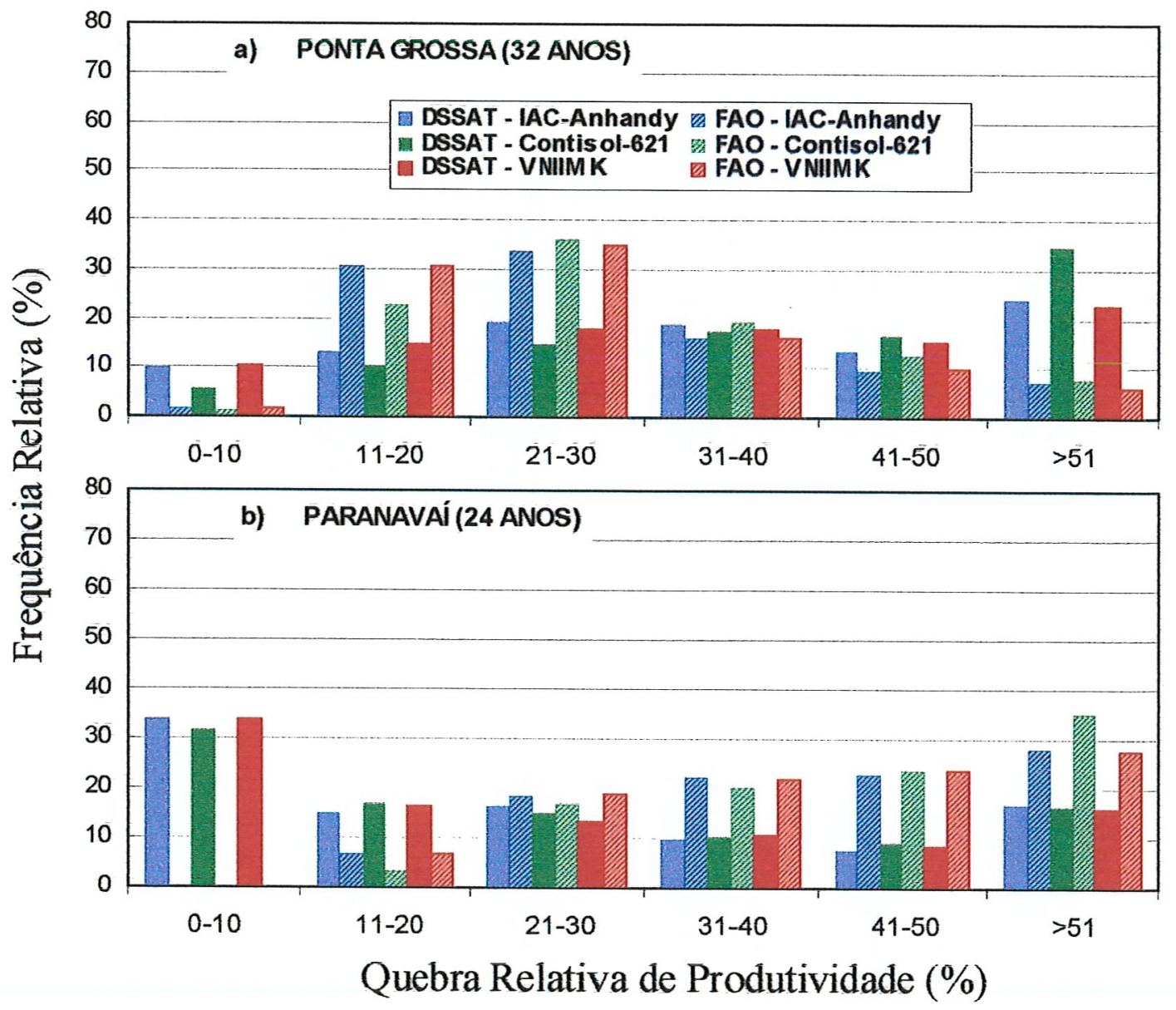

Figura 34 - Frequências Relativa de Quebra Relativa de Produtividade simulada pelo modelo FAO e DSSAT para todas as datas de semeadura analisadas, para os cultivares IAC-Anhandy, Contisol-621 e VNIIMK, nas cidades de Ponta Grossa (a) e Paranavaí (b), no Estado do Paraná.

Pode-se observạar nạ Tạbela 11 que as cidades de Ribeirão Preto e Manduri foram os locais onde ocorreram as menores diferenças médias entre os modelo FAO e DSSAT, da ordem de 5 a $6 \%$, seguida de Ponta Grossa, Piracicaba e Paranavaí onde as diferenças médias foram de $9,12,18 \%$, respectivamente. 
Tabela 11- Diferença média absoluta, máxima e mínima entre os valores de Quebra Relativa de Produtividade simuladas pelos modelo FAO e DSSAT para cada localidade.

\begin{tabular}{|c|c|c|c|c|c|}
\hline LOCAL & Diferença & $\begin{array}{c}\text { TAC-Anhandy } \\
\text { Q. } \\
(\%)\end{array}$ & $\begin{array}{c}\text { Contisol-621 } \\
\text { Q. } \\
(\%)\end{array}$ & $\begin{array}{c}\text { VNIIVK } \\
\text { Q. } \\
(\%)\end{array}$ & $\begin{array}{c}\text { GERAL } \\
\text { Q. } \\
(\%)\end{array}$ \\
\hline \multirow[t]{3}{*}{ Piracicaba } & Média Absoluta & 70 & 12 & 13 & 12 \\
\hline & Máxima & 18 & 20 & 41 & 41 \\
\hline & Minima & 1 & 1 & 0 & 0 \\
\hline Ribeirāo & Média Absoluta & 6 & 6 & 7 & 6 \\
\hline \multirow[t]{2}{*}{ Preto } & Máxima & 13 & 11 & 11 & 30 \\
\hline & Mínima & 0 & 0 & 3 & 0 \\
\hline \multirow[t]{3}{*}{ Manduri } & Média Absoluta & 5 & 2 & 6 & 5 \\
\hline & Máxima & 12 & 8 & 11 & 12 \\
\hline & Mínima & 1 & 0 & 0 & 0 \\
\hline Ponta & Média Absoluta & 7 & 12 & 8 & 9 \\
\hline \multirow[t]{2}{*}{ Grossa } & Máxima & 13 & 20 & 13 & 20 \\
\hline & Mínima & 2 & 7 & 1 & 1 \\
\hline \multirow[t]{3}{*}{ Paranavai } & Média Absoluta & 18 & 20 & 18 & 18 \\
\hline & Máxima & 26 & 29 & 26 & 29 \\
\hline & Minima & 4 & 8 & 5 & 4 \\
\hline \multirow[t]{3}{*}{ GERAL } & Média Absoluta & 9 & 70 & 10 & \\
\hline & Máxima & 26 & 29 & 41 & \\
\hline & Minima & 0 & 0 & 0 & \\
\hline
\end{tabular}

A maior diferença entre os modelos FAO e DSSAT ocorreu na cidade de Piracicaba com o cultivar VNIIMK apresentando uma diferença máxima de $41 \%$.

Em função do exposto e como pode ser visualizado na Figura 35, as cidades do Estado de São Paulo, apresentaram boa relação entre as Q simuladas pelos modelos FAO e DSSAT, resultando em um $\mathrm{r}^{2}$ mínimo de 0,94 em Manduri para o cultivar Contisol-621. Ainda na Figura 35, pode-se verificar que as Q simuladas pelo modelo FAO tenderam a ser maiores que as do modelo DSSAT, devido às variações da PP (Figura 17) e às constantes superestimativas de PR pelo modelo DSSAT (Figura 24). 

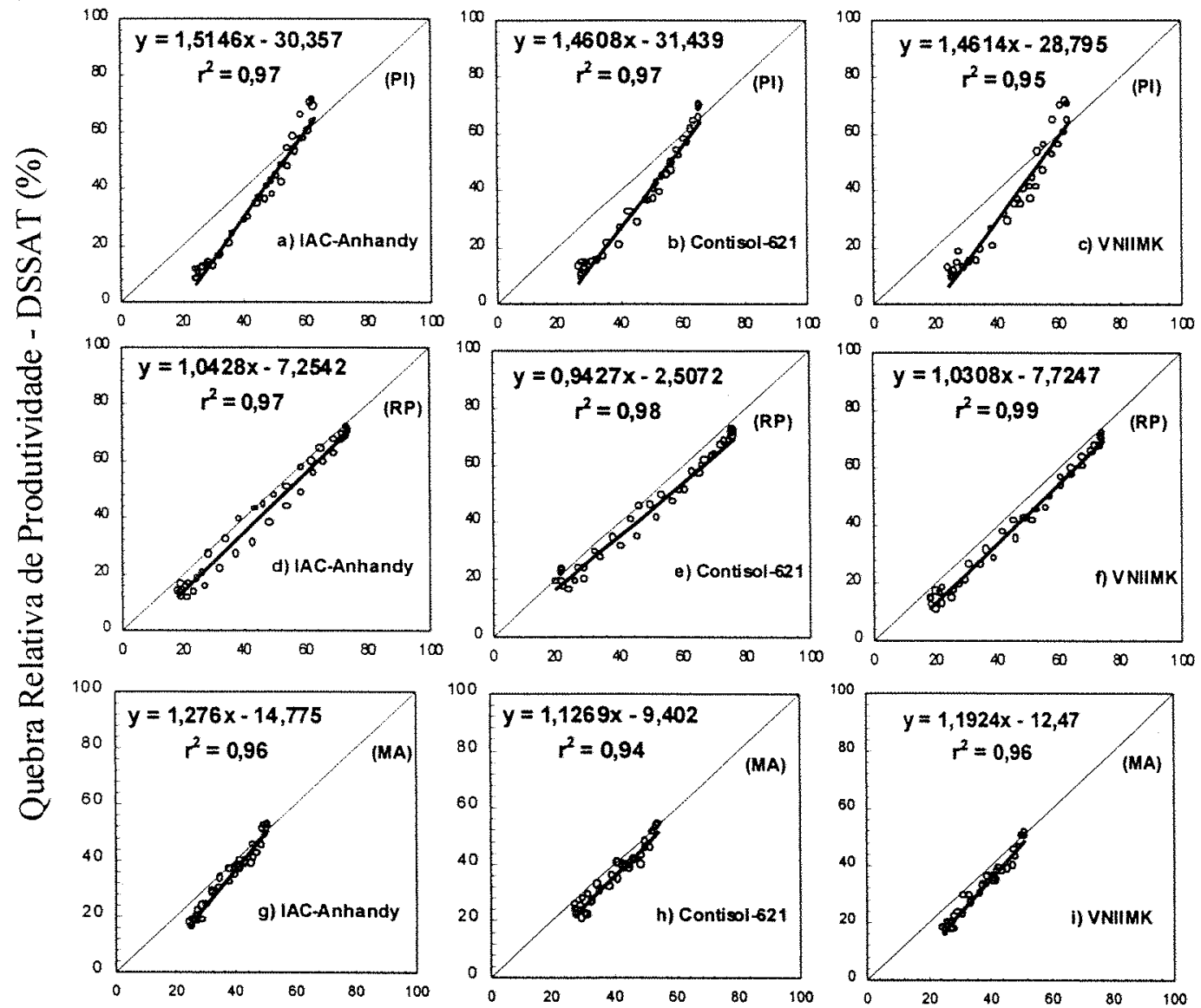

Quebra Relativa de Produtividade - FAO (\%)

Figura 35 - Relação entre as Quebras Relativas de Produtividade simuladas pelos modelos FAO e DSSAT para os cultivares IAC-Anhandy, Contisol-621 e VNIIMK para Piracicaba (PI), Ribeirão Preto (RP) e Manduri (MA), no Estado de São Paulo.

Na Figura 36 observa-se que na cidade de Ponta Grossa não houve boa relação entre os modelos FAO e DSSAT, pela baixa amplitude das Q simuladas pelos dois modelos, decorrente das variações da PP (Figura 18.a) e da baixa PR (Figura 25) simulada pelo modelo DSSAT. 

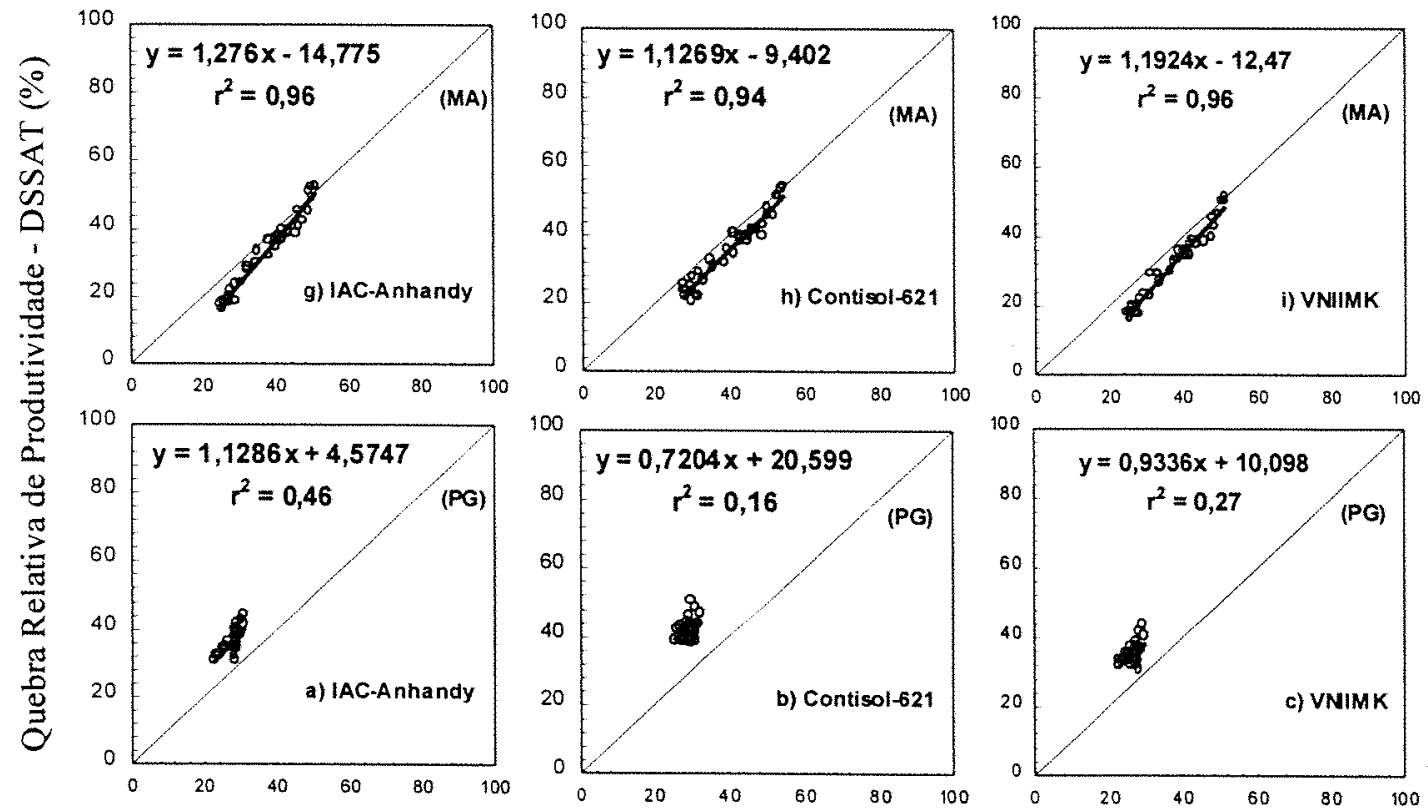

Quebra Relativa de Produtividade - FAO (\%)

Figura 36 - Relação entre as Quebras Relativas de Produtividade simuladas pelos modelos FAO e DSSAT para os cultivares IAC-Anhandy, Contisol-621 e VNIIMK para Ponta Grossa (PG), Paranavaí (PA), no Estado do Paraná.

Já em Paranavaí as relações melhoraram, em comparação à Ponta Grossa, mas devido à baixa variação da $\mathrm{Q}$ simulada pelo modelo FAO (Figura 36) os valores de $\mathrm{r}^{2}$ ficaram entre 0,52 e 0,63 . 


\section{CONCLUSÕES}

Devido ao exposto, pode-se concluir que:

1) Foi possível a calibração dos coeficientes genéticos, $\mathrm{P} 1, \mathrm{P} 2$ e $\mathrm{P} 5$, utilizados pelo modelo DSSAT com os dados simulados e observados na localidade de Monte Alegre do sul, SP.

2) Observou-se que as maiores diferenças, entre os modelos FAO e DSSAT/OILCROPSUN, ocorreram nas estimativas de Produtividade Potencial. Já a simulação de Produtividade Real foi semelhante entre os modelos, tanto para as localidades do Estado de São Paulo como para as do Paraná, com exceção de Paranavaí, onde houve a maior diferença. Por fim, a Quebra Relativa de Produtividade nas diferentes datas de semeadura foi também próxima entre os modelos, com exceção também de Paranavai. Apesar destas diferenças na cidade de Paranavaí, notou-se que ambos os modelos determinaram as mesmas épocas de semeadura para a obtenção das maiores produtividades, com ou sem irrigação, podendo ser utilizados para estudos agrometeorológicos.

3) As melhores épocas de semeadura para a produção em sequeiro determinado pelos dois modelos para os cultivares IAC-Anhandy, Contissol-621 e VNIIMK, são entre 01/10 e 20/01 nas cidades de Piracicaba, Ribeirão Preto e Manduri, no Estado de São Paulo. Nas cidades do Estado do Paraná, as melhores épocas de semeadura são entre 01/04 e 01/10 em Ponta Grossa e entre 01/07 e 20/11 em Paranavaí. Já as melhores épocas de semeadura em condições irrigadas são entre 01/04 e 01/09 nas localidades do Estado de São Paulo, entre 01/04 e 01/09 em Ponta Grossa e entre 10/07 e 01/02 em Paranavaí, no Estado do Paraná. 


\section{REFERÊNCIAS BIBLIOGRÁFICAS}

ADDISCOTT, T. M.; WAGENET, R. J. Concepts of solute leaching in soils: A review of modelling approaches, J. Soil Sci., v.36, p.411-424, 1985.

AGGARWAL, P. K.; PENNING DE VRIES, F. W. T. Potential and water limited wheat yield in ricebased cropping systems in southeast Asia. Agric. Syst., v.30, p. 49-69, 1989.

ALFONSI, R. R. Épocas de semeadura para a cultura do milho (Zea Mays. L.) baseadas na probabilidade do atendimento hídrico em fases fenológicas críticas para o Estado de São Paulo. Piracicaba, 1996. 137p. Tese Doutorado. Escola Superior de Agricultura "Luiz de Queiroz", Universidade de São Paulo.

ALLARD, H. A.; GARDNER, W. W. Further observations on the response of various species of plants to length of day. U. S. Dep. Agric. Tech. Bull. n 727, 35p., 1940.

ALMEIDA, A. P. O girassol e considerações sobre sua cultura em Angola. Gazeta Agrícola de Angola, Luanda, v.15, n.1, p. 38-52, 1970.

ALVAREZ DEL TORO, J. A. Respuesta del girasol (Helianthus annuus L.) a un suministro variable de agua de riego y de nitrogenio. Ph.D. diss. ETSIA, Univ. de Córdoba, Spain, 1987.

ANDERSON, W. K. Some factors influencing yield and adaptation in sunflower. Ph.D. Thesis, University of new England, Armidale, N.S.W., 36p., 1977.

ANDERSON, W. K.; SMITH R. C. G. McWILLIAM, J. R. A systems approach to the adaptation of sunflower to new environments. II. Effects of temperature and radiation on growth and yield. Field. Crops Res., v.1, p.153-163, 1978 b. 
ANDERSON, W. K.; SMITH, R. C. G.; McWILLIAM, J. R. A systems approach to the adaptation of sunflower to new environments. I. Phenology and development. Field Crops Res., v. 1, p. 142-52, 1978a.

ANGELOCCI, L. R.; VILLA NOVA, N. A. Temperatura do ar e do solo: aspectos físicos e agronômicos. In: ESALQ, Departamento de Física e Meteorologia. Agrometeorologia. Piracicaba, ESALQ, Departamento de Física e Meteorologia, p.1-27, 1985.

ÅNGSTRÖN, A.; Solar abd terrestrial radiation. Q. J. Meteor. Soc. London, v.50, p. 121-126, 1924.

ANGUS, J. F.; MONCUR, M.W. Models of growth and development of wheat in relation to plant nitrogen. Aust. J. Agric. Res., v.36, p. 537-544, 1985.

ANTUNES, P. M.; DOURADO NETO, D.; FANCELLI, A. L. Modelo Matemático para previsão do acúmulo de matéria seca das épocas de florescimento e do ponto de maturidade fisiológica na cultura de milho. In: Congresso Brasileiro de Agrometeorologia, 10, 1997, Piracicaba. Anais. Piracicaba: Sociedade Brasileira de Agrometeorologia, p.179-181,1997.

ARNOLD, C. Y. The determination and significance fo the base temperature in a linear leaf unit system. Proc. Am. Soc. Hortic. Sci., v.74, p.430-445, 1959.

ASARE, D. K.; SAMMIS, T. W.; ASSADIAN, H. FOWLER, J. F. Evaluating three cotton simulation models under different irrigation regimes. Agric. Water. Manage, v.22, p. 391-407, 1992.

ASSAD, E. D. Metodologias para o zoneamento de riscos climáticos no Brasil. In: CONGRESSO BRASILEIRO DE AGROMETEOROLOGIA, 11, Florianópolis, 1999. Anais. Florianópolis: Sociedade Brasileira de Agrometeorologia, 1999, p.79-85.

BARBIERI, V.; TERUEL, D. A.; SILVA, J. G. Balanço Hídrico de Thornthwaite \& Mather modificado para estimativa de deficiência nas culturas. In: CONGRESSO BRASILEIRO DE AGROMETEOROLOGIA, 10., Piracicaba, 1997. Anais. Piracicaba: Sociedade Brasileira de Agrometeorologia; ESALQ, 1997, p. 587-589.

BARBIERI, V.;TUON, R.L. Metodologia para estimativa da producao potencial de algumas culturas. ESALQ, Departamento de Fisica e Meteorologia, 1992.17 p. 
BARNI, N. A.; BERLATO, M. A.; BERGAMASCHI, H.; RIBOLDI, J. Rendimento máximo do girassol com base na radiação solar e temperatura: II produção de fitomassa e rendimento de grãos. Pesquisa Agropecuária Gaúcha, Porto Alegre, v. 1, n.2, p.201-216, 1995.

BARNI, N. A.; BERLATO, M. A; BERGAMASCHI, H.; RIBOLDI, J. Modelo agrometeorológico de predição do rendimento do girassol: I. Relação entre rendimento e indice hídrico. Pesquisa Agropecuária Gaúcha, Porto Alegre, v.2, n.1, 1996.

BARROS, A. H. C.; COSTA, L. C. Um modelo para a estimar a produtividade do milho (zea mays L.). In: CONGRESSO BRASILEIRO DE AGROMETEOROLOGIA, 11, Florianópolis, 1999. Anais. Florianópolis: Sociedade Brasileira de Agrometeorologia, 1999, p.334.

BELL, M. A.; FISCHER, R. A. Using yield prediction models to assess yield gains: A case study for wheat. Field Crop Res., v.36, p. 161-166, 1994.

BERNARDO, D. J.; WHITTLESEY, N. K.; SAXTON, K. E.; BASSETT, D. L. Irrigation optimization under limited water supply. TRANSATIONS of the ASAE, v.31, n.3, 712-719p., 1988.

BEVITÓRI, R.; BALLA, A. J. Estudo de época de semeadura e densidade de plantas de girassol no estado de Goiás. In: REUNIÃO NACIONAL DE PESQUISA DE GIRASSOL, 12, Campinas, 1997. Resumos. Campinas: Fundação Cargill, 1997. P57.

BIRCH, E. B. Guidelines for crop sunflower yields. In: FARMING in South Africa. Pretória: Department of Agriculture, p. 1-6, 1982

BOOTE, K, J.; JONES, J. W.; PICKERING, N. B. Potential uses and limitations of crop models. Agronomy Journal, v. 88, p.704-716, 1996.

BOOTE, K. J.; JONES, J. W.; HOOGENBOOM, G.; WILKERSON, G.G.; JAGTAP, S. S. PNUTGRO V1.02: Peanut Crop Growth Simulation Model, User's guide. Fla. Agric. Exp. Stn., Journal no. 8420. University of Florida, Gainesville, 1989.

BOOTE, K. J.; PICKERING, N. B. Modeling photosynthesis of row crop canopies. HortScience, v. 29, p. 1423-1434, 1994. 
BOWEN, H. D.; COLWICK, R. F.; BATCHELDER, D. G. Computer simulation of crop production: Potential and hazards. Agric. Eng., 54(10):42-45, 1973.

BRIGGS, L. J.; SHANTZ, H. L. The water requirement of plants. I. Investigations in the Great Plains in 1910 and 1911. Bull. ${ }^{\circ}$ 284. U.S. Bur. Plant Ind., Washington, D. C., 1913.

BROWN, D. M.; CHAPMAN, I. J. Soybean development units for zones and varieties in the great lakes region. Agron. J., v.53, p.306-308, 1961.

BROWN, J. F.; KAJORNCHAIYAKUL, P.; SIDDIQUI, M. Q; ALLEN, S. J. Effects of rust on growth and yield of sunflower in Australia. Proc. 6th Int. Conf., Bucarest, Romania, p. 639-646, 1974.

CÂMARA, G. M. S. Potencial da cultura do girassol para rotação com cana-de-açucar. In: Reunião Nacional de Pesquisa de Girassol, 7, 1997, Campinas. Resumos. Piracicaba, p. 1-4, 1997.

CÂMARA, G.M.S. Introdução à cultura do girassol. Apostila. Piracicaba, Departamento de Agricultura, ESALQ-USP. 1998. 10p.

CAMARGO, M. B. P.; BRUNINI, O.; MIRANDA, M. A. C. Modelo agrometeorológico para estimativa da produtividade para a cultura da soja no Estado de São Paulo. Bragantia, Campinas, v.45, n.2, p.279-292, 1986.

CAMARGO, M. B. P.; ORTOLANI, A. A.; PEDRO JÚNIOR, M. J.; ROSA, S. M. Teste de modelo agrometeorológico de estimativa de produtividade para laranja valência. In: CONGRESSO BRASILEIRO DE AGROMETEOROLOGIA, 11, Florianópolis, 1999. Anais. Florianópolis: Sociedade Brasileira de Agrometeorologia, 1999, p. 330.

CAMPBELL, A. T.; ATHAYDE, M. L. F. Efeito de datas de semeadura no comportamento de dois genótipos de girassol. I. Aspectos fenológicos e agronômicos. Pesquisa Agropecuária Brasileira, v. 23, n.4, p.371-378, 1988.

CARDOSO, C. O.; FARIA, R. T.; FOLEGATTI, M. V. Simulação do ciclo de cultivo e risco no estabelecimento da cultura de milho "safrinha"semeada em diferentes épocas, através do modelo CERES-maize. In: CONGRESSO BRASILEIRO DE AGROMETEOROLOGIA, 11, Florianópolis, 1999. Anais. Florianópolis: Sociedade Brasileira de Agrometeorologia, 1999, p.324. 
CHAPMAN, S. C.; HAMMER, G. L.; MEINKE, H. A sunflower simulation model: I. Model development. Agron. J., v. 85, p. 725-735, 1993.

CHARLES-EDWARDS, D. A.; DOLEY, D.;RIMMINGTON, G. M. Modellong plant growth and development. Academic Press, Sydney, 235p., 1986.

CHIMENTI, C. A.; HALL, A. J. Sensibilidad del número de rutos por capítulo de girasol (Helianthus annuus L.) a cambios en el nivel de radiación durante la ontogenia del cultivo. p. 27-28. In: Actas Reunión Argentina de Fisiologia Vegetal, 14a, Huerta Grande, Córdoba. Mar. 1992. Anais. Soc. Argentina de Fisiología Vegetal, Huerta Grande. 1992, p.300.

COBIA, D. W.; ZIMMER, D. E. Sunflower production and marketing. North Dakota University of Agriculture and Applied Science. Extension Bulletin 25, 73p, 1978.

COCK, J. H.; FRANKLIN, D.; SANDOVAL, G.; JURI, P. The ideal cassava plant for maximum yield. Crop. Sci., v. 19, p. 217-279, 1979.

COLSON, J.; WALLACH, D.; BOUNIOLS, A.; DENIS, J. B.; JONES, J. W. Mean squared error of yield prediction br SOYGRO. Agron. J., v. 87, p. 397-402, 1995.

CONNOR, D. J.; JONES, T.R. Response of sunflower to strategies of irrigation: II. Morphological and physiological responses to water stress. Field Crops Res., v. 12, p. 91-103, 1985.

COSTA, L. C. Modelagem e simulação em Agrometeorologia. Folheto apresentado durante o X Congresso Brasileiro de Agrometeorologia, Piracicaba, 6 p., 13 a 18 de julho de 1997.

CROSS, H. Z.; ZUBER, M. S. Prediction of flowering dates in maize based on different methods of estimating thermal units. Agron. J., v. 64, p.351-355, 1972.

De Wit, C. T. Photosynthesis of leaf canopies. Agric. Res. Rep., v. 663, p. 1-57, 1965.

De WIT, C. T.; GOUDRIAAN, J. Simulation of ecological processes. Centre for Agricultural Publishing and Documentation - PUDOC, Wageningen, The Netherlands, 159p., 1974.

De WIT, C. T.; GOUDRIAAN, J.; van LAAR, H.H;PENNING DE VRIES, F. W. T.; RABBINGE, R.; van KEULEN, H.; LOUWERSE, W.; SIBMA, L.; de JONGE, C. Simulation of assimilation, 
respiration, and transpiration of crops. Simulation Monographs. Wageningen, the Netherlands. Ed. Pudoc, 1978.

DOORENBOS, J.; KASSAM, A. H. Yield response to water. Roma: FAO. 193p. (FAO Irrigation and Drainnage Paper, 33), 1979.

DUCHON, C. E. Corn yield prediction using climatology. J. Climate Appl. Meteorol., v.25, p.581-590, 1986.

DUNCAN, W. G.; LOOMIS, R. S.; WILLIAMS, W. A..; HANAU, R. A model for simulating photosynthesis in plant communities. Hilgardia, v.38, p. 181-205, 1967.

DYER, H. J.; SKOK, J.; SCULLY, N. J. Photoperiodic behaviour of sunflower. Bot. Gaz., Chicago, v.121, p.50-55, 1959.

EGLI, D. B.; BRUENING, W. Planting date and soybean yield: Evaluation of environmental effects with a crop simulation model: SOYGRO. Agric. For. Meteorol., v.62, p.19-29, 1992.

EL-SHARKAWY, M. A.; HESKETH, J. D. Effects of temperature and water deficit on leaf photosynthetic rates of different species. Crop. Sci. Res. V4, p. 514-518, 1964.

EMPRESA BRASILEIRA DE PESQUISA AGROPECUÁRIA. Centro Nacional de Pesquisa de soja. Indicações técnicas para o cultivo do girassol. Londrina: EMBRAPA, CNPSo, 1983. (Documento, 3).

FANCELLI, A. L.; KAEHN, D.;SILVA, D. M. J. A. Tecnologia da produção de sementes de girassol. Piracicaba. Departamento de Agricultura ESALQ-USP. 1980.60 p.

FARIA, R. T. Utilização de modelos de simulação como ferramenta para zoneamento agrícola. In: CONGRESSO BRASILEIRO DE AGROMETEOROLOGIA, 11, Florianópolis, 1999. Anais. Florianópolis: Sociedade Brasileira de Agrometeorologia, 1999, p.32-37.

FERRAUDO, A. S.; ANDRÉ, R. G. B.; PINHO, S. Z. Modelo Agrometeorológico para estimar o rendimento de grãos de milho. Revista Brasileira de Agrometeorologia, Santa Maria, v.3, p.93-96, 1995. 
FICK, G.N.; ZIMMERMAN, D. C.; Variability in soil content among heads and seeds within heads of sunflowers (Helianthus annuus L.). J. Am. Oil. Chem. Soc., v. 50, p. 529-531, 1973

GALLAGHER, H. N.; BISCOE, P. V. Radiation absorption, growth and Yield of cereals. J. Agric. Sci., Cambridge, v.91, p. 47-60, 1978.

GILMORE, E.; ROGERS, J. S. Heat units as a method of measuring maturity in corn. Agronomy Journal, v.50, p. $611-615,1958$.

GIMÉNEZ, C. Resistencia la sequía de cultivares de girasol bajo condiciones de campo. Ph.D. diss. ETSIA, Univ. de Córdoba, Spain, 1985.

GIMENO, V.; FERNÁNDEZ, J. M.; FERERES, E. Winter plantings as a means of drought escape in sunflower. Field. Crop. Res., v.22, p. 307-316, 1989.

GLOVER, J.; McCULLOCH, J. S. G. The empirical relation between solar radiation and hours of sunshine. Quartely Journal of Royal Meteorology Soc., v. 84, p. 84, p. 172-175, 1958.

GODWIN, D. C.; JONES, C. A. Modeling nitrogen dynamics in soil-plant system. p. 287-320. In: J. Hanks and J. T. Ritchie (ed) Modeling plant and soil systems. Agron. Monogr. 31. ASA, CSSA, and SSSA, MADISON, W1, 1991.

GOODWIN, D.; RITCHIE, J.; SINGH, U.; HUNT, L. A. A user's guide to CERESwheat - V2.10, $2^{\text {nd }}$ ed. Int. Fertilizer Development, Ctr. Muscle Shols, AL, 1990.

GOYNE, P. J., SCHNEITER, A. A.; CLEARY, K. C.; CREELSMAN, R.; STEGMEIER, W.; WOODING, F. Sunflower genotypes response to photoperiod and temperature in field environments. Agron. J., v.81, p. 826-831, 1989.

GOYNE, P. J.; HAMMER, G. L. Phenology of sunflower cultivars. II. Controlled-environment studies of temperature and photoperiod effects. Australian Journal of Research, v. 33, p. 251-261, 1982.

GOYNE,P.J.; WOODRUFF, D. R.; CHURCHETT, J. D. Environmental causes of yield variationin raingrown sunflower in Central Queensland. Australian Journal of Experimental Agriculture and Animal Husbandry, Melbourne, v. 18, p. 129-134, 1978. 
GOYNE,P.J.; WOODRUFF, D. R.; CHURCHETT, J. D. Prediction of flowering sunflowers. Australian Journal of Experimental Agriculture and Husbandry., v.17, p. 475-481, 1977.

GRIMM, S. S.; JONES, J. W.; BOOTE, K. J.; HESKETH, J. D. Parameter Estimation for predictin flowering date of soybean cultivars. Crop. Sci., v.33, p. 137-144, 1993.

HABERMANN, H. H.; WALlACE, R. H. Prediction of flowering sunflowers genotypes. Am. J. Bot, v.45, p-479-82, 1958.

HALL, A. J.; CHIMENTI, C. A.; VILELA, F.; FREIER, G.Timing of water stress effects on yield components of sunflower, p. 131-136. In: Int. Sunflower Conf., 11th, Mar del Plate, Argentina. Mar. 1985. Int. Sunflower Assoc., Mar del Plata.

HALL, A. J.; CONNOR, D.J.; WHITFIELD, D.M. Root respiration during grain filling in sunflower. Plant Soil, v. 121, p. 57-66, 1990.

HAMMER, G. L.; GOYNE, P. J.; WOODDRUFF, D. R. Phenology of sunflower cultivars. III. Models for prediction in field environments. Aust. J. Agric. Res., v.33, p. 263-274, 1982.

HANKS, J.; RITCHIE, J. T. Modeling plant and soil systems. Agron. Monogr. 31, ASA, CSSA, and SSSA, Madison, WI, 1991.

HANKS, R. J.; RASMUSSEN, V. P. Predicting crop production as related to plant water stress. Advances in Agronomy, New York, v.45, p. 193-215, 1982.

HARRIS, H. C.; McWILlIAM, J. R.; MASON, W. K. Influence of Temperature on Oil Content and Composition of Sunflower Seed. Australian Journal of Agriculture Research, Armidale, 29, p. 1203-1212, 1978.

HEARN, A. B.; BROOK, K. D. A case study of the application of a knowledge-based system to cotton pest management: A tale of two technologies. Al Applic. Nat. Resour. Manage. v.3, p.60-64, 1989.

HOIRE, T. Simulation of sunflower growth. I. Formulation and parametrization of dry matter production, leaf photosynthesis, respiration and partitioning of photosynthates. Bull. Nat. Inst. Agric. Sci. (Japan) Ser. A, v.4,p. 45-70, 1977. 
HOOGENBOOM, G.; WHITE, J. W.; JONES, J. W.; BOOTE, K. J. BEANGRO V.1.01. Dry bean crop growth simulation model: User's guide. Florida Agric. Exp. Stn. Journal no. N-00379. Agric. Engineering Dep. and Agronomy Dep., Univ. of Florida, Gainesville, 1991.

INSTITUTO AGRONÔMICO DE CAMPINAS. Instruções agrícolas para as principais culturas econômicas: Boletim 200. Campinas. 396 p. 1998.

IBSNAT. Decision support system for agrotechnology transfer V2.1 (DSSAT V2.1). Dep. Agron. Soil Sci., Coll. Trop. Agric. Human Resources, Univ. of Hawaii, Honolulu, 1989.

IVES, P. M.; HEARN, A. B. The SIRATAC system for cotton pest management in Australia. p. 251-268. In: P.S. Teng (editor) Crop loss assessment and pest management. APS Press, St. Paul, MN, 1987.

JAME, Y. W.; CUTFORTH, W. Crop growth models for decision support systems. Can. J. Plant Sci, v.76, p. 9-19, 1996.

JENSEN, M. E. Water consumption br agricultural plants. In: KOZLOWSKI, T. T., (Ed.). Water deficits and plant growth. New York: Academic, 1968. V.2, p.48.

JONES, C. A.; KINIRY, J. R. CERES-Maize. A simulation model for maize growth and development. Texas A\&M University Press, College Station. 1986.

JONES, J. W.; BOOTE, K. J.; HOOGENBOOM, G.; JAGTAP, S. S.; WILKERSON, G. G. SOYGRO v5.42- soybean crop growth simulation model: User's guide. Fla. Agric. Exp. Stn. J. no. 8304 Univ. of Florida Gainesville, 1989.

JONES, J. W.; BOOTE, K. J.; JAGTAP, S. S.; WILKERSON, G. G.; HOOGENBOOM, G.; MISHOE, J. W. SOYGRO V5.4-Technical documentation. Agric. Eng. Dep. Res. Rep., University of Florida, Gainesville, 1987.

KEATING, B. A.; McCOWN, R. L.; WAFULA, B. M. Adjustment of nitrogen inputs in response to seasonal forecast in a region with high climatic risk. p. 233-252. In F. Penning de Vries et al. (editor) Systems approaches for agricultural development, v.2. Proc. Int. Symp., Bankok, Thailand, 2-6 Dec. 1991. Kluwer Acad. Publ., Dordrecht, Netherland, 1993. 
KEEFER, G. D.; McAlliSTER, J. E.; URIDGE, E. S.; SIMPSON, B. W. Time of planting effects on development, yield and oil quality of irrigated sunflower. Aust. J. Exp. Agric. Anim. Husb., v.16, p. $417-422,1976$.

LANGRIDGE, D. F.; GOODMAN, R. D. Astudy on pollination of sunflower (Helianthus annuus L. ) Australian Journal of Experimental Agriculture and Animal Husbandry, Melbourne, v. 14, p. 201-204, 1974.

LOOMIS, R. S.; WILLIAMS, W. B. Maximum crop productivity: na estimate. Crop Science, Madison, v. 3, p. 67-72, 1963.

MARC, J.; PALMER, J. H. Photoperiod sensitivity of inflorescence initiation and development in sunflower. Field Crops. Res., v.4, p. 155-164, 1981.

MARC, J.; PALMER, J. H.; Determination of the lengh of the vegetative and pre-floral stages in the dayneutral plant Helianthus annuus by chilling pulses. J. Exp. Bot., v.29, p. 367-373, 1978.

MARC, J; PALMER, J. H. Relationship between water potentical and leaf and inflorescence initiation in Helianthus annuus. Physiol. Plant., v.36, p.101-104, 1976.

MARIN, F. R.; SENTELHAS, P. C.; UNGARO, M. R. G. Risco climático para épocas de semeadura da cultura do girassol no Estado de São Paulo. In: Congresso Brasileiro de Agrometeorologia, 11/Reunião Latino-Americana de Agrometeorologia, 2. Resumos. Florianópolis 1999 (CDROM).

MASSIGNAM, A. M.; ANGELOCCI, L. R. Determinação da temperatura-base e de graus-dia na estimativa da duração dos subperiodos de desenvolvimento de três cultivares de girassol. Revista Brasileira de Agrometeorologia, Santa Maria, v.1, n.1,p.71-79, 1993a.

MASSIGNAM, A. M.; ANGELOCCI, L. R. Relações entre temperatura do ar, disponibilidade hídrica no solo, fotoperíodo e duração de sub-períodos fenológicos do girassol. Revista Brasileira de Agrometeorologia, v.1; p.63-69, 1993b.

MATZENAUER, R.; BERGAMASCHI, H.; BERLATO, M. A.; RIBOLDI, J. Relações entre rendimento de milho e variáveis hídricas (1). Revista Brasileira de Agrometeorologia, Santa Maria, v. 3, p. 85$92,1995$. 
MILLER, J. F.; ROATH, W. W. Compensatory response of sunflower to stand reduction applied at different plant growth stages. Agron. J., v.74, p. 119-121, 1982.

MONSI, M.; SAEKI, T. Uben den lichtfaktor in den pflanzengeseilschaften un seine bedeutung fur die stoff produktion. Japan Journal of Botany, Tokio, v. 14, p.22-52, 1953.

MONTEITH, J. L. The quest for balance in crop modeling. Agronomy Journal, v. 88, p. 695-697, 1996.

MONTEITH, J. L. Consevative behaviour in the response of crops to waterand light. p. 3-16. IN: R. Rabbinge et al. (editor) Theoretical production ecology: Reflections and prospects. Pudoc, Wageningen, 1990.

MONTEITH, J. L. Does light limit crop production? In: C. B. Johnson (Editor), Physiological Processes Limiting Plant Productivity. Butterworths, London, p. 23-28, 1981.

MONTEITH, J. L. Light distribution and photosynthesis in field crops. Annals fo Botany, Oxford, v. 29, p.17-37, 1965.

MORAES, S. A.; UNGARO, M. R. G.; MENDES, B. M. J. "Alternaria helianthi” Agente causal de doença em girassol. Campinas, Fundação Cargill, 20p., 1983.

MUCHOW, R. C.; HAMMER, G. L.; CARBERRY, P. S. Optimising crop and cultivar selection in response to climatic risk. p. 235-262. In: R. C. Muchow and J. A. Bellamy (ed) Climatic risk in crop production: models and management for the semiarid tropics and subtropics. C. A. B. International, Wallingford, UK, 1991.

ONISHCHENKO, M. A. Effects of mineral fertilizers on seed yield and quality of sunflower. In: Research Work on Oil Crops, Maikop, p. 47-51 (Abstracted in Field Crop Abstr, v. 24, p.25-31), 1968.

ORESKES, N.; SHRADER-FRECHETTE, K.; BELITZ, K. Verification, validation, and confirmation of numerical models in the earth sciences. Science (Washington, DC), v. 263, p. 641-646, 1994.

ORTOLANI, A. A.; SENTElHAS, P. C.; CAMARGO, M. B. P.; PEZZOPANE, J. E. M.; GONÇALVES, P. S. Modelos agrometeorológico para estimativa da produção anual e sazonal de látex em seringueira. evista Brasileira de Agrometeorologia, Santa Maria, v. 4, n.1, p. 147-150, 1996. 
PASSIOURA, J. B. Sense and nonsense in crop simulation. J. Aust. Inst. Agric. Sci., v.39,p. 181-183, 1973.

PASSIOURA, J. B. Simulation Models: Science, Snake Oil, Education, or Engineering? Agron. Journal, v.88,p. $690-694,1996$.

PASSIOURA, J. B., Roots and drought resistance. Agric. Water Manage. v.7, p. 265-280. 1983.

PAUL, M. J.; LAWLOR, D. W.; DRISCOLL, S. P. The effect of temperature on photosynthesis and carbon fluxes in sunflower and rape. J. Exp. Bot. v. 41, p. 547- 555, 1990.

PEART, R. M.; CURRY, R. B. Agricultural Systems Modeling and Simulation.Ed. Marcel Dekker, Inc. University of Florida, Gainsville, Florida, 696p., 1998.

PEDRO JÚNIOR, M. J.; MASCARENHAS, H. A. A.; TISSELFI FILHO, O.; ANGELOCCI, L R. Análise de crescimento em soja. Turrialba, San Jose, v.35, n.4, p.323-7, out./dez. 1985.

PEDRO JÚNIOR, M.J.; CAMARGO, M. B. P; BRUNINI, O.; ALFONSI, R. R.; ORTOLANI, A. A.; MIRANDA, M. A. C. Teste de um modelo para estimativa de profundidade da soja. In: Congresso Brasileiro de Agrometeorologia, 3, Campinas, 1983. Resumos. Campinas. Sociedade Brasileira de Agrometeorologia. 1984. P. 138-139.

PELEGRINI, B. Girassol uma planta solar que das américas conquistou o mundo. Icone Editora. $117 \mathrm{p}, 1985$

PENNING DE VRIES, F.W.T. Crop production in relation to availability of nitrogen. p. 213-247. In: F.W.T. Pening de Vries and H. H. van Laar (ed) Simulation of plant growth and crop production. PUDOC, Wageningen, Netherlands, 1982.

PENNING DE VRIES, P. K. T.; KROPFF, M. J.; TENG, P. S. KIRK, G. J. D. Systems simulation at IRRI. IRRI Res. Pap. Ser. 151, IRRI, Manila, Philippines, 1991.

PEZZOPANE, J. E. M.; LIMA, P. C. S.; CUNHA, G. M.; ESPOSTI, M. D. D.; SANTOS, A. R. Zoneamento climático de perda da produtividade potencial do feijoeiro, em função de déficit hidrico, na Região Sul do Espírito Santo. In: Congresso Brasileiro de Agrometeorologia, 10, Piracicaba, 1997. Resumos. Piracicaba. Sociedade Brasileira de Agrometeorologia. 1997. P. 342-343. 
PHILIP, J. R. Soils, natural science and models. Soil Sci., v. 151, p.91-98, 1991.

PRÈSCOTT, J., A.; Evaporation from a water surface in relation to solar radiation. Trans. R. Soc. Aust. v. 64, p. $114-118,1940$.

PRIESTLEY, C. H. B.; TAYLOR, R. J. On the assessment of surface heat flux and evaporation using large-scale parameter. Monthly Weather Res., v. 100, p. 81-92, 1972.

RABBINGE, R; RIJSDIJK, F. H. EPIRE: A disease and pest management system for winter wheat, taking acount of micrometeorological factors. EPPO Bull., v. 13, p. 297-305, 1983.

RADFORD, B. J. Influence of size of achenes sown and depth of sowing on growth and yield of dryland oilseed sunflowers (Helianthus anuus) on the Darling Downs. Aust. J. Exp. Agric. Anim. Husb., v.17, p. 489-494, 1977.

RAWSON, H. M.; DUNSTONE, R. L. Simple relationships describing the responses of leaf growth to temperature and radiation in sunflower. Aust. J. Plant Physiol., v. 13, p. 321-327, 1986.

RAWSON, H. M.; DUNSTONE, R. L.; LONG, M. J.; BEGG, J. E. Canopy development, light interception and seed production in sunflower as influenced by temperature and radiation. Aust. $\mathbf{J}$. Plant Physiol. v.11, p. 255-265, 1984.

RAWSON, H. M.; HINDMARSH, J. H. Effects of temperature on leaf expansion in sunflower. Aust. J. Plant Physiol., v.9, p. 209-219, 1982.

RAWSON, H. M.; HINDMARSH, J. H. Light, leaf expansion and seed yield in sunflower. Aust. J. Plant Physiol., v. 10, p. 25-30, 1983.

RAWSON, H. M.; TURNER, N. C. Recovery from water stress in five sunflower (Helianthus annuus L.) cultivars II. The development of leaf area. Aust. J. Plant. Physiol., v.9, p. 449- 460, 1982.

REYES, F. G. R.; GARIBAY, C. B.; UNGARO; M. R. G.; TOLEDO; M. C. F. Girassol, cultura e aspectos químicos, nutricionais, tecnológicos. Fundação Cargill. Campinas, 86p. 1985. 
RITCHIE, J. T. A user-oriented model of the soil water balance of wheat. p. 293-305. In: W. Day and R. K. Atkins (ed) Wheat growth and modelong. Plenum, New York, 1989.

RITCHIE, J. T. Climate and soil water. In: Moving up the Yield Curve: Advances and Obstacles. Am. Soc. Agron. Special Publication No 39, Madison, W1, p.1-23, 1980.

RITCHIE, J. T. Specifications of the ideal model for predicting crop yields. p.97-122 In: R. C. Muchow and J. A. Bellamy (ed). Climatic risk in crop production: models and management for semiarid tropics and subtropis. CAD Interational, Wallingford, UK, 1991.

RITCHIE, J. T.; GODWIN, D. C.; SINGH, U. Soil and weather inputs for the IBSNAT crop models. In: Proc. IBSNAT Symp.: Decision Support System for Agrotechnology Transfer, Las Vegas, NV.p. 1618 october 1989.Par I: Symposium Proceedings. Dep. of Agronomy and soil Science. College of Tropical Agric. and Human Resources Univ. of Hawaii, Honolulu, 1990.

RITCHIE, J. T.; OTTER, S. Description and performance of CERES-wheat: Auser-oriented wheat yield model. USDA-ARS Grassland, Soil and Water Laboratory, Temple, Texas, 37p., 1983.

ROBINSON, R. G. Production and culture. In Sunflower Science and Technology, ed J. F. Carter, Series $n^{\circ} 19$, p. 89-143. Am Soc. Agron., Madison, 1978.

ROESSING, A.C. Situação Mundial das Oleaginosas. Informe Econômico. Londrina, Empresa Brasileira de Pesquisa Agropecuária. Centro Nacional de Pesquisa de Soja. v., n.1, p. 5-26. 1997.

ROLIM, G. S.; SENTElHAS, P. C.; BARBIERI, V. Planilhas no ambiente Excel para os cálculos de balanços hídricos: normal. sequencial. de cultura e de produtividade real e potencial. Revista Brasileira de Agrometeorologia, v.6, n.1, p.133-137, 1998.

ROSSI, R. O. Girassol. Editora Tecnoagro Ltda. Curitiba. 333p. 1997.

ROTTA, A. 1.; LOURENÇÃO, A. L.; MORAES, S. A. Levantamento Pedológico da Estação Experimental de Monte Alegre do Sul, SP. Bragantia, Campinas, v.42: p. 281-288, 19

SADRAS, V. O.; HALL, A. J. Patterns of water availabity for sunflower crops in semi-arid central Argentina. A simulation-based evaluation of their interactions with cropping strategies and cultivar traits. Agric. Sys. v. 31, p. 221-238, 1989. 
SADRAS, V.O.; VILLALOBOS, F.J.; FERERES, E.; WOLFE, D.W. Leaf responses to soil water deficits: Comparative sensitivity of leaf expansion rate and leaf condutance in field-grown sunflower (Helianthus annuus L.). Plant. Soil, v. 153, p. 189-194, 1993.

SCHNEITER, A. A.; MILLER, J. F. Description of sunflower growth stages. Crop Science, Madison, v. 21, p. $901-903,1981$.

SCHNEITER, A. A.; MILLER, J.F.; Description of sunflower growth stages. Crop. Sci. v.21, p.901-903, 1981.

SCHNEITER, A.; JONES , J. M.; HAMMOND, J. J. Simulated hail research in sunflower: Defoliation. Agron. J., p, 79, p. 431-434, 1987.

SCHUSTER, W.; BOYE, R. Der Einfluss von Temperatur und Tageslange auf verschiedene Sonnenblumensorten unter Kontrollierten Klimabedingungen und im Freiland. Z. Pflanzenzucht., v. 65, p. 151-176, 1971.

SENTELHAS, P. C.; NOGUEIRA, S. S. S.; PEDRO JÚNIOR, M . J.; SANTOS, R. R. Temperatura-base e graus-dia para cultivares de girassol. Revista Brasileira de Agrometeorologia, Santa Maria, v.2, p. $43-49,1994$.

SENTElhas, P. C.; PEZzOPANE J. M.; UNGaRO, M. R. G.; MORAeS, S. A.; DUdienas, C. Aspectos climáticos relacionados à ocorrência da mancha de alternária em cultivares de girassol. Fitopatologia Brasileira, v. 21, p. 464-469, 1996.

SENTELHAS, P. C.; UNGARO, M. R. G. Índices bioclimático para a cultura do girassol. Piracicaba. Sci. agric., Piracicaba, v.55, n.1, p.73-78, jan./abr. 1998.

SIDDIQUI, M. Q.; BROWN, J. F.; ALLEN, S. J. Growth stages of sunflower and intensity indices for white blister and rust. Plant Dis. Rep., v.59, p. 7-11, 1975.

SILVA, W. S. Aptidões climáticas para as culturas do girassol, mamona e amendoim. Informe Agropecuário, Belo Horizonte, v.7, m.82, p. 24-28, 1981. 
SINCLAIR, T. R.; DE WIT, C. T.; Analysis of the carbon and nitrogen limitations to soybean yield. Agron. J., p.68, p. 319-324, 1976.

SMITH, R. C. G.; ANDERSON, W. K.; HARRIS, H.C. A systems approach to the adaptation of sunflower to new environments. III. Yield predictions for continental Australia. Field Crops Res., v.1, p.215-228, 1978.

SOARES, A.S. Modelo para avaliação do efeito do déficit do excesso hídrico sobre o rendimento do milho na localidade de Urussanga, Santa Catarina. Dissertação Mestrado. ESALQ. Janeiro de 1996. $88 \mathrm{p}$.

STEER, B. T.; MILROY, S. P.; KAMONA; R. M. A model to simulate the development, growth and yield of irrigated sunflower. Field Crops Res., v. 32, p. 83-99, 1993.

STEER, B.T.; HOCKING, P.J. Nitrogen nutrition of sunflower (Helianthus annuus L.): Acquisition and partitioning of dry matter and nigtrogen by vegetative organs and their relationship to seed yield. Field Crops Res. v.9, p. 237-251, 1984.

STOYANOVA, Y. Sunflower crops and their problems in Bulgaria. Proc. 6th Int. Sunflower Conf., Bucharest, Romania, p. 43-6, 1974.

TAKAMI, S.; TURNER, N. C.; RAWSON, H. M. Leaf expansion of four sunflower (Helianthus annuus L.) cultivars in relation to water deficits. I. Patterns during plant development. Plant Cell Environ., v.4, p. $399-407,1981$.

TALHA, M.; OSMAN, F. Effect of soil water stress on water economy and oil composition in sunflower (Helitanthus annuus L.), J. Agric. Sci., v.84, p. 49-56, 1975.

THOMÉ, V.M.R.; ZAMPIERI, S.; BRAGA, H.J.; PANDOLFO, C.; SILVA JÚNIOR, V.P.; BACIC, I.L.Z.; LAUS NETO, J. A.; SOLDATELI, D.; GEBLER, E.F.; DALLE ORE, J. DE A.; ECHEVERRIA, L.C.R.; RAMOS, M.G.; CAVALHEIRO, C.N.R.; DEEKE, M.; MATTOS, J.F.; SUSKI, P.P. Zoneamento agroecológico e socioeconômico do Estado de Santa Catarina In: CONGRESSO BRASILEIRO DE AGROMETEOROLOGIA, 11, Florianópolis, 1999. Anais. Florianópolis: Sociedade Brasileira de Agrometeorologia, 1999, p.119. 
THOMPSON, L. M. Weather and technology in the prediction of corn in the Corn Belt. Agronomy Journal, Madison, v.61, p.453-456, 1969.

THORNLEY, J. H. M. A model of a biochemical swith and its applications to flower initiation. Am. Bot., v.36, p. $861-871,1972$.

THORNLEY, J. H. M. Mathematical models in plant physiology: a quantitative aproach to problems in plant and crop physiology. London: Academic Press, London, 1976. 318p.

THORNTHWAITE, C. W. An approach toward a regional classification of climatic. Geographical Review, v. 38, p. 55-94, 1948.

THORNTHWAITE, C. W.; MATHER. R. J. The Water Balance. New Gersey: Laboratory of Climatology, v. 8, 1955, 104p. (Publication in Climatology).

TRAPANI, N.; HALL, A. J.; SADRAS, V. O.; VILELA, F. Ontogenetic changes in radiation use efficiency of sunflower (Helianthus annuus L.) crops. Field Crops Res., v.29, p. 301-316, 1992.

TRAPANI, N.; HALL, A. J.; VILLALOBOS, F. J. Pre-anthesis partitioning of dry matter in sunflower (Helianthus annuus L.) crops. Fields Crops Res. v. 37, p. 235-246, 1994.

TRAPANI, N.; SADRAS, V.O; VILELA, F.; HALL, A.J. A phisiological analysis of the growth and yield of two sunflower cultivars. p.136- 141. In: Proc. Int. Sunflower Conf., 12th, Novi Sad, Yugoslavia. Sept. 1988. Int. Sunflower Assoc., Novi Sad.

TSUJI, G. Y:; UEHARA, G: BALAS, S. DSSAT: a decision support system for agrotechnology transfer. Version 3. Vols. 1, 2 and 3. University of Hawaii, Honolulu, HI, 1994.

UNGARO, M. R. G. Instruções para a cultura do Girassol. Boletim Técnico No 105 . Instituto Agronômico de Campinas. Campinas. 26 p., 1986

UNGARO, M. R. G. Recomendações técnicas para o cultivo do girassol. Correio Agrícola. fevereiro, p. 314- 319,1981 . 
UNGARO, M. R. G.; SENTELHAS, P. C; TURATTI, J. M.; SOAVE, D. Influência da temperatura do ar na composição de aquênios de girassol. Pesquisa Agropecuária Brasileira, v. 32, n.4, p.351-356, 1997.

UNGER, P. W. Sunflower. In: STEWART, B. A.; NIELSEN, D. R. Irrigation of agricultural crops. Agronomy Series, Winsconsin, n. 30, p. 775-794, 1990

VAN KEULEN, H; WOLF, J. Modelling of agricultural production: weather, soils and crops, pudoc, Wageningen, The Netherlands. Simulation Monograph Series, 1986.

VILlALOBOS, F. J.; HALL, A. J.; RITCHIE, J. T.; ORGAZ, F. OILCROP-SUN: A development, growth, and yield model of the sunflower crop. Agronomy Journal, v. 88, p.403-415, 1996.

VILLALOBOS, F. J.; RITCHIE, J. T. The effect of temperarture on leaf emergence rates of sunflower genotypes. Field Crops Res. v. 29, p. 37-46, 1992.

VILLALOBOS, F. J.; SADRAS, V. O.; SORIANO, A.; FERERES, E. Planting density effects on dry matter partitioning and productivity of sunflower genotypes. Field Crops Res., v.36, p. 1-11, 1994.

WANG, J. Y. A critique of heat unit approach to plant response studies. Ecology, Brooklyn, 41(4): 785$790,1960$.

WARRINGTON, I. J.; KANEMASU, E. T. Corn growth response to temperature and photoperiod II. Leaf initiation and leaf-appearance rates. Agron. J., v. 75. p. 755-761, 1983.

WEISS, A. From crop modelling to information systems for decision making. p. 285-290. In: J. F. Griffiths (editor) Handbook of agricultural Meteorology. Oxford Univ. Press, New York, 1994.

WENT, F. W. The experimental control of plant growth. Chron. Bot., v17, 336p.,1957.

WHITFIELD, D. M.; CONNOR, D. J.; HALL, A. J. Carbon dioxide balance of sunflower (Helianthus annus) subjected to water stress during grain filling. Field Crops Res., v. 20, p. 65-80, 1989.

WILliaMS, G. D. V., FAUTLEY, R. A.; JONES. K. H.; STEWART, R. B.; WHEATON, E. E. Estimating impact of climatic change on agriculturein Saskatchewan, Canada. p.221-379. In: M. L. Parry, T. R. Carter and N.T. Konijn (eds). The impact of climatic variation on agriculture. Vol 1: 
Assessments in cool temperature and cold regions. Kluwer Academic Publishers, Dordrecht, The Netherlands, 1988.

YEGAPPAN, T. M.; PATON, D. M.; GATES, C. T.; MULLER, W. J. Water stress in sunflower (Helianthus annuus L.): I. Effect on plant development. Ann. Bot. (London), v.46, p. 61-70, 1980. 
ANEXO 1 - Dados observados referente à duraçāo de cada sub-periodo dos cultivares IAC-Anhandy, Contisol-621 e VNIIMK, em diferentes datas de semeadura no ano de 1988 e 1989, na localidade de Monte Alegre do Sul, SP.

\begin{tabular}{|c|c|c|c|c|c|c|}
\hline \multicolumn{7}{|l|}{ IAC-Anhandy } \\
\hline Datas de & $\mathrm{T1}$ & T2 & T3 & $\mathrm{T4}$ & T5 & IAFmáximo \\
\hline Semeadura & $\begin{array}{l}\text { (Semeadura - } \\
\text { Emergencia) }\end{array}$ & $\begin{array}{l}\text { (Emergéncia - } \\
\text { Fim da fase juvenill }\end{array}$ & $\begin{array}{l}\text { (Fim đa fase Juveril - } \\
\text { Iniciaçăo Fioral) }\end{array}$ & $\begin{array}{l}\text { (iniciaçăo Fioral - } \\
\text { Primeira Antese) }\end{array}$ & $\begin{array}{l}\text { (Primeira Antese - } \\
\text { Maturidade Fisiológica) }\end{array}$ & $\begin{array}{c}\text { da cultura } \\
\left(\mathrm{m}^{2} \cdot \mathrm{m}^{-2}\right)\end{array}$ \\
\hline $14 / 7 / 88$ & 7 & 6 & 46 & 14 & 16 & 3,36 \\
\hline $22 / 4 / 88$ & 8 & 16 & 36 & 33 & 24 & 1,47 \\
\hline $18 / 5 / 88$ & 10 & 5 & 56 & 16 & 46 & 0,85 \\
\hline $17 / 6 / 88$ & 11 & 20 & 52 & 37 & 15 & 1,74 \\
\hline $15 / 7 / 88$ & 14 & 27 & 25 & 33 & 17 & 1,75 \\
\hline $23 / 8 / 88$ & 7 & 9 & 40 & 18 & 23 & 4,33 \\
\hline 19/9/88 & 9 & 19 & 25 & 32 & 9 & 2,88 \\
\hline $19 / 10 / 88$ & 6 & 9 & 46 & 15 & 21 & 2,73 \\
\hline $2 / 2 / 89$ & 8 & 15 & 37 & 27 & 16 & 2,84 \\
\hline $7 / 3 / 89$ & 7 & 4 & 40 & 9 & 36 & 2,47 \\
\hline $5 / 4 / 89$ & 6 & 12 & 47 & 31 & 36 & 3,07 \\
\hline $5 / 5 / 89$ & 10 & 10 & 59 & 23 & 26 & 2,81 \\
\hline $2 / 6 / 89$ & 8 & 21 & 51 & 31 & 12 & 2,98 \\
\hline $5 \pi / 89$ & 12 & 29 & 38 & 33 & 17 & 3,25 \\
\hline $11 / 8 / 89$ & 10 & 9 & 51 & 24 & 21 & 3,34 \\
\hline $1 / 9 / 89$ & 9 & 17 & 28 & 30 & 28 & 2,52 \\
\hline $3 / 10 / 89$ & 7 & 9 & 42 & 17 & 23 & 2,75 \\
\hline $30 / 10 / 89$ & 7 & 11 & 40 & 21 & 15 & 2,38 \\
\hline $15 / 12 / 89$ & 5 & 17 & 33 & 20 & 19 & 2,94 \\
\hline \multicolumn{7}{|l|}{ Contisol- 621} \\
\hline DATAS & T1 & $\mathrm{T} 2$ & T3 & T4 & T5 & IAFmáximo \\
\hline $14 / 1 / 88$ & 7 & 6 & 50 & 15 & 9 & 3,73 \\
\hline $22 / 4 / 88$ & 8 & 13 & 42 & 27 & 30 & 0,47 \\
\hline $18 / 5 / 88$ & 10 & 4 & 54 & 18 & 39 & 0,84 \\
\hline $17 / 6 / 88$ & 11 & 20 & 45 & 38 & 15 & 0,95 \\
\hline $15 / 7 / 88$ & 14 & 28 & 18 & 28 & 23 & 1,28 \\
\hline $23 / 8 / 88$ & 7 & 7 & 36 & 19 & 32 & 4,01 \\
\hline $19 / 9 / 88$ & 9 & 14 & 23 & 35 & 12 & 2,84 \\
\hline $19 / 10 / 88$ & 6 & 14 & 29 & 27 & 22 & 2,54 \\
\hline $2 / 2 / 89$ & 8 & 10 & 35 & 17 & 24 & 2,67 \\
\hline $7 / 3 / 89$ & 7 & 8 & 30 & 18 & 25 & 1,83 \\
\hline $5 / 4 / 89$ & 6 & 12 & 44 & 30 & 20 & 3,23 \\
\hline $5 / 5 / 89$ & 10 & 10 & 55 & 27 & 28 & 2,50 \\
\hline $2 / 6 / 89$ & 8 & 8 & 59 & 18 & 30 & 3,77 \\
\hline $5 / 7 / 89$ & 12 & 13 & 47 & 21 & 31 & 2,95 \\
\hline $11 / 8 / 89$ & 10 & 6 & 52 & 17 & 27 & 2,17 \\
\hline $1 / 9 / 89$ & 9 & 11 & 40 & 19 & 23 & 2,47 \\
\hline $3 / 10 / 89$ & 7 & 12 & 33 & 22 & 25 & 2,77 \\
\hline $30 / 10 / 89$ & 7 & 12 & 39 & 22 & 15 & 2,35 \\
\hline $15 / 12 / 89$ & 5 & 12 & 35 & 17 & 25 & 2.31 \\
\hline \multicolumn{7}{|l|}{ VNIIMK } \\
\hline DATAS & $T 1$ & $\mathrm{~T} 2$ & T3 & T4 & T5 & IAFmáximo \\
\hline $14 / 1 / 88$ & 7 & 6 & 50 & 15 & 9 & 3,84 \\
\hline $22 / 4 / 88$ & 8 & 13 & 48 & 24 & 24 & 0,79 \\
\hline $18 / 5 / 88$ & 10 & 7 & 58 & 21 & 48 & 1,11 \\
\hline $17 / 6 / 88$ & 11 & 21 & 51 & 39 & 13 & 1,67 \\
\hline $15 / 7 / 88$ & 14 & 37 & 18 & 40 & 16 & 2,37 \\
\hline $23 / 8 / 88$ & 7 & 11 & 40 & 21 & 28 & 4,33 \\
\hline 19/9/88 & 9 & 19 & 25 & 32 & 19 & 4,64 \\
\hline $19 / 10 / 88$ & 6 & 15 & 40 & 24 & 18 & 3,02 \\
\hline $2 / 2 / 89$ & 8 & 14 & 37 & 26 & 19 & 3,91 \\
\hline $7 / 3 / 89$ & 7 & 17 & 34 & 32 & 19 & 2,77 \\
\hline $5 / 4 / 89$ & 6 & 8 & 53 & 29 & 20 & 3,44 \\
\hline $5,5 / 89$ & 10 & 12 & 53 & 33 & 21 & 3,04 \\
\hline $2 / 6 / 89$ & 8 & 21 & 51 & 31 & 25 & 3,48 \\
\hline $5 / 7 / 89$ & 14 & 12 & 52 & 25 & 19 & 3,30 \\
\hline $11 / 8 / 89$ & 10 & 10 & 50 & 24 & 24 & 3.14 \\
\hline $1 / 9 / 89$ & 9 & 17 & 28 & 30 & 28 & 3,17 \\
\hline $3 / 10 / 89$ & 7 & 10 & 41 & 19 & 21 & 3,46 \\
\hline $30 / 10 / 89$ & 7 & 12 & 38 & 22 & 15 & 2,39 \\
\hline $15 / 12 / 89$ & 5 & 16 & 34 & 20 & 19 & 3,25 \\
\hline
\end{tabular}




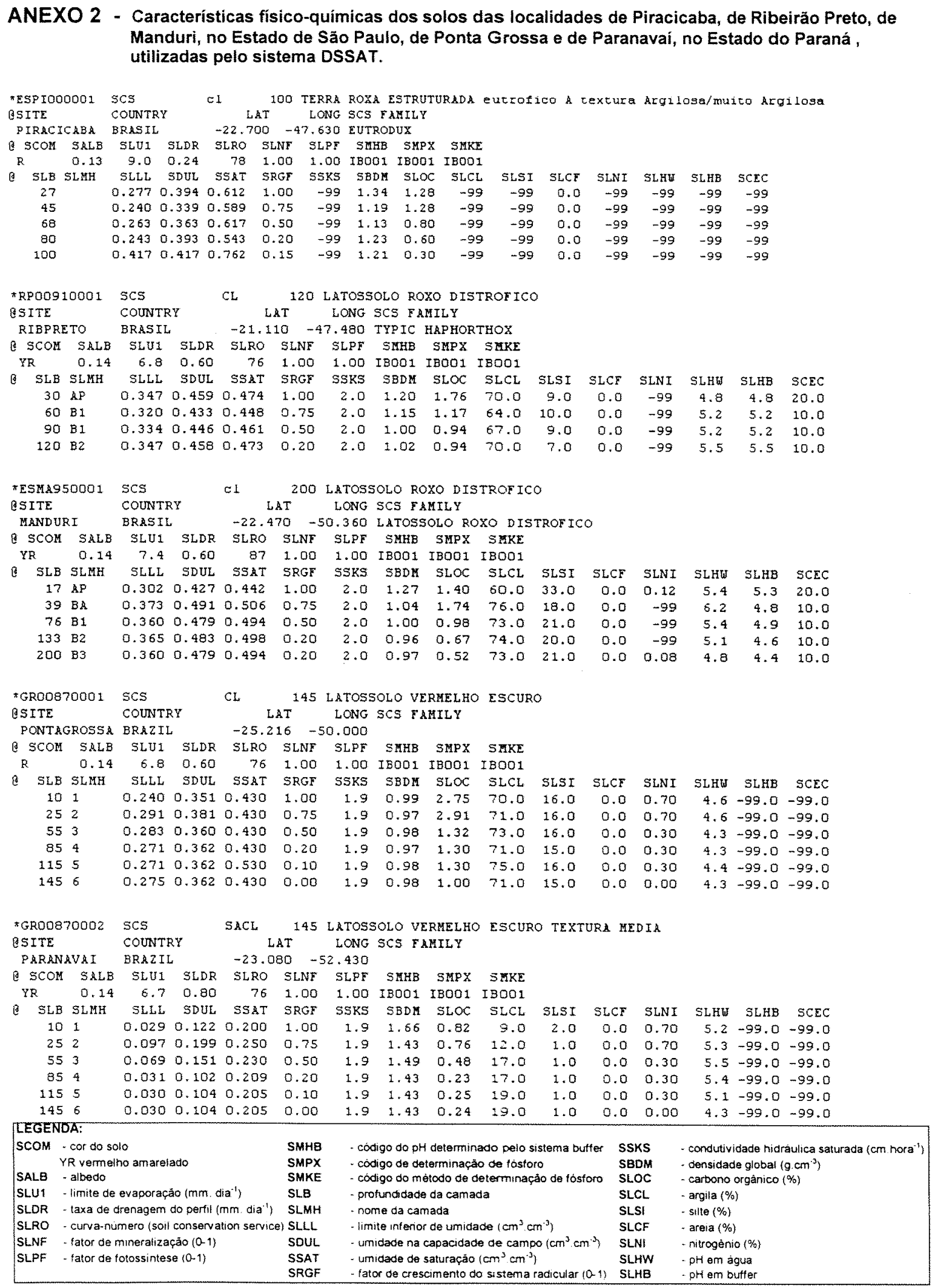




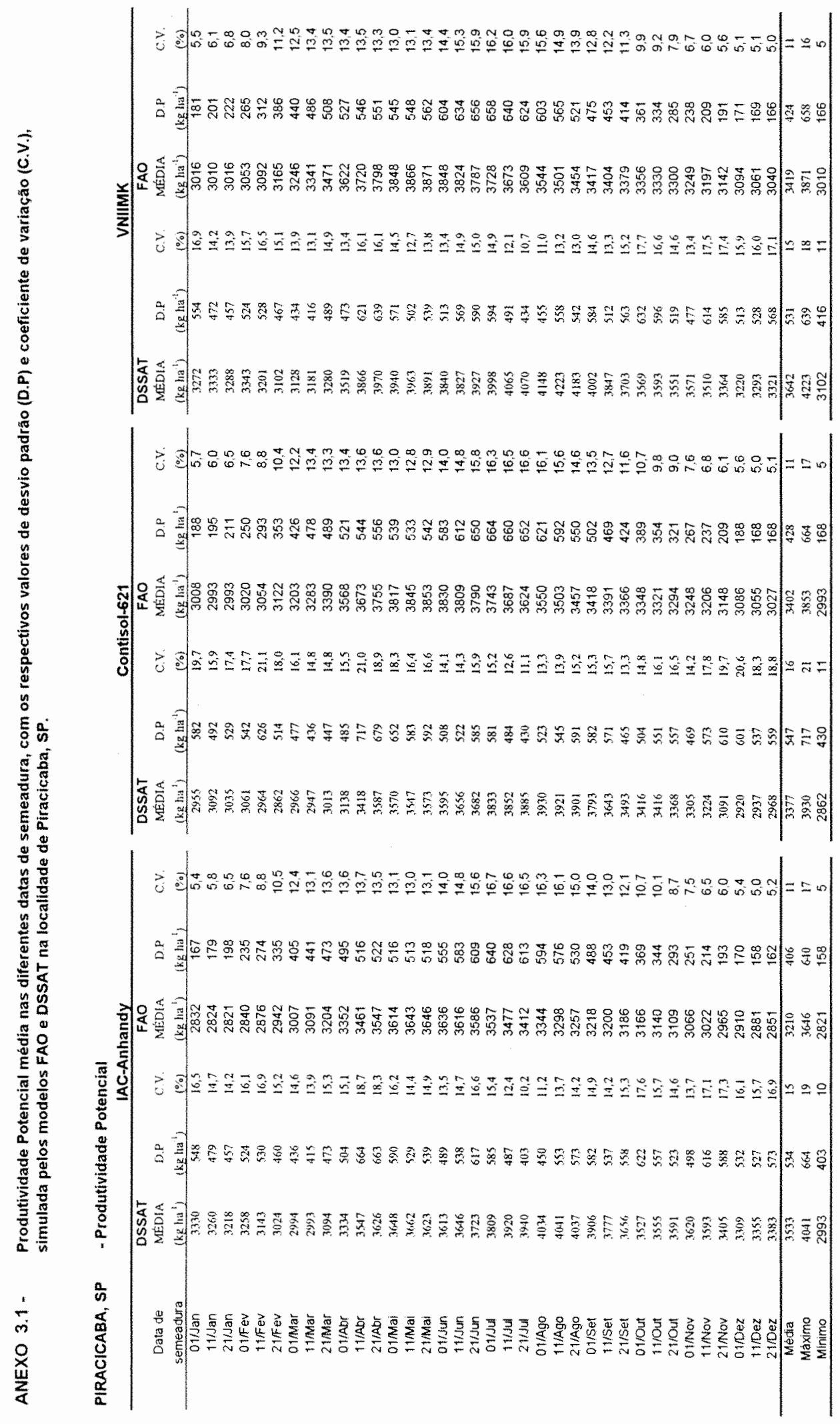




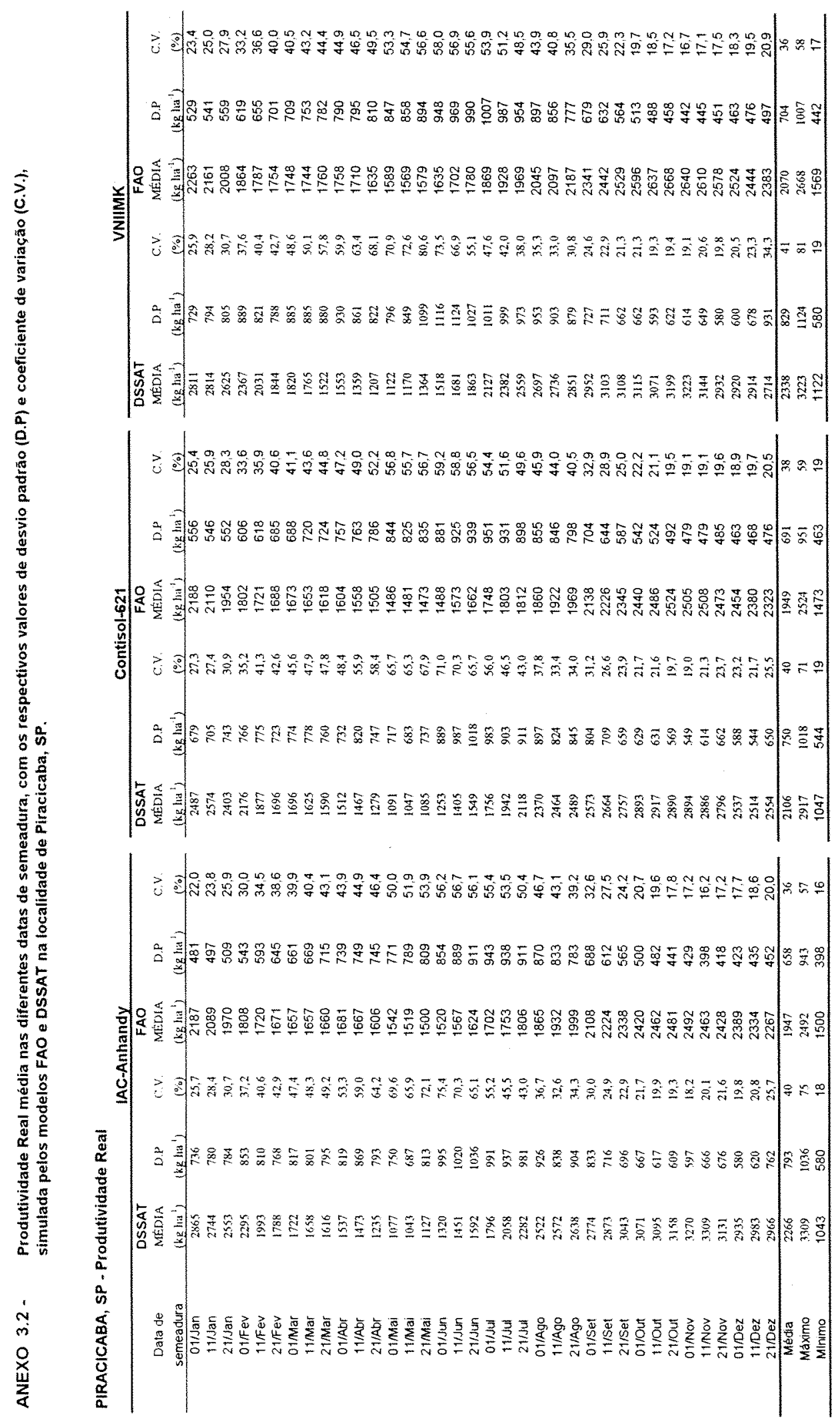




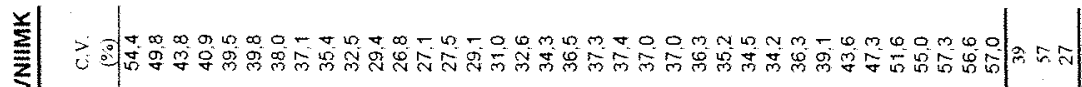

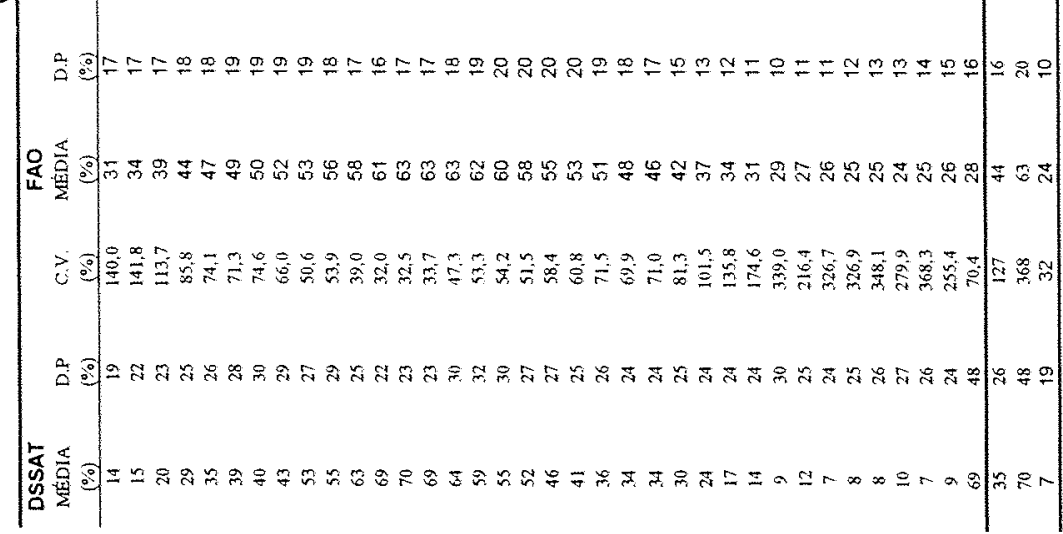

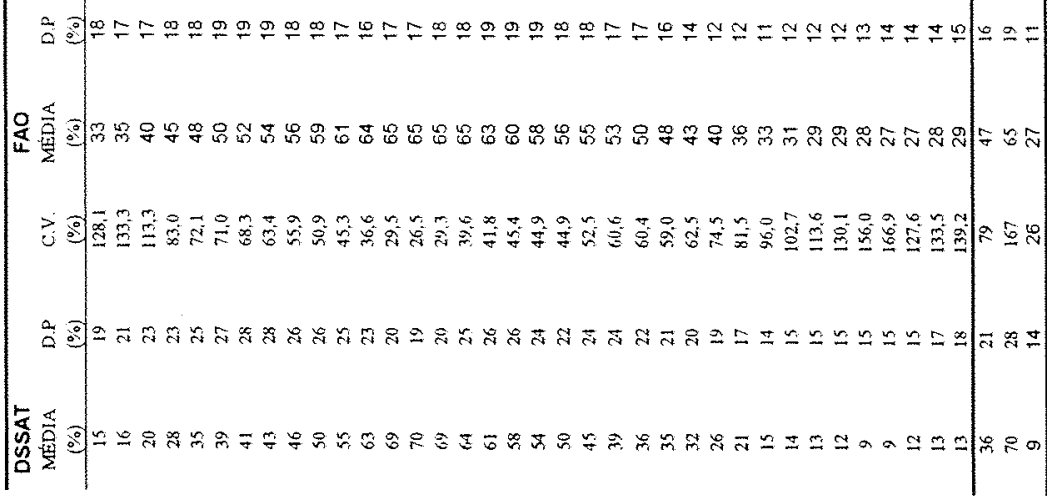

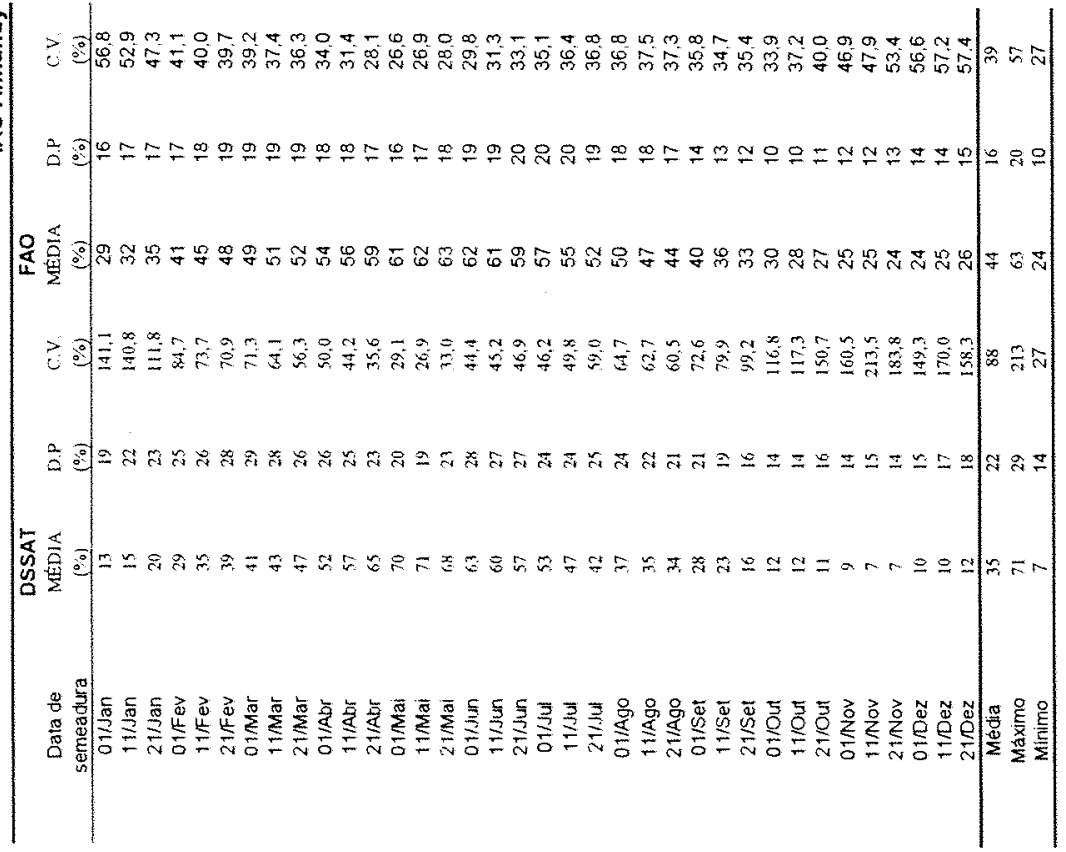



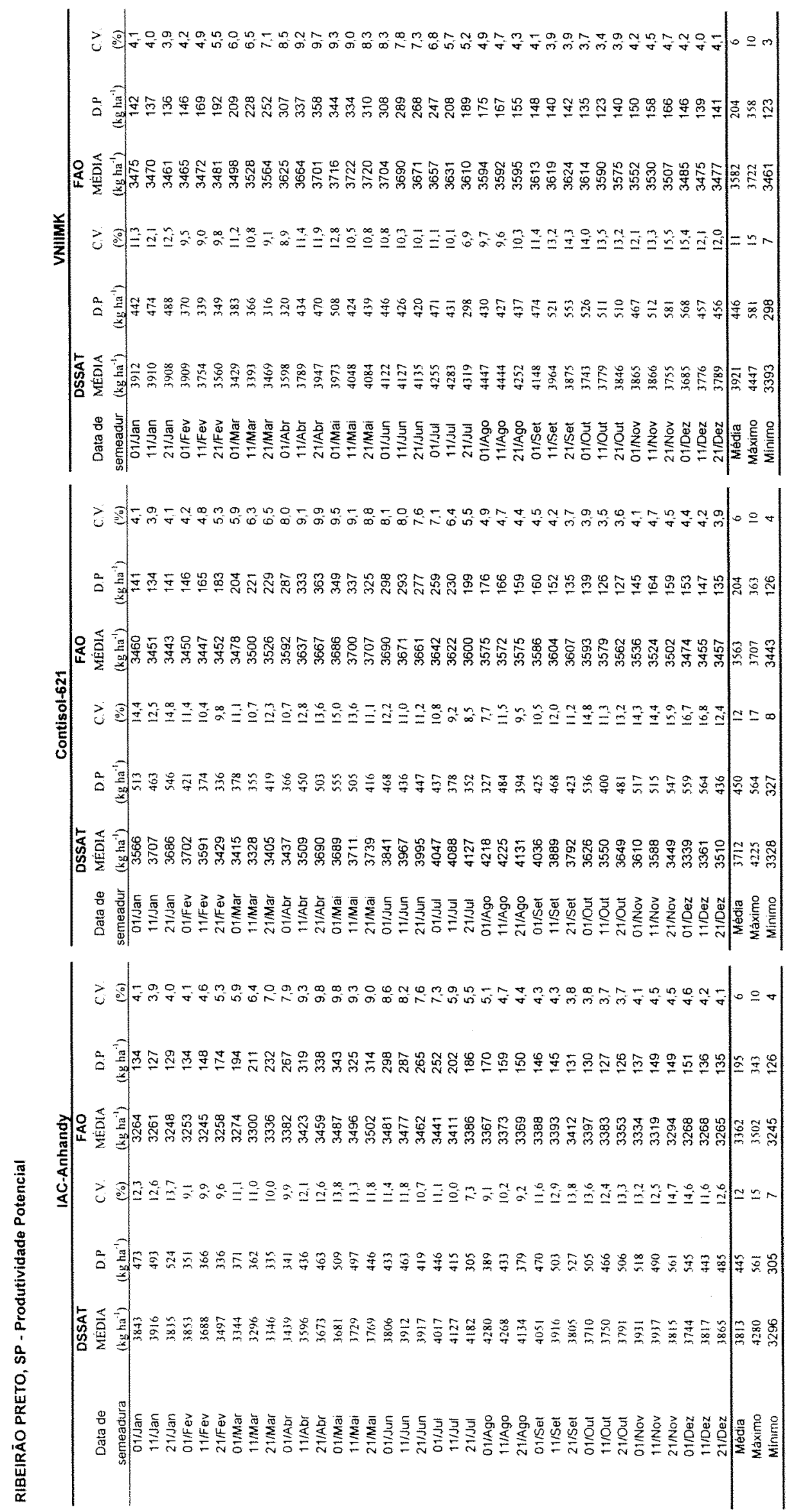


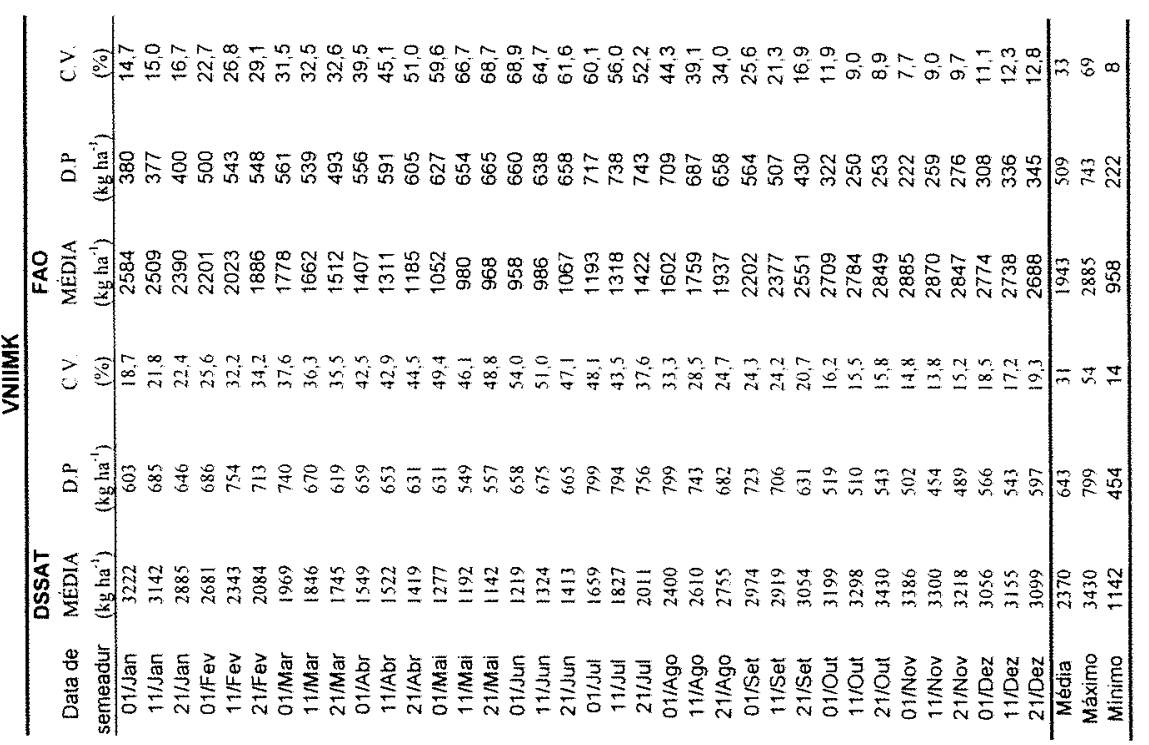

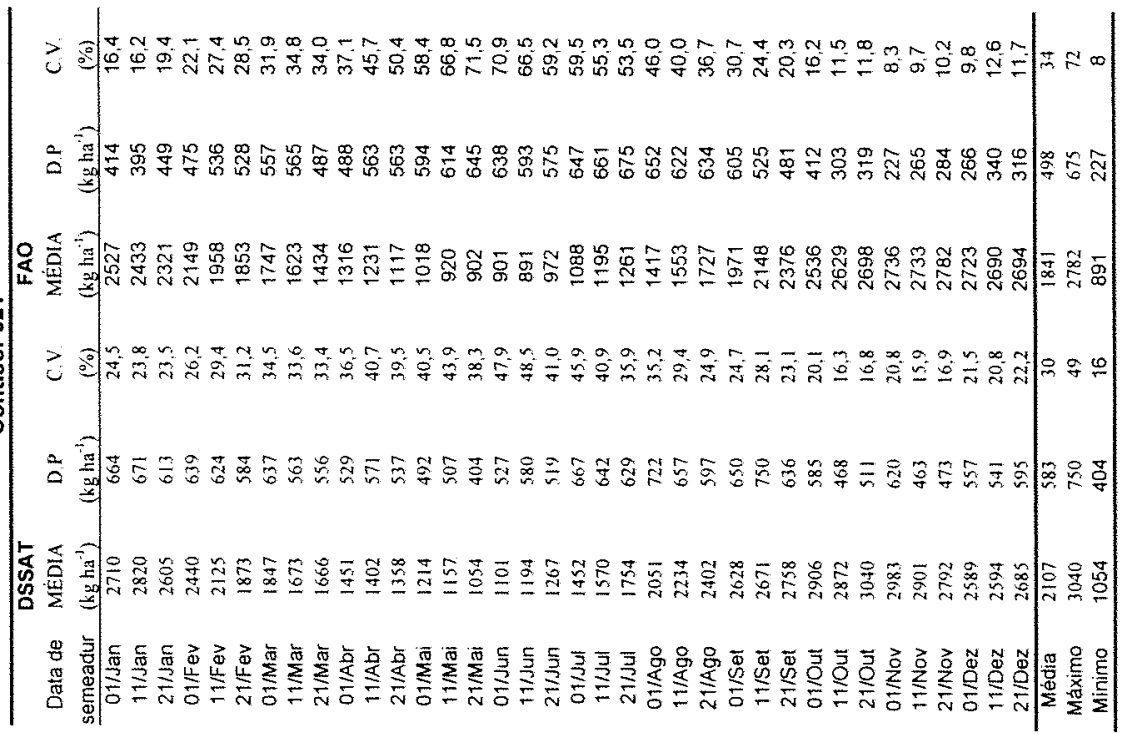

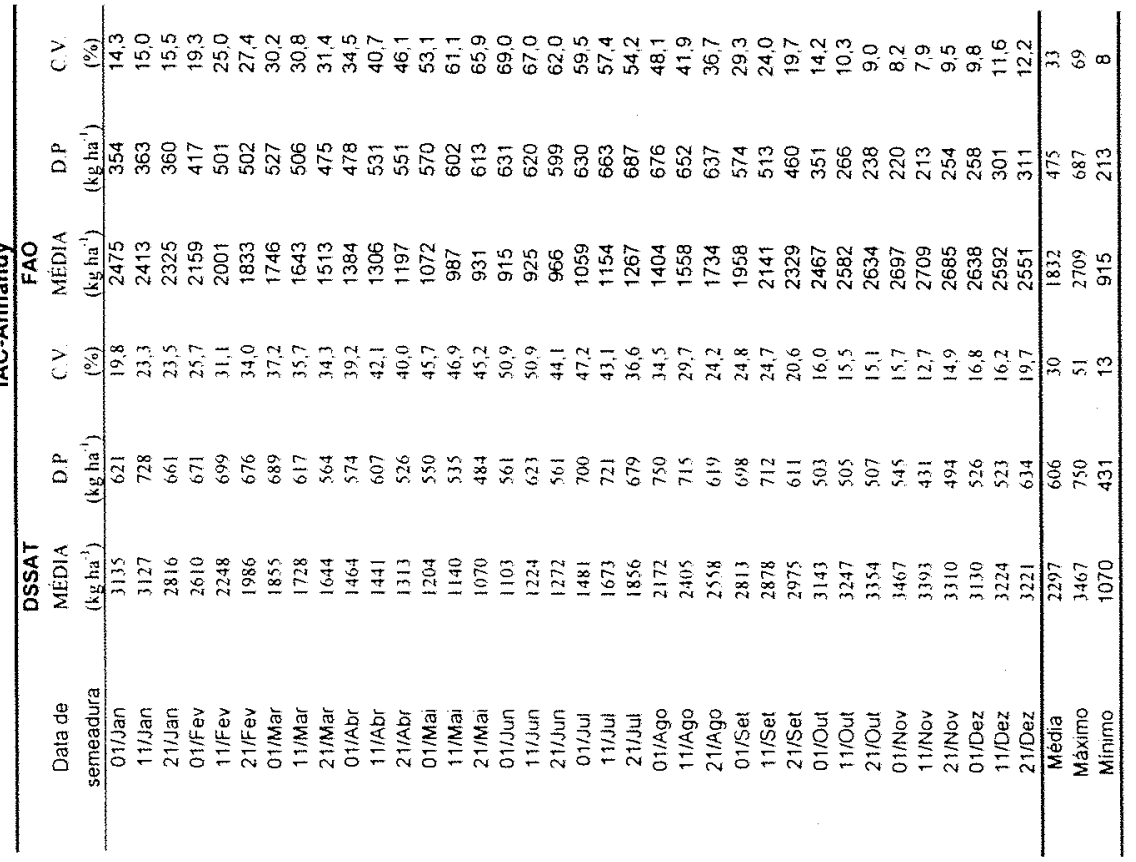




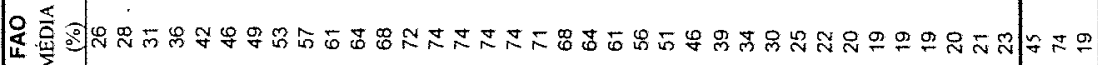

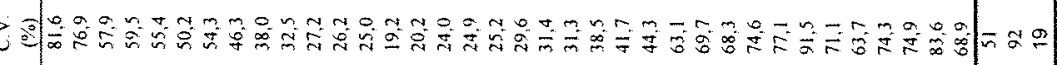

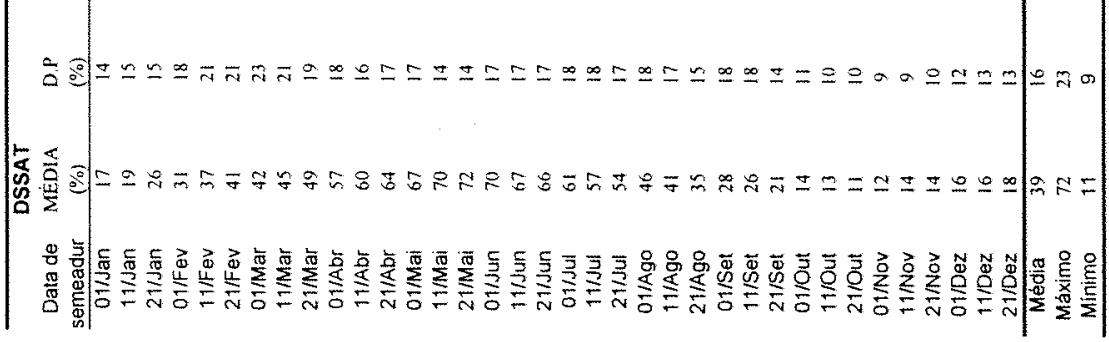

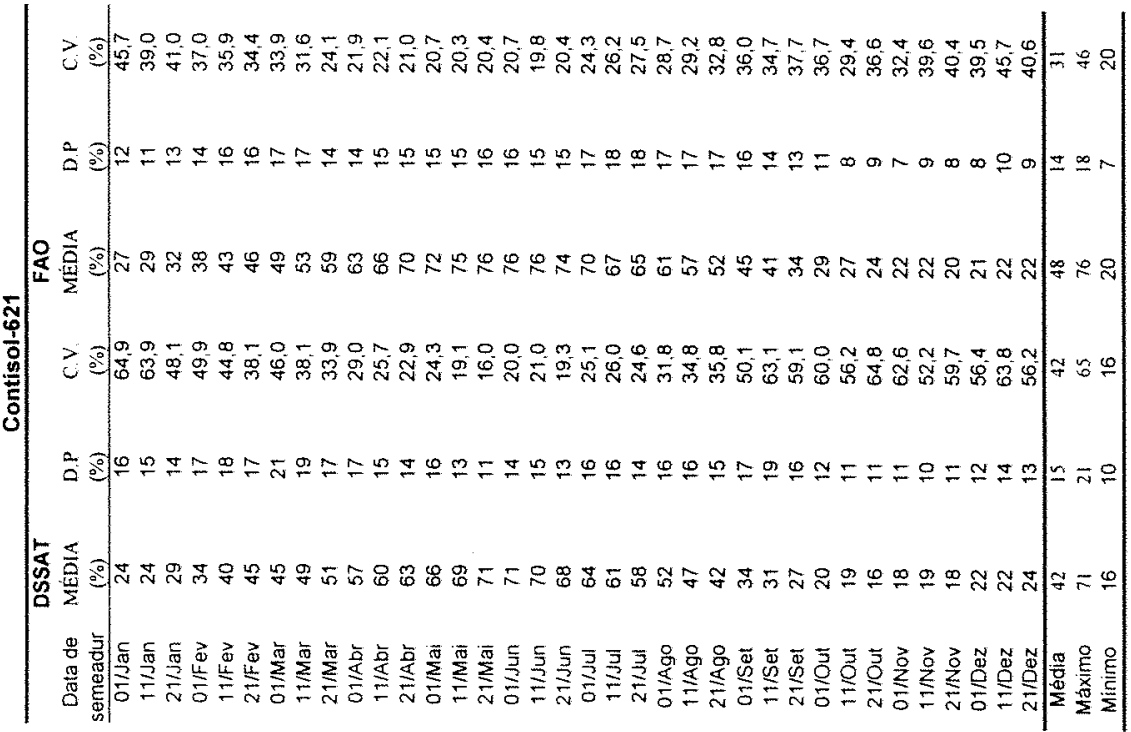

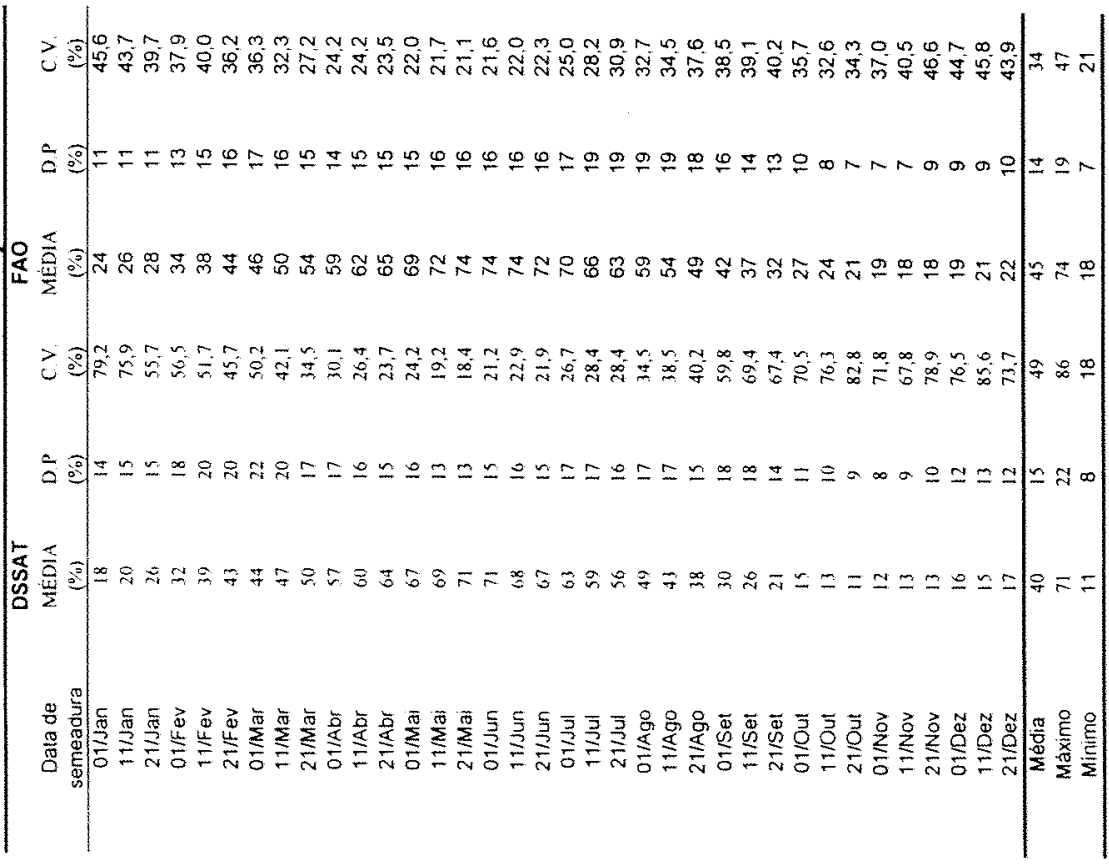




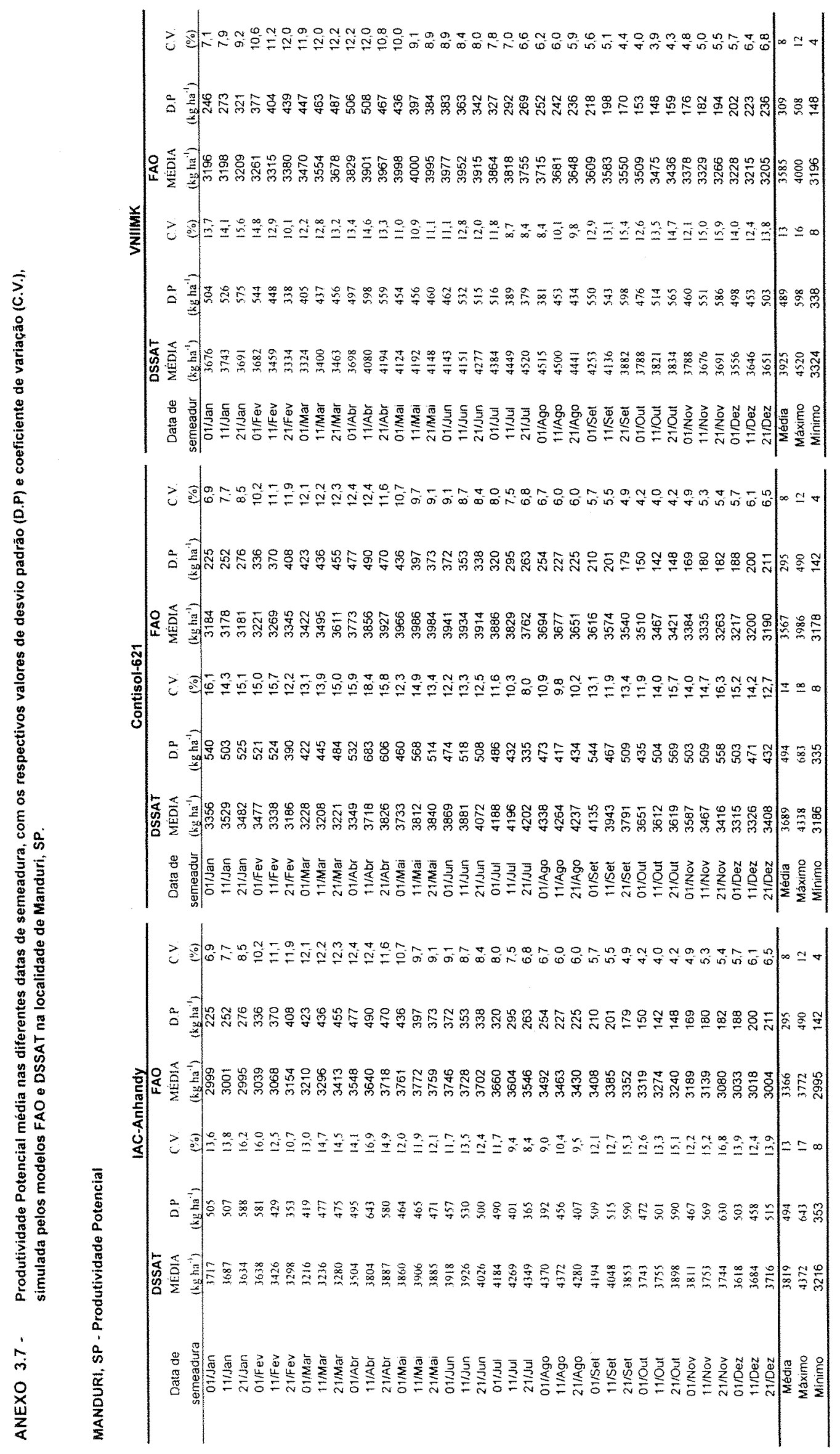


|

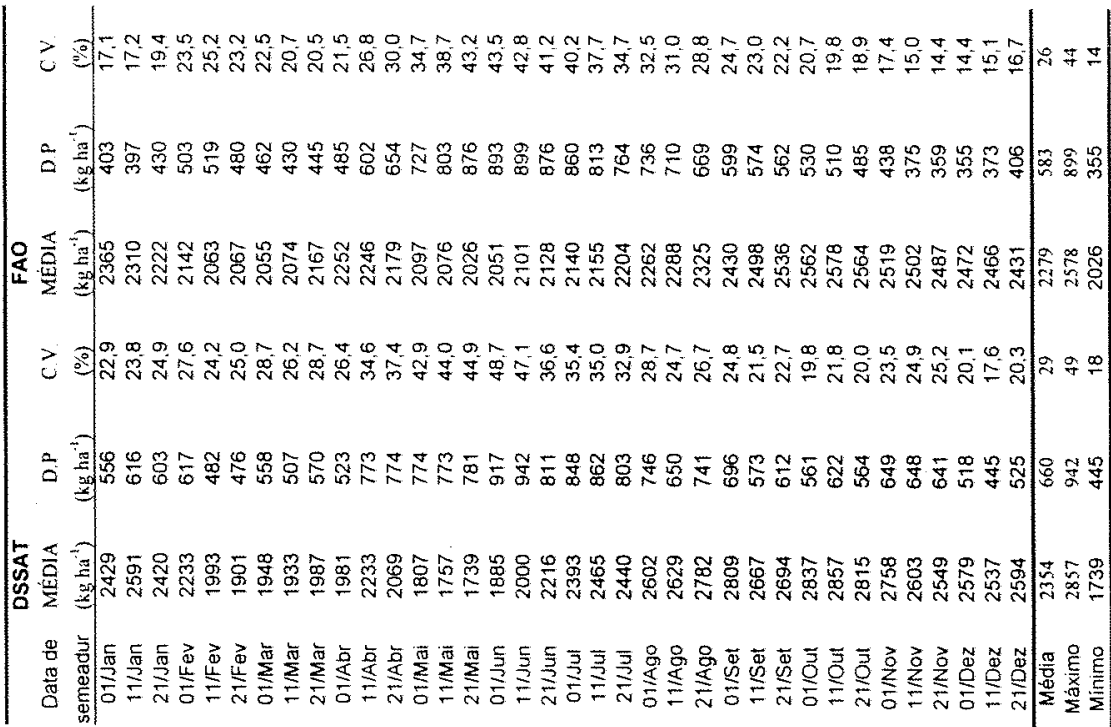

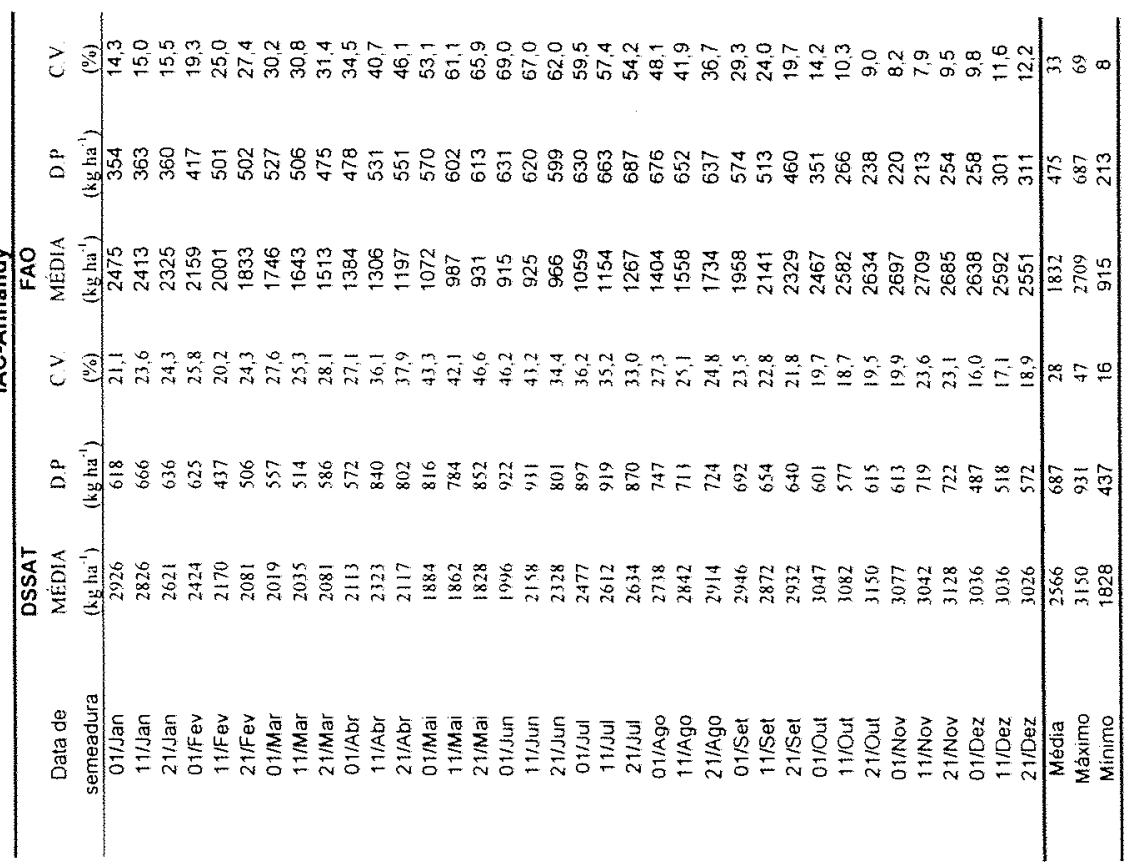



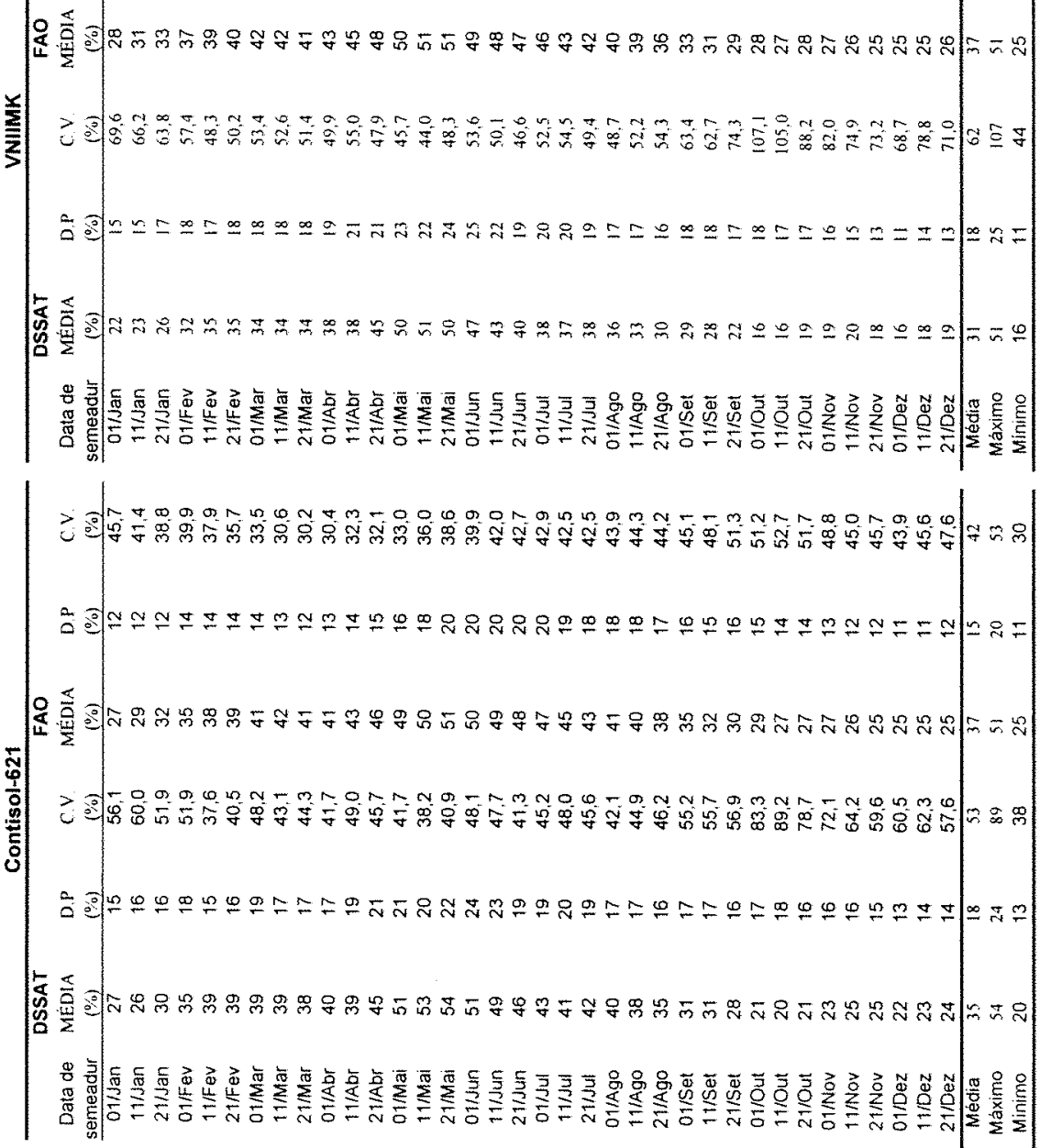

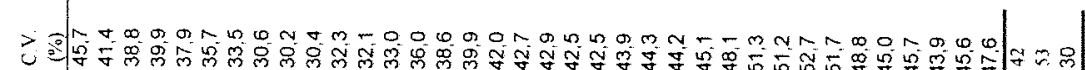

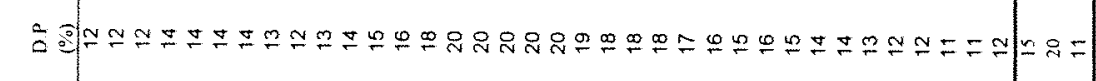




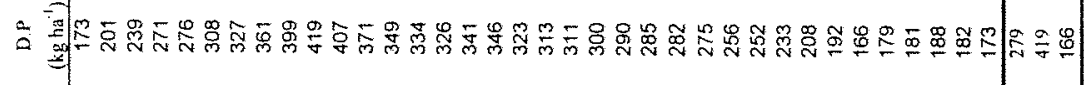

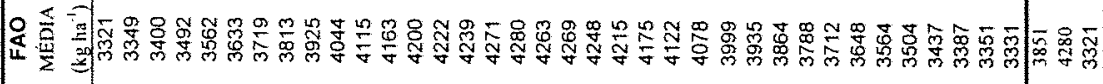

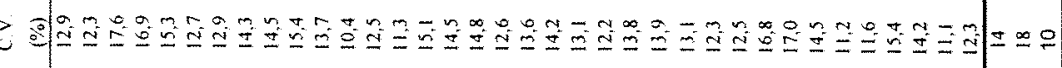

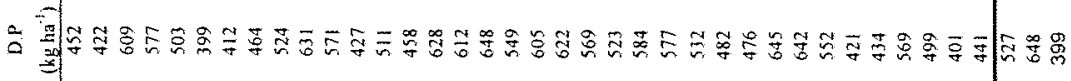

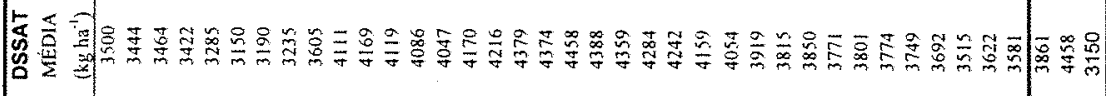

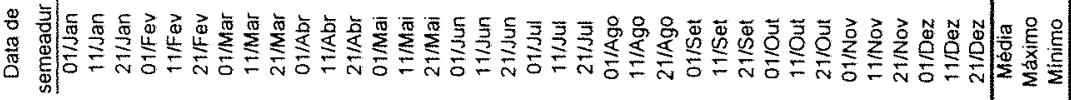

|

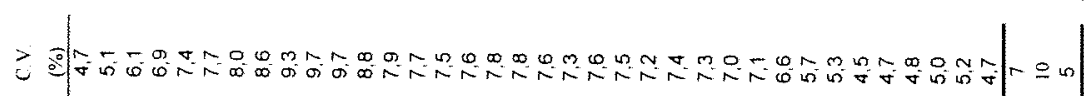

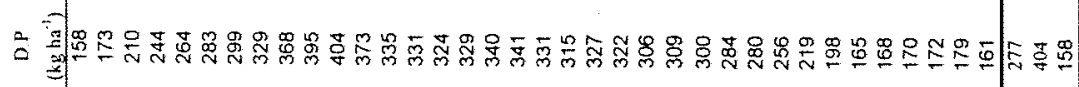

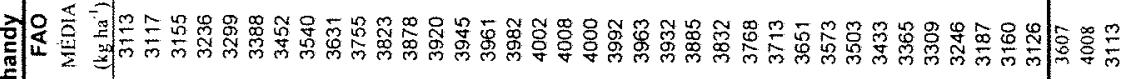

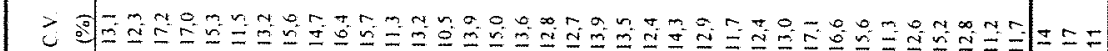

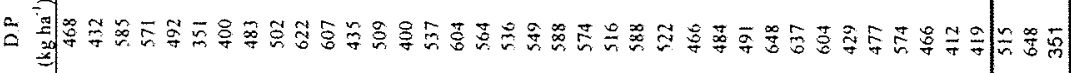

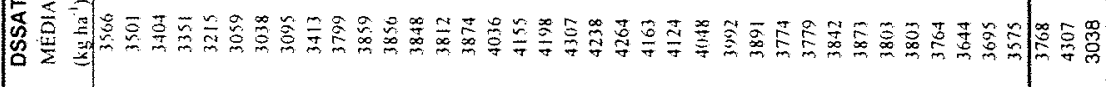



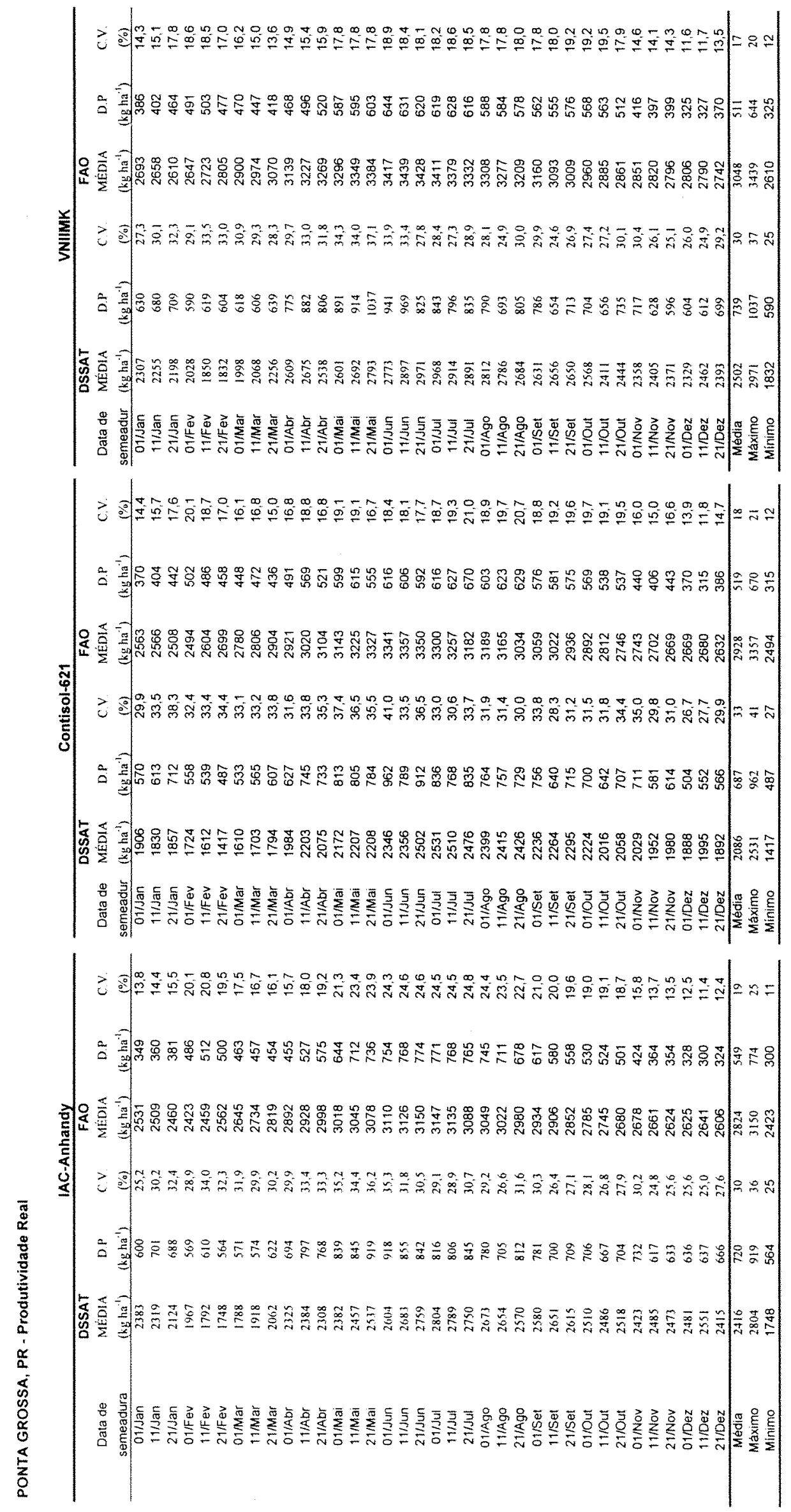

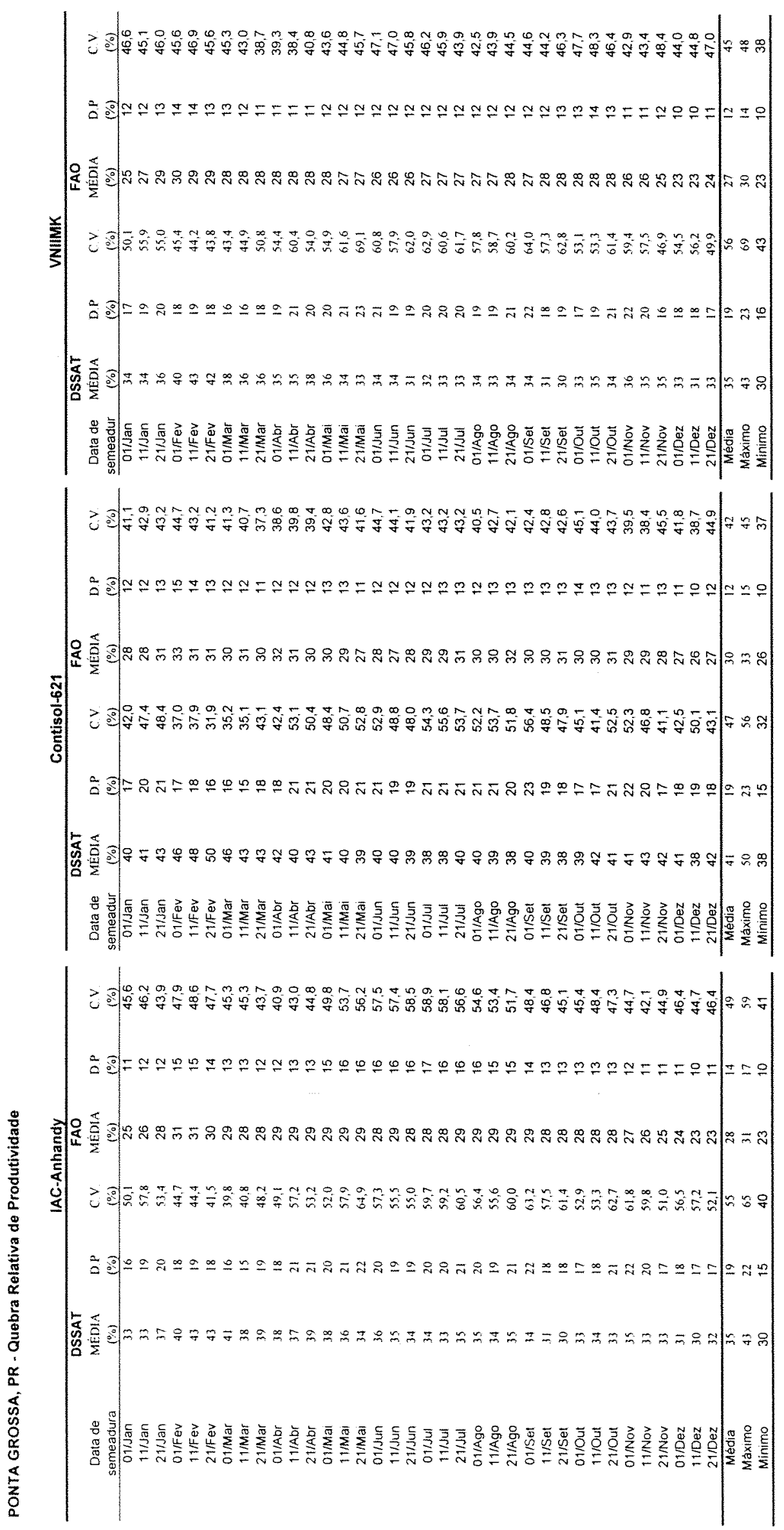


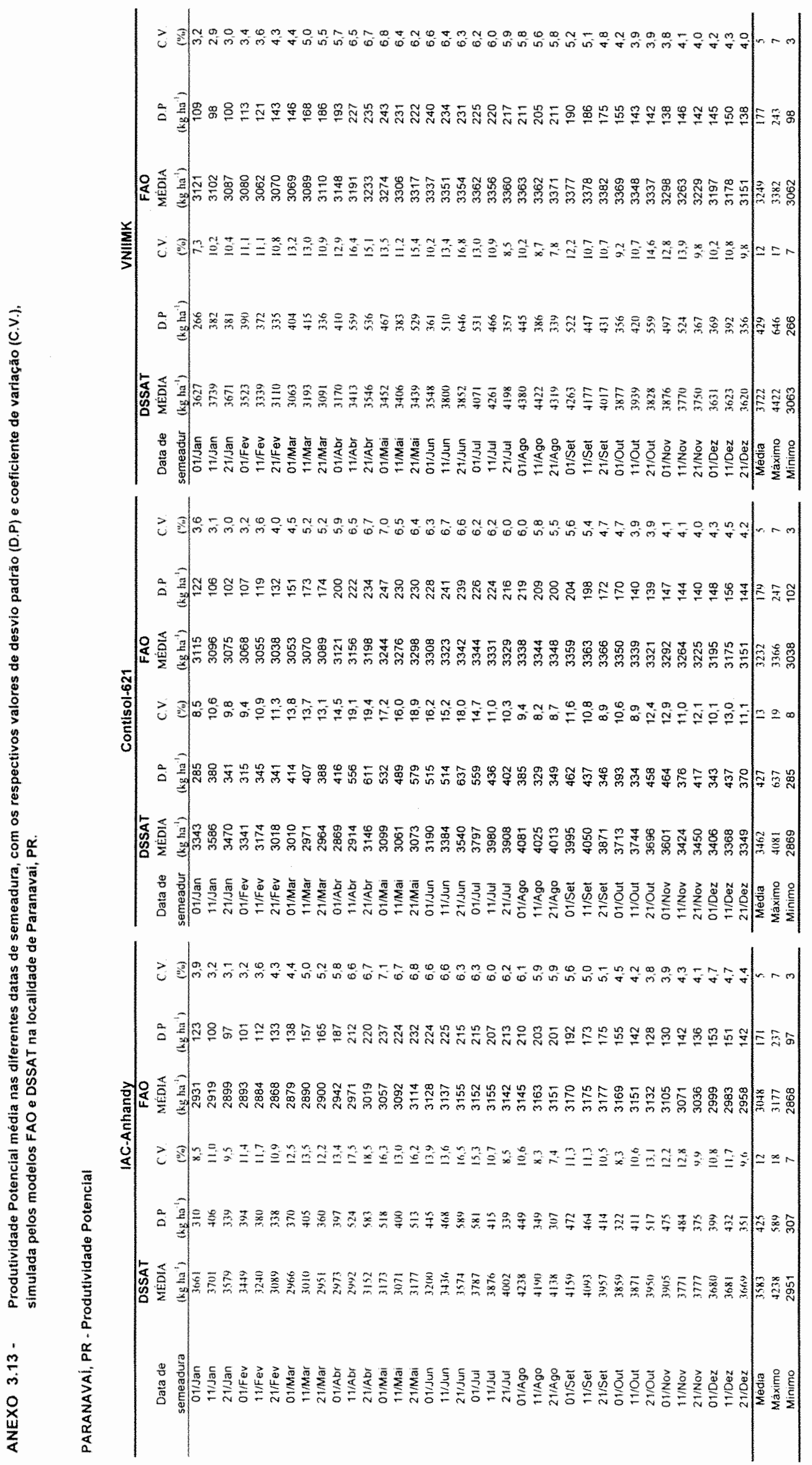




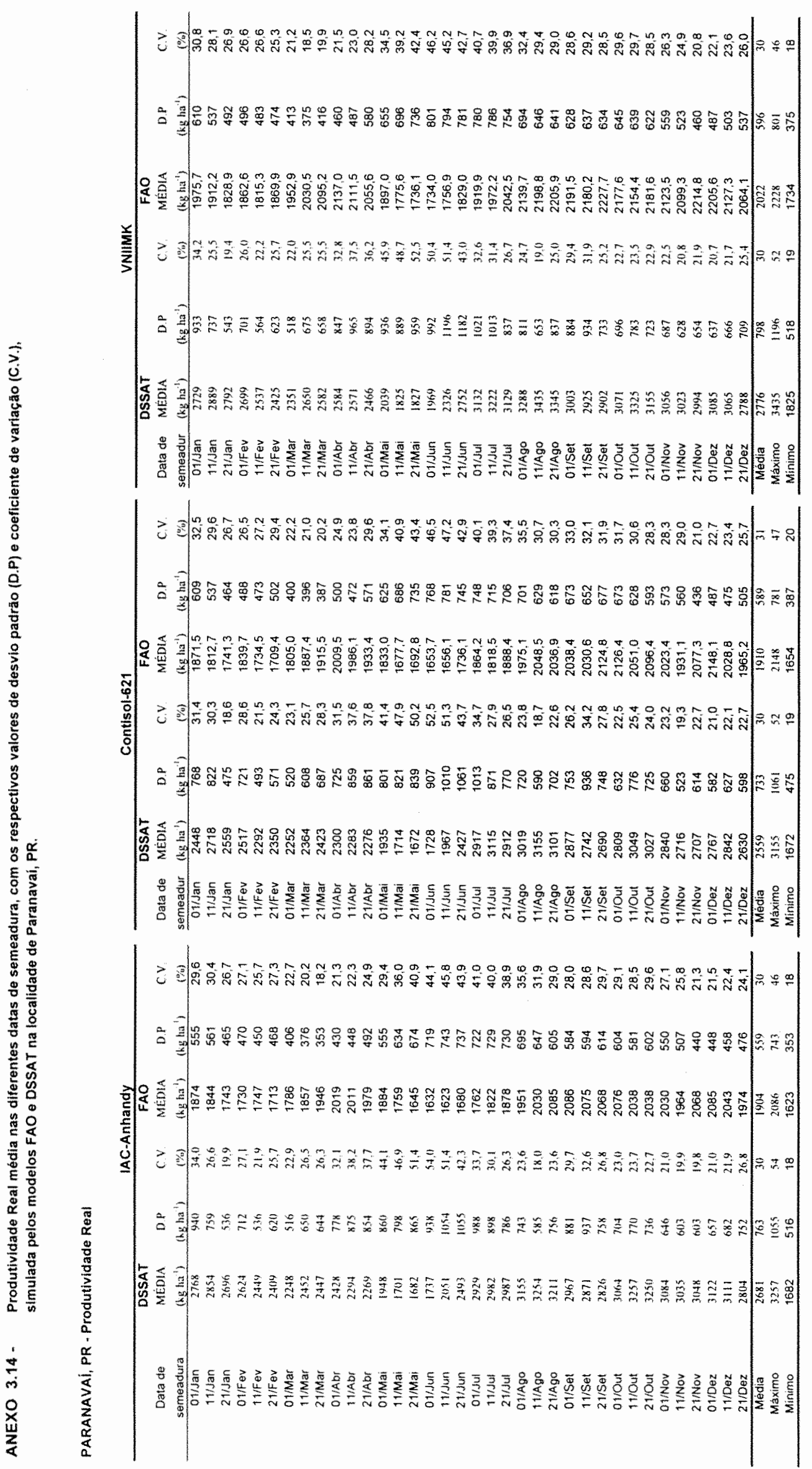




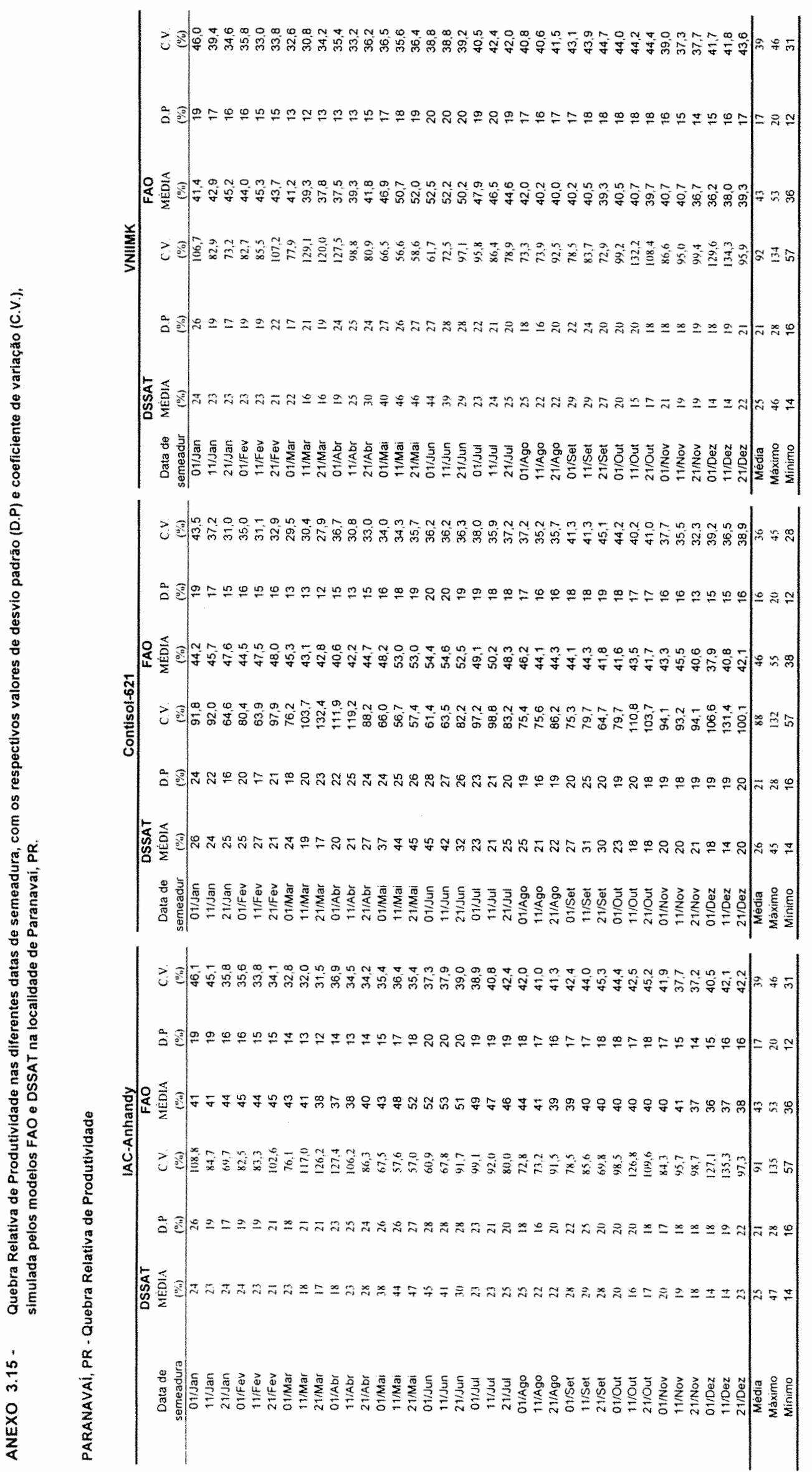

